University of Louisville

ThinkIR: The University of Louisville's Institutional Repository

Electronic Theses and Dissertations

$5-2014$

\title{
A realization and analysis : the manifestation of Franz Schubert within Manuel Maria Ponce's Sonata romantica.
}

Parker S. Scinta

University of Louisville

Follow this and additional works at: https://ir.library.louisville.edu/etd

Part of the Composition Commons, and the Music Theory Commons

\section{Recommended Citation}

Scinta, Parker S., "A realization and analysis : the manifestation of Franz Schubert within Manuel Maria Ponce's Sonata romantica." (2014). Electronic Theses and Dissertations. Paper 1286.

https://doi.org/10.18297/etd/1286

This Master's Thesis is brought to you for free and open access by ThinkIR: The University of Louisville's Institutional Repository. It has been accepted for inclusion in Electronic Theses and Dissertations by an authorized administrator of ThinkIR: The University of Louisville's Institutional Repository. This title appears here courtesy of the author, who has retained all other copyrights. For more information, please contact thinkir@louisville.edu. 


\title{
A REALIZATION AND ANALYSIS: THE MANIFESTATION OF FRANZ SCHUBERT WITHIN MANUEL MARÍA PONCE'S SONATA ROMÁNTICA
}

\author{
By \\ Parker S. Scinta \\ B.M., University of Louisville, 2011 \\ M.M., University of Louisville, 2013
}

\begin{abstract}
A Thesis
Submitted to the Faculty of the University of Louisville School of Music in Partial Fulfillment of the Requirements for the Degree of
\end{abstract}

\author{
Master of Music \\ Division of Composition and Music Theory \\ School of Music \\ University of Louisville \\ Louisville, Kentucky
}

May 2014 
Copyright 2014 by Parker S. Scinta

All rights reserved 



\section{A REALIZATION AND ANALYSIS: THE MANIFESTATION OF FRANZ SCHUBERT WITHIN MANUEL MARÍA PONCE'S SONATA ROMÁNTICA}

By

Parker S. Scinta

B.M., University of Louisville, 2011

M.M., University of Louisville, 2013

A Thesis Approved on

April 24, 2014

By the following Thesis Committee:

Thesis Director

Dr. Mark Yeary

Dr. Rebecca Jemian

Dr. Stephen Mattingly 


\section{DEDICATION}

This thesis is dedicated to my late grandmother,

Mrs. Marguerite Joyce Scinta. 


\section{ACKNOWLEDGEMENTS}

I would like to first express my deepest gratitude to Dr. Mark Yeary for his supervision, encouragement, and faith in this project. His invaluable knowledge and patience assisted me to conceive, organize, and develop my ideas to the best of my ability. Also, to Dr. Stephen Mattingly, whose continuous guidance, support, and passion for the guitar, has motivated me throughout my career and inspired me to pursue this present topic. Of course, thank you to Dr. Rebecca Jemian, whose musical understanding and passion for theory has consistently motivated me during the final phases of this project.

Thank you to Mark Dickson and everyone in the Dwight Anderson Music Library for your patience and acquiring my numerous literary sources. A special thanks to Dr. Anne Marie de Zeeuw for helping me discover my admiration for music theory and encouraging my graduate endeavors. Additionally, thank you to all the faculty, staff, and students at the University of Louisville School of Music for your wisdom and encouragement that has inspired me everyday.

I would also like to thank my family who have supported me in countless ways and driven me to become the best musician and person possible. Finally, to my fiancé, Allison, for her unwavering patience, love, and support throughout this project and my graduate career. 


\begin{abstract}
A REALIZATION AND ANALYSIS: THE MANIFESTATION OF FRANZ SCHUBERT WITHIN MANUEL MARÍA PONCE'S SONATA ROMÁNTICA Parker S. Scinta
\end{abstract}

April 24, 2014

Within early twentieth-century guitar repertoire, Manuel María Ponce's Sonata Romántica distinguishes itself in both quality and historical significance. The manifestation of Franz Schubert's compositional idioms within this work exhibits Ponce's intense understanding of Romantic harmonic and formal treatment, in addition to his imitative compositional ability. The main aim of this document is to discover the specific ways in which Ponce emulates Schubert by incorporating comparative and Schenkerian analyses. This investigation examines Ponce's treatment of harmonic, motivic and formal structures to reveal the unique aesthetic qualities that distinguish the piece as a guitar sonata in the manner of Schubert. In particular, an examination of the Sonata Romántica suggests a possible chronological organization that reflects Schubert's evolution of musical forms and genres. An analysis of the collaborative efforts between guitarist Andrés Segovia and Ponce reveals the possible motivations to the Sonata Romántica's conception, including the choice to emulate Schubert. 


\section{TABLE OF CONTENTS}

\begin{tabular}{|c|c|}
\hline & PAGE \\
\hline DEDICATION ............... & .......iii \\
\hline ACKNOWLEDGMENTS. & .......iv \\
\hline ABSTRACT ................. & $\ldots . . . \mathrm{V}$ \\
\hline LIST OF MUSICAL EXAMPLES. & ...vviii \\
\hline LIST OF FIGURES.................. & .....ix \\
\hline
\end{tabular}

\section{CHAPTER 1:}

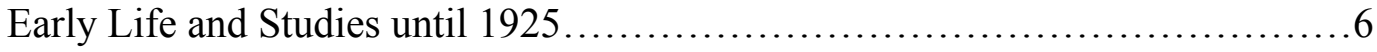

Influence of Paul Dukas, Nadia Boulanger, and Igor Stravinsky.................9

The Guitar Repertoire and the Influence of Schubert...........................12

The Segovia-Ponce Relationship.........................................17

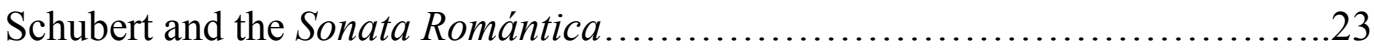

\section{CHAPTER 2:}

Schubert's First Movement Sonata-Allegro Form ….......................26

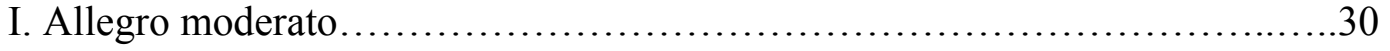

\section{CHAPTER 3:}

Schubert's Lied........................................................ 47

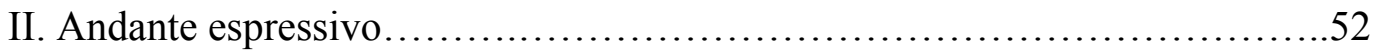

\section{CHAPTER 4:}

Schubert's Moment Musical ...............................................61

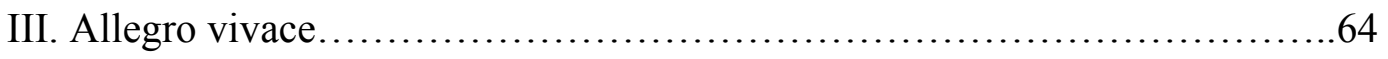




\section{CHAPTER 5:}

Schubert's Finale: Rondo, Variation, and Fantasy...........................74

IV. Allegro non troppo e serioso..................................... 75

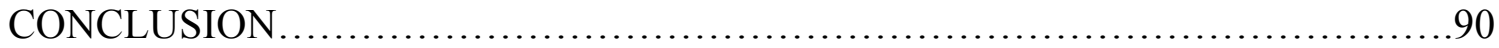

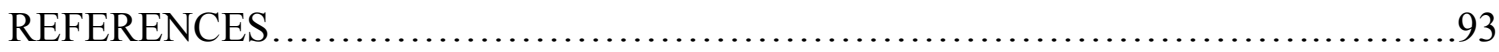

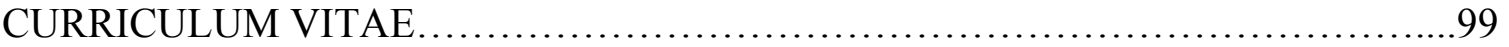




\section{LIST OF MUSICAL EXAMPLES}

MUSICAL EXAMPLE

PAGE

2.1 Franz Schubert, Piano Sonata in A minor, D. 537, mm. 1-28..................27

2.2A Franz Schubert, Piano Sonata in A major, D. 664, mm. 1-15...................32

2.2B Manuel Ponce, Sonata Romántica I. Allegro moderato, mm. 1-17.............32

3.1A Franz Schubert, Der Lindenbaum, mm. 7-12............................50

3.1B Franz Schubert, Der Lindenbaum, mm. 28-32.........................50

4.1A Franz Schubert, Moment Musical, op. 94/5, mm. 1-9.......................65

4.1B Manuel Ponce, Sonata Romántica III. Allegro vivace, mm. 1-9................65

4.2A Franz Schubert, Moment Musical, op. 94/6, mm. 1-10......................67

4.2B Manuel Ponce, Sonata Romántica III. Allegro vivace, mm. 66-73................67

5.1A Franz Schubert, Piano Sonata in Bb major, D. 960, Arpeggiated Figure............................................. 77

5.1B Manuel Ponce, Sonata Romántica IV. Allegro non troppo e serioso Arpeggiated Figure............................................. 77

5.2 Manuel Ponce, Sonata Romántica IV. Allegro non troppo e serioso

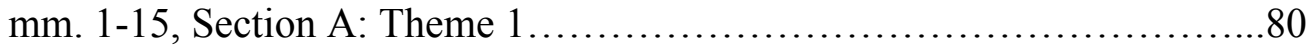

5.3A Manuel Ponce, Sonata Romántica IV. Allegro non troppo e serioso mm. 83-90, Recapitulation in minor II .............................82

5.3B Manuel Ponce, Sonata Romántica IV. Allegro non troppo e serioso mm. 37-44, Section B: Theme 2 ..................................83

5.4A Franz Schubert, Piano Sonata in A minor, D. 845 IV. Rondo, mm. 477-484, Half Note Figure....................................88

5.4B Manuel Ponce, Sonata Romántica IV. Allegro non troppo e serioso mm. 142-149, Half Note Figure. 


\section{LIST OF FIGURES}

FIGURE

PAGE

2.1 Manuel Ponce, Sonata Romántica I. Allegro moderato

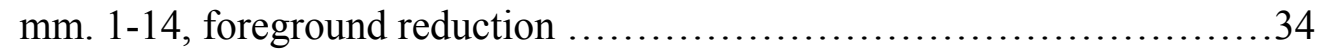

2.2 Manuel Ponce, Sonata Romántica I. Allegro moderato

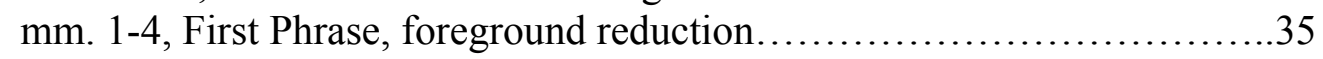

2.3 Manuel Ponce, Sonata Romántica I. Allegro moderato middleground reduction............................................ 36

2.4 Manuel Ponce, Sonata Romántica I. Allegro moderato Deeper middleground reduction...................................... 36

2.5 Motivic and Thematic Material............................................ 38

2.6 Manuel Ponce, Sonata Romántica I. Allegro moderato $\mathrm{mm}$. 14-34, foreground reduction.

2.7 Manuel Ponce, Sonata Romántica I. Allegro moderato mm. 63-74, development foreground reduction

2.7 Manuel Ponce, Sonata Romántica I. Allegro moderato mm. 63-74, development foreground reduction (cont.)

3.1A Manuel Ponce, Sonata Romántica II. Andante espressivo mm. 1-4, Theme I.

3.1B Manuel Ponce, Sonata Romántica II. Andante espressivo mm. 20-23, Theme 2

3.2 Manuel Ponce, Sonata Romántica II. Andante espressivo mm. 12-19, foreground reduction I.

3.3 Manuel Ponce, Sonata Romántica II. Andante espressivo middleground reduction.

3.4A Manuel Ponce, Sonata Romántica II. Andante espressivo Theme I, foreground reduction. 
3.4B Manuel Ponce, Sonata Romántica II. Andante espressivo

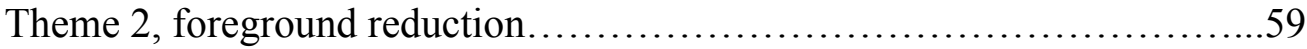

4.1 Manuel Ponce, Sonata Romántica III. Allegro vivace $\mathrm{mm} .1-66$, A section middleground reduction...............................70

4.2 Manuel Ponce, Sonata Romántica III. Allegro vivace $\mathrm{mm} .66-113$, B section, middleground reduction.........................73

5.1 Table of Schubert's Irregular Recapitulations................................. 85

5.1 Table of Schubert's Irregular Recapitulations (Cont.)..........................86 


\section{INTRODUCTION}

The centenary of Franz Schubert's death in 1928 regenerated interest in his piano sonatas, fantasies, and moments musicaux, escalating his popularity and prompting discussion and speculation pertaining to his catalogue. Scholar O. E. Deutsch wrote a number of articles on the subject of Schubert's catalogue during this year, two ${ }^{1}$ of which comment on recent assertions that Schubert possibly composed original works for guitar. ${ }^{2}$ The articles came primarily as a response to Richard Schmid's 1918 essay Schubert als Gitarrist (Schubert as a guitarist), which claimed that Schubert composed for the guitar. ${ }^{3}$ Deutsch and other musicologists vehemently denied such assertions, dismissing them as erroneous speculations. Debating the prominence of the guitar in Schubert's works, or even his affection for the instrument, is beyond the scope of this paper. ${ }^{4}$ However, some documents reveal the guitar set as an accompaniment in Schubert's vocal works. ${ }^{5}$

\footnotetext{
${ }^{1}$ These two articles are O.E. Deutsch, Schubert ohne Gitarre in 'Schubert-Gabe der Oesterreichische Gitarre-Zeitschrift' herausgegeben von Jakob Ortner und Gustav Moissl, Wien (Juni) 1928, Verlag der Oesterreichische Gitarre-Zeitschrift. Friedrich Hofmeister \& Co. pp. 18-26 and O.E. Deutsch, Franz Schubert. Quartett fur Flöte, Gitarre, Bratsche und Violoncello. Besprechung. in: Zeitschrift fir Musikwissenschaft, Leipzig, October 1928, S. 124-126. Both articles cited in Reinhard Van Hoorickx, "Schubert's Guitar Quartet," Societe Belge de Musicologie, 31 (1977): 117, http://www.jstor.org/stable/3686191 (accessed January 30, 2014).

${ }^{2}$ Van Hoorickx, 117.

${ }^{3}$ Schmid's essay is no longer available; however, Van Hoorickx' essay summarizes both arguments.

${ }^{4}$ A more detailed approach of the subject can be found in Stephen Mattingly, "Franz Schubert's chamber music with guitar: A study of the guitar's role in Biedermeier Vienna" (D.M. treatise, Florida State University, 2007).

${ }^{5}$ Deutsch's catalogue only contains one instance of the guitar: Terzetto D. 80 for three male voices and guitar. Most appearances of the guitar in Schubert's repertoire occur as transcriptions, most likely at the liberty of publisher Anton Diabelli, of other instrumental accompaniments in posthumous editions.
} 
Nonetheless, the notion of such a substantial figure composing original works for the guitar piqued the curiosity of composers and guitar enthusiasts alike.

Parallel to this debate, guitarist Andrés Segovia (1893-1987) and Mexican composer Manuel María Ponce (1882-1948) attempted to establish the guitar as reputable concert instrument and create a more substantial repertoire. At Segovia's behest, Ponce composed the Sonata Romántica as an homage to Schubert during the centenary of his death in $1928{ }^{6}$ Subtitled Homage to Franz Schubert who loved the guitar, Ponce avoids directly attributing the piece to Schubert. However, Ponce did create several false attributions to deceased composers in an attempt to garner more attention for the guitar repertoire. ${ }^{7}$ Ponce, also a music critic and researcher, ${ }^{8}$ was aware of the fervor surrounding Schubert and the guitar, and the suggestive subtitle may be understood as shrewdly encouraging the mistaken concepts of Schubert as an enthusiast of the instrument.

Early in their letters, Segovia and Ponce originally referred to this piece as the Sonata on Schubert, ${ }^{9}$ suggesting a more intimate relationship involving additional Schubertian characteristics and procedures. Before the Sonata Romántica s inception, Ponce completed the Sonata Clásica in 1927 as a tribute to guitarist and composer Fernando Sor; the work contains many features that invoke Sor's compositional style. However, Ponce applies the traditions of Sor to a lesser extent in the Sonata Clásica than

\footnotetext{
${ }^{6}$ Though it was not published until 1929, the composition began in May of 1928. Because of the extensive delays with the final movement, Segovia did not perform the piece in its entirety until March 23, 1929.

${ }^{7}$ The most famous piece composed in this manner was the Suite in A minor attributed to lutenist Silvius Leopold Weiss. (See further)

${ }^{8}$ Virginia Covarrubias Ahedo, "Three Main Chamber Music Works for Strings and Piano by the Mexican Composer Manuel M. Ponce” (Doctoral Essay University of Miami, 2008), 11.

9 Andrés Segovia, The Segovia-Ponce Letters, ed. Miguel Alcázar, trans. Peter Segal (Columbus, Ohio: Editions Orphée, 1989), 38.
} 
he does Schubert's characteristics within the Sonata Romántica. Ponce's compositional style presents this piece as an embodiment of Schubert imagined through the guitar medium.

The Sonata Romántica closely follows Schubert's harmonic, tonal, and thematic characteristics, applying them within his four-movement piano sonata paradigm. Ponce establishes intentional references to specific moments of Schubert, attempting to encapsulate the numerous ideas that integrate into a Schubertian aesthetic. Thus, the primary goal of this project is to extract those elements that allow this piece to seem distinctly Schubertian within each movement. Leo Welch cites many references to Schubert in the first movement of the Sonata Romántica in his treatise $;{ }^{10}$ however, his analysis is limited to the first-movement sonata form of Ponce. Revisiting the first movement through a more analytical approach reveals a more detailed comparative relationship to Schubert. A preliminary investigation of Schubert's specific forms and genres provides sufficient evidence for such claims. Expanding upon Welch's investigative research, this document examines how the Sonata Romántica acts as a realization of Schubert's multiple instrumental forms, embodying the characteristics of the lied, moment musical, sonata-allegro, and sonata-rondo. By providing insight into these particular Schubert paradigms, an understanding of Ponce's methodology begins to emerge. The formulation of such assertions begins with an examination into the fourmovement piano sonata model according to Schubert. The application of Schenkerian, harmonic, and thematic analyses to each movement of the Sonata Romántica establishes the Schubertian connection.

\footnotetext{
${ }^{10}$ Leo Welch, "First Movement Sonata Style of Manuel Ponce in his Sonatas for Solo Guitar" (D.M. treatise, Florida State University, 1995).
} 
Understandably, one must beware the caveats of such an endeavor by considering the extent to which Ponce incorporates his own compositional style. Welch comments on Ponce's style within the Sonata Romántica:

... it is more difficult than in the Sonata Clásica to identify exact sources of inspiration that Ponce borrowed from Schubert's music ${ }^{11}$... Ponce subordinates his own personal style to write a work that could possibly have passed for a Schubert sonata. It appears that he painstakingly copies virtually all aspects of Schubert's compositional style... The growth of the sonata design mirrors what Schubert would have written... ${ }^{12}$

Although portions of this study consider the implications of Ponce's own compositional voice against Schubert's, its primary purpose is to encapsulate and extract the distinct Schubertian moments. As this document exemplifies, it is apparent that Ponce possessed a thorough knowledge of Schubert's catalogue, and this knowledge allowed him to compose a seemingly original work of Schubert through the guitar. By outlining the definitive characteristics of Schubert's piano sonatas, short character pieces, and lieder, one may definitively identify their utilization and application within the Sonata Romántica. $^{13}$

The ensuing study considers the specific ways in which Ponce references Schubert through model composition, ${ }^{14}$ in addition to his possible motivation for choosing Schubert. Subsequent chapters examine the individual movements of the Sonata Romántica, providing analytical comparisons and specific citations to establish the characteristic connection to Schubert. Ponce's development and evolution of Schubert's

\footnotetext{
${ }^{11}$ Welch, 82.

${ }^{12}$ Ibid., 103.

${ }^{13}$ Additional research into Ponce's compositions that do not suggest a model compositional approach may provide supplementary evidence to Ponce's originality in his utilization of the Schubert paradigm. However, this project limits itself to the extraction of the Schubertian elements as exhibited within the Sonata Romántica.

${ }^{14}$ Model composition is not to be confused with the term imitation or other compositional techniques, model composition is used to denote Ponce's ability to mimic specific compositional styles and procedures.
} 
piano sonata form manifests within the four-movement structure of the Sonata Romántica; signifying a type of chronological progression through Schubert's works. Each section attempts to establish the evidentiary support of the Sonata Romántica as an amalgamation of Schubert's form and genre by examining Schubert's lied, early sonataallegro form, moment musical, and finale form. 


\section{CHAPTER 1}

\section{EARLY LIFE AND STUDIES UNTIL 1925}

Manuel María Ponce was born in the town of Fresnillo in Zacatecas, Mexico on December 8, 1882. Born to a musical family, he began his studies on the piano at age four with his sister, Josefina, until he moved to Aguascalientes to study with Cipriano Ávila. ${ }^{15}$ He was a gifted pianist and at the age of five produced his first piano composition. ${ }^{16}$ In Aguascalientes, he joined the choir at Saint Diego where he became assistant organist in $1895 .{ }^{17}$ A child prodigy, he became the principle organist by the age of sixteen. Ponce moved to Mexico City in 1901 to study piano with Vicente Mañas and harmony with Eduardo Gabrielli. He applied for admission to the National Conservatory; however, the administration refused to acknowledge his previous studies and only allowed Ponce entrance at the primary level. Frustrated, he withdrew after only one year. $^{18}$

During the early part of the twentieth century, Ponce developed his compositional technique by exploring Mexican folks songs. It was at this time that he developed a fondness for Romantic piano works imported from Europe. In 1904, Ponce departed on his first trip to Europe in pursuit of a European education in music. In Bologna, Ponce

\footnotetext{
${ }^{15}$ Peter S. Poulos, "Towards a Contemporary Style: Manuel M. Ponce's neoclassical Compositions for Guitar" (Thesis, University of Cincinnati: College Conservatory of Music, 1994), 10.

${ }^{16}$ Corazón Otero, Manuel M. Ponce and the Guitar (Somerset, England: Musical New Services Limited, 1980), 8.

${ }^{17}$ Ibid., 9.

${ }^{18}$ Ahedo, 2.
} 
studied harmony, counterpoint, fugue, and orchestration with Cesare Dall'Olio, Luigi

Torchi, and Ebrico Bossi. ${ }^{19}$ In a letter from Bossi to Ponce's harmony teacher Gabrielli,

Bossi reflects on why he initially rejected Ponce as a student and his explanation to

Ponce:

In 1905 one should write music of $1905 \ldots$ or even 1920 , but never music of 1830. You have talent, but you lack knowledge of musical technique. My occupations keep me from taking you on as a student, but I will recommend you to professor Dall'Olio, Puccini's teacher; in that way, you will have, though distantly, an illustrious fellow student. ${ }^{20}$

In 1905, he moved to Berlin to attend the Stern'sches Konservatorium der Musik and studied with Edwin Fisher. Additionally, Ponce had the opportunity to study with Martin Krause, a disciple of Liszt. ${ }^{21}$ It was here that Ponce began to develop his technique in Romantic music through the influence of Liszt's Romantic School. Ponce's Germanic education would heavily influence his compositional style. Krause was a demanding teacher, often making his students play the preludes from J.S. Bach's WellTempered Clavier transposed into different keys. Ponce wrote in a letter to his brother about a particular moment during his audition that exemplified the German nationalistic superiority:

I played Hummel's Sonata and my etude... The Director, with an ironic smile, said in German: Italian style! In that phrase, I got the German's victorious musical pride over the Italians, since the modern composers of this nationality follow more or less the path traced by the colossal Wagner. $^{22}$

\footnotetext{
${ }^{19}$ Ahedo, 3 .
}

${ }^{20}$ Bossi's letter to Gabrielli dated 2 February 1905. Cited from Manuel María Ponce: A BioBibliography (Westport, CT: Praeger Publishers, 2004), p. 4.

${ }^{21}$ Poulos, 11.

${ }^{22}$ Yolanda Moreno Rivas, Rostros del Nacionalismo en la Musica Mexicana: un ensayo de interpretation (Faces of nationalism in Mexican music: an Interpretive essay), 2nd ed. (Mexico: UNAM Escuela Nacional de Musica, 1995), 92, Manuel M. Ponce, quoted in Ahedo, 3. 
Ponce's familiarity with Schubert's work, in addition to his training in the German Romantic School, suggests this time as a possible precursor to his choice of Schubert as a point of inspiration.

Ponce returned to Mexico in 1907, accepted a position as an instructor of music at the National Conservatory in Mexico City, and eventually appointed Professor of Piano in 1918. He began primarily teaching the music of French impressionists ${ }^{23}$ and in 1912 was responsible for organizing the first all-Debussy recital in Mexico. ${ }^{24}$ During this time, Ponce began to gain recognition as a scholar, lecturer, and leading Mexican nationalist composer. Carnegie Hall and broadcast radio variety shows frequently performed Ponce's most famous folk song, Estrellita. Performance venues in the United States frequently programmed Ponce's compositions; however, Ponce attended only one concert of his works, in 1916 in New York City. Critics labeled his works as unoriginal and obsolete. His unfavorable reception left Ponce with a reasonable distain for New York and he never returned to the United States.

Upon the beginning of the Mexican Revolution (1910-1920), Ponce began to compose mostly in the folk genre. Ponce fled to Havana, Cuba and resided there from 1915 to 1917. The conservatory where Ponce worked in Mexico shut down and left him without students or source of income. ${ }^{25}$ The various cultural influences in Cuba greatly affected Ponce's compositional style. Inspired by the local folk music, Ponce produced numerous works during this time, referencing the formal structures of Liszt and Chopin learned during his first tenure in Europe.

\footnotetext{
${ }^{23}$ Ahedo, 4.

${ }^{24}$ Poulos, 12.

${ }^{25}$ Jorge Barrón Corvera, Manuel María Ponce: A Bio-Bibliography (Westport, CT: Praeger Publishers, 2004), 8.
} 
In 1917, the National Symphony of Mexico City appointed Ponce as conductor. Ponce also became a prolific writer, serving as editor for Revista Musical de Mexico for the next several years. By the time Ponce was forty-three years old, his dissatisfaction with his compositional direction encouraged him to explore educational possibilities abroad. ${ }^{26}$ Aware of the atonal and dodecaphonic works of European composers, Ponce traveled to Europe for a second time to revitalize his compositional language. ${ }^{27}$ The Ministry of Education of Mexico City commissioned Ponce to study in Europe in 1925, allowing him to enroll in the École Normale de Musique under the tutelage of Paul Dukas and Nadia Boulanger.

\section{Influence of Paul Dukas, Nadia Boulanger, and Igor Stravinsky}

Ponce's position and experience studying in Paris with Paul Dukas proved influential in determining the output of model compositions. Paul Dukas, composer and contemporary of Debussy, accepted Ponce into the École Normale de Musique as a student. This period marks what many historians cite as the modernista phase of his career. Alejandro L. Madrid-González divides Ponce's work into three stylistic periods:

1) Early Romantic style (1898-1915)

2) Nationalist folk and chamber music (1915-1924)

3) Modernist work (1925-1948) ${ }^{28}$

This categorical approach largely ignores Ponce's Parisian work, especially within the guitar repertoire. The categorical approach listed above excludes many of Ponce's

${ }^{26}$ Kevin Manderville, "Manuel Ponce and the Suite in A minor: Its Historical Significance and an Examination of Existing Editions" (D.M.A. treatise, Florida State University, 2005), 6.

27 Ahedo, 9.

${ }^{28}$ Alejandro L. Madrid-González, "Writing Modernist Avant-Garde Music in Mexico: Performativity, Transculturation, and Identity After the Revolution" (Ph.D. diss., Ohio State University, 2003), 115. 
compositions, including his pastiche ${ }^{29}$ works. Ponce later wrote about his intentions of moving to Europe:

In 1925, my wife and I decided to travel to Europe, to Paris. We planned to stay for six months but lived there for nine years... Paul Dukas, who soon honored me with his sympathy and friendship, got me a job; I personally acquainted myself with the best creators of that timecomposers, performers, writers, painters, actors... the Parisian atmosphere cast a spell on us and retained us. ${ }^{30}$

Ponce intended to expand his technical and compositional language, which was often seen as too conservative and outdated, ${ }^{31}$ through his studies with Boulanger and Dukas. Ponce's training with Dukas allowed him to develop and embrace his post-Romantic techniques while simultaneously honing his imitative skills. It was in Paris that Ponce found joy composing in varying compositional styles and periods. Upon the completion of his tenure in Paris in 1932, Dukas stated:

The compositions of Manuel M. Ponce have the stamp of the most distinguished talent. They cannot be classified according to any scholastic criteria. I would feel reticent to assign him a grade even if it were the highest one, in order to express my satisfaction at having had a disciple so outstanding and personal. ${ }^{32}$

Ponce's compositional tendencies allowed him to transition into the resurging Classical and Romantic practices in the French contemporary music culture of the 1920s.

Russian composer Igor Stravinsky, arguably the first to explore the new aesthetic of neo-classicism, experimented with the forms and procedures of passé composers in his 1920 ballet Pulcinella. However, unlike Ponce, Stravinsky employs a more satirical element within this genre, supplemented with his own unique compositional voice.

Ponce's studies in avant-garde compositional styles and techniques examined the genesis

${ }^{29}$ Work written in the direct manner and compositional style of a previous composer.

${ }^{30}$ F. Gómez Hidalgo, "Creadores de México. El maestro Ponce," Estampa (Mexico City), 2 February 1943, 15-16 cited in Corvera, 13.

${ }^{31}$ See Bossi letter above.

${ }^{32}$ Dukas quoted in Corvera, 14. 
and development of these neo-classical practices. Though not composed in the typical neo-classical manner, the Sonata Romántica exhibits a certain Stravinskian influence. Ponce states in an interview in 1928:

My recent compositions are different from the previous. There are those who make modern music for fashion, or because they feel the need to be in vogue. I do not. If I write modern music it is because my style has been honestly modified by getting in contact with this new world of notes... Above all, Igor Stravinsky... is for me the genius... he who has followed the parabolic projection of his inspiration will agree that this master has no comparison. ${ }^{33}$

While Ponce composed the Sonata Romántica at the behest of Segovia, who had a rather conservative taste in repertoire, his model compositions or "newly discovered" works may have been may have been less desirable to larger audiences had it not been for Stravinsky's prominence. It would be imprudent to assume Ponce had not studied Stravinsky's scores and stylistic tendencies while living in Paris near the Ballet Russe and contributing as a researcher and critic for the Gaceta Musicál, which Ponce founded. Stravinsky's work and success in the field of dated forms and procedures allowed Ponce to compose his pastiche works with wider acceptance.

Ponce's studies with Dukas reveal more about his pastiche imitations and conceptions. Composition classes with Dukas consisted of imitative procedures pertaining to certain stylistic periods or compositional manners. Dukas would frequently perform piano sonatas in the manner of a specific composer and exemplify the characteristics of that person. Dukas' assignment of Beethoven strongly affected Ponce and his future work in the field of model composition. Ponce wrote of his experience in Dukas' composition course:

\footnotetext{
${ }^{33}$ Ricardo Miranda, "Exploration y Sintesis en la Musica de Manuel M. Ponce (primera parte)" (Exploration and synthesis in the music by Manuel M. Ponce [first part]) Pauta, July-September, 1998, 63 cited in Ahedo, "Three Main Chamber Music Works," 71.
} 
His course dealt with advanced composition and critical analysis of musical works. Seated in front of a piano, surrounded by his disciples, which made quite an international group, he corrected and criticized the most diverse works: a symphonic fragment, an excerpt for piano, a sonata, a fugue, a string quartet...

The second half of the class was used by the teacher to analyze and comment on the most beautiful works of musical literature. He developed a vast plan, which covered the noblest forms used by the greatest musicians: the sonata, the variation, the quartet, the symphony, etc. The course of 1927 ended with a complete study of Beethoven's Quartets: a beautiful homage in the year of his [Beethoven's] anniversary! ${ }^{34}$

The impact of working with Dukas in this manner, in addition to Ponce's delight in studying Beethoven's String Quartets, possibly encouraged the composition of the Sonata Romántica a year later during the centenary of Schubert's death.

Ponce also had an opportunity to study with the renowned pedagogue, Nadia Boulanger. Dukas and Boulanger used contrasting pedagogical methods: Dukas emphasized the applied approach of imitating composers with certain stylistic idiosyncrasies, whereas Boulanger used a more individualized approach to develop each composer's unique voice. Dukas would become much more influential to Ponce as a composer; however, another student of Boulanger, Edgar Varèse, would become a good friend of Ponce and later encourage his more modernist works.

\section{The Guitar Repertoire and the Influence of Schubert}

Through 1928, many people recognized the guitar through the concert repertoire of Segovia, which featured numerous arrangements and transcriptions of Classical and Baroque works with few original contemporary guitar compositions. The guitar repertoire of the nineteenth century features hundreds of compositions, although few of the

\footnotetext{
${ }^{34}$ Letter from Ponce quoted in Nuevos escritos musicales, 168, 170, cited from Corvera, 14.
} 
composers of these works wrote outside of the instrument. ${ }^{35}$ Solo guitar repertoire of the early twentieth-century retained perceptible Romantic influence, as opposed to the works of progressive composers such as Richard Strauss, Stravinsky and Schoenberg, ${ }^{36}$ all of whom composed in contemporary idioms. Many of the early twentieth-century guitar compositions were composed in manners representative of twenty to thirty years prior. One can trace this delayed stylistic tendency to the late eighteenth-century guitar composers Fernando Sor (1778-1839) and Mauro Giuliani (1781-1829), who consistently composed in the Classical style well into the nineteenth-century. Segovia contributed to the conservative tendencies of contemporary guitar compositions by requesting repertoire composed in Romantic, Classical, or Baroque fashions. Though the compositions of guitarists such as Francisco Tárrega (1852-1909) and Miguel Llobet (1878-1938) are highly respected today, early twentieth-century guitar composers faced ridicule through comparisons to other Romantic composers. Segovia cites the harsh critical reaction against the guitar by a member of the Ateneo $^{37}$ :

I have little to say about the guitar concert because I didn't have the patience to sit it out so I left before the second part was over. That stupid young fellow is making useless efforts to change the guitar... The guitar responds to the passionate exaltation of Andalusian folk-lore, but not to the precision, order, and structure of classical music. Only a fool would dare violate the laws, which separate these two worlds, the flesh and the spirit, the senses and the intellect. ${ }^{38}$

Another critic attending the same concert states:

\footnotetext{
${ }^{35}$ Some of these exceptions are Fernando Sor and Mauro Giuliani who composed a wide variety of works and were not primarily known for their guitar compositions.

${ }^{36}$ Schoenberg included the guitar in his Serenade, op. 24. He began composing this work in 1920 , suggesting the guitar may have been involved with the first dodecaphonic composition.

37 The Ateneo Cientifico, Literario y Artístico de Madrid is a private cultural institution dedicated to the preservation of art, science and literature located in Madrid, Spain.

${ }^{38}$ Andrés Segovia, Andrés Segovia: An Autobiography of the Years 1893-1920, trans. W.F. O’Brien, (New York: Macmillan Publishing Company, 1976), 71.
} 
I think the nature of the instrument is more suitable for the minor works of Albéniz and Malats, for instance. They tell me this young fellow even plays Bach fugues. To me, this seems like teaching a dog to do clever tricks. What would be really interesting - if we knew the instrument better and if the guitar were to attract enough virtuosos - would be to create a typical Spanish repertoire for it. ${ }^{39}$

This last statement effectively summarizes the obstacles of early guitarists and composers for the guitar, especially in Spain. Many of these criticisms arose from the ignorance of the critics' familiarity with the instrument. The disdain for the instrument and its supporters did not cease at the limited available repertoire, but extended to the instrument itself. Vocal contempt for the instrument stemmed primarily from Spain, where they culturally associated the guitar as a folk-instrument performed in cafés. ${ }^{40}$ These negative connotations plagued Segovia throughout his career in his attempt to achieve a broader acceptance for the instrument in schools, conservatories, and universities. At the beginning of Ponce and Segovia's relationship, no educational program existed for the guitar. However, the collaborations with Ponce greatly improved the guitar's position as a reputable concert instrument by the middle of the twentieth-century, increasing its frequency in higher education institutions. Segovia reflects on his struggles with the instrument and its reputation in his 1976 autobiography:

I found the guitar almost at a standstill - despite the noble efforts of Sor, Tárrega, Llobet and others... the guitar lacked a legitimate or even usable repertoire, today a surprising number of works have been and continue to be written for it by renowned composers. ${ }^{41}$

Critical responses to Segovia's repertoire reveal contempt towards original guitar compositions and a condescending attitude towards transcriptions:

\footnotetext{
${ }^{39}$ Segovia, 73.

${ }^{40}$ These declarations of contempt may be magnified as Segovia himself perpetuated much of the information regarding the guitar in the early twentieth-century. It is evident by the works of Schoenberg that the guitar was not as neglected as originally perceived by Segovia. However, the guitar did lack a substantial solo repertoire from well-known composers.

${ }^{41}$ Ibid., viii.
} 
Their Eminences ${ }^{42}$ were crossing themselves at the thought of a sacrilegious spree in the hall, while the young ones snickered at the word "music," when I mentioned that your repertoire includes Haydn, Mozart, Schubert... They actually believed I was talking about some hilarious musical parody! ${ }^{43}$

Hence, the collaboration with a composer who could help establish a more substantial guitar repertoire becomes more historically significant. The guitar lacked substantial repertoire among the established compositional figures of the nineteenth-century. The gap in the guitar repertoire among reputable composers, in addition to the piano becoming the primary chamber instrument in the nineteenth century, contributed to this lack of recognition. Ponce's guitar sonatas became a momentous contribution to the guitar canon as their length and complexity are rarely approached in other known guitar compositions. Ponce's imitative composition allowed Segovia an attempt to silence the critics with performances reflecting the works of significant and respected composers. The Sonata Romántica became the first of Ponce's sonatas to imitate a composer of such magnitude, representing a figure from the first Viennese School. ${ }^{44}$

Although Ponce and Segovia supported the erroneous assumption of Schubert's affectionate relationship with the guitar, it would not be difficult for mass audiences to accept this notion. Given Schubert's large output of various chamber music works, in addition to the unusual instrumentation of the Arpeggione Sonata, it is conceivable that those uninvolved with his cataloguing would accept the flawed notion over other late Classical contemporaries such as Mozart or Beethoven, thereby making Schubert the most appropriate choice among composers of the First Viennese School. Schubert's

\footnotetext{
${ }^{42}$ Members of the Ateneo.

${ }^{43}$ Pepe Chacón quoted in Andrés Segovia, 64-65.

${ }^{44}$ Other model compositions include the Sonata Clásica and the Suite in A minor, which is still
} attributed to Weiss in some recordings. 
sonatas were not well known or studied by many through the beginning of the twentieth century. ${ }^{45}$ Alfred Brendel cites that even Rachmaninov, in 1928, admitted to César Saerchinger that he had not realized sonatas by Schubert existed. ${ }^{46}$ Though Segovia and Ponce did not directly attribute the piece as Schubert, most likely due to the fervor surround his works during his centenary, their assumption of Schubert's affection furthered the possibilities for a more respectable future for guitar compositions. Segovia and Ponce agreed to publish the Sonata Romántica as a dedication to Schubert instead of directly attributing the piece to him, circumventing any possible rebuttal from Schubert scholars. The claim of Schubert's affection for the guitar becomes much more difficult to contradict, as much as it is to prove.

Many variables contributed to influencing Segovia and Ponce's choice of Schubert as a compositional model. Ponce suffered from numerous economic misfortunes during his stay in Paris. ${ }^{47}$ The stipend ensured by the Mexican government did not arrive and Ponce became dependent on various business ventures, such as the Gaceta Musicál. Segovia's rising popularity, and a growing demand for new repertoire, became a hopeful initiative for Ponce's compositions. Segovia previously established a close relationship with Schott publishers and made numerous suggestions to Ponce regarding negotiations of royalties. Segovia recognized Ponce's poor economic situation and attempted to offer personal compensation:

I am enthusiastic about the [Schubert] Sonata. I work night and day... It is the only thing I work on... Today I have written to Schott, he will speak to you immediately about the terms. If you have need for money ask me but do not undersell the Sonata. So sign a contract asking for ten percent of

\footnotetext{
${ }^{45}$ Deutsch published Schubert's catalogue in 1951.

${ }^{46}$ Alfred Brendel, "Schubert's Piano Sonatas, 1822-1828," On Music (Chicago Review Press: Chicago), 134.

${ }^{47}$ Otero, 43.
} 
the sales, and that they tell you the number of issues that will be run off, how many sold, you can change the form of the agreement... But do not say, for anything, that I had given you advice. ${ }^{48}$

Schubert's historical influence impacted Ponce beyond the temporary resurgence of his works. Ponce's compositional education in Germany greatly affected his compositional education and future. Romanticism pervaded much of his earlier compositions, resulting in many viewing Ponce's style as outdated for twentieth-century composition, as referenced by Bossi in his letters. Ironically, this particular compositional tendency possibly allowed the Sonata Romántica to become a convincing Schubertian composition.

\section{The Segovia-Ponce Relationship}

Ponce's work with guitar began with the introduction to Andrés Segovia in 1923. Ponce attended Segovia's Mexico City debut in June of the same year, acting as a music critic for El Universal in Mexico City. Ponce wrote in his review of Segovia's concert:

To hear the notes of the guitar played by Andrés Segovia is to experience a feeling of intimacy and the well-being of the domestic hearth; it is to evoke remote and tender emotions wrapped in the mysterious enchantment of things of the past; it is to open the spirit to dreams, and to live some delicious moments in the surroundings of pure art that the great Spanish artist knows how to create... ${ }^{49}$

Segovia, aware of Ponce's work as a great Mexican composer, reached out to him directly. ${ }^{50}$ In an attempt to establish a more substantial guitar repertoire, Segovia often pursued many non-guitarist composers. Aware of the reputation of the guitar as primarily a folk instrument, Segovia hoped that Ponce's work would elevate its stature to the

\footnotetext{
${ }^{48}$ Alcázar, 38 .

${ }^{49}$ Manuel Ponce, "Musical Chronicles" El Universal, June 5, 1923 cited from Manderville, 6.

${ }^{50}$ Poulos, 22.
} 
concert stage. Ponce's relationship with Segovia was a prime factor in the development of the Sonata Romántica. The relationship between the two figures, before and during the compositional process, provides essential insight to the genesis of the piece and the collaborative efforts in creating a more substantial guitar repertoire.

This partnership marked the beginning of one of the most significant relationships for the classical guitar repertoire in the twentieth century. Segovia hailed Ponce as the most important composer for the guitar in the period. ${ }^{51}$ Segovia and Ponce would have a slight falling out in 1924, but rekindled their relationship during Ponce's second European trip in 1926. During this period, Ponce became acquainted with many influential composers, such as Varèse, Rodrigo, and Villa-Lobos. In his dissertation, Jay Smith postulates that the compositions of Joaquín Rodrigo (1901-1999) and Heitor VillaLobos (1887-1959), 52 along with Segovia's demand for repertoire, sparked the beginning of Ponce's fascination with the guitar. ${ }^{53}$ While Rodrigo and Villa-Lobos produced many guitar works in their lifetime, the majority of their output came well after their time together in Paris. Although neither claimed the guitar as their primary instrument, they each had a significant impact on the twentieth-century guitar repertoire. ${ }^{54}$

Unfortunately, only Segovia's letters to Ponce survived, leaving a limited understanding of their collaborative efforts. Segovia's letters claim Ponce's were likely

${ }^{51}$ Alcázar, 50.

52 These two composers shaped the compositional trajectory of the twentieth-century guitar repertoire. It is impossible to overstate the importance each had in developing significant works for the guitar. Joaquín Rodrigo most notably composed the Concerto de Aranjuez, while Villa-Lobos' 12 Etudes are among the most widely performed concert works.

53 Jay Smith, "An Overview and Performance Guide to Manuel Ponce's Sonata III for Solo Guitar" (D.M.A. treatise, University of North Texas, 2006), 3.

${ }^{54}$ Rodrigo's primary instrument was the piano. Villa-Lobos' instrument was the cello; however, he had some introduction to the guitar in Brazil. 
destroyed with his other belongings during the Spanish Civil war in $1936 .^{55}$ The Segovia/Ponce letters reveal that a close friendship had quickly emerged. Ponce, not having worked with the guitar in a compositional capacity, relied heavily on Segovia's suggestions and input. Many times, as was the case with the Sonata Romántica, Ponce composed on the piano and offer the music to Segovia for revisions.

Segovia delighted in presenting Ponce's work in various concerts throughout Europe and North America. Ponce's imitative abilities were becoming convincing enough to fool expert musicologists. Segovia, unrelenting in his pursuit to create a respectable atmosphere for the guitar on the concert stage, encouraged Ponce to write more original guitar repertoire in the styles of established composers. Segovia frequently attributed the pastiche sonatas to the impersonated composer.

The most famous deception came with Ponce's Suite in A minor attributed to lutenist Silvius Leopold Weiss (1687-750), ${ }^{56}$ referred to as Julius in Segovia’s letters. Initially, Segovia intended to attribute the Suite to J.S. Bach. However, because Bach's works were too thoroughly documented to permit a false attribution, Segovia settled on Weiss. ${ }^{57}$ Segovia provides some insight as to the process Ponce most likely took in arranging his guitar compositions:

The Julius Weiss Suite is in my fingers. It is beautiful, and I am thinking of playing it in New York on the 8th. But I need another gigue.... The one you wrote for me is too innocent for an ending. Spend fifteen minutes at the piano, and write one for me all in arpeggios, with some notes set apart for a melody, sometimes on top and others on the bottom.... Okay? ${ }^{58}$

\footnotetext{
55 Alcázar, 168.

${ }^{56}$ Virtuoso and contemporary of Bach.

${ }^{57}$ Manderville, 21.

${ }^{58}$ Alcázar, 49.
} 
Segovia included Ponce's compositions on most of his concert programs and attributed his works to various composers. ${ }^{59}$ Segovia delighted in informing curious spectators of the true origins of the pieces and their composer. A particular encounter between Segovia and Heitor Villa-Lobos, who was introducing Segovia to his Preludes, shows Segovia's joy of deceiving listeners:

I could not help then resisting the temptation of having him know the suite in a minor that you wrote for me.... I waited a while, so the comparison (to his Preludes) would not be too violent, in the meantime, I played the concerto of Castelnuovo, accompanied by Paquita, and afterward, I played the Suite, with no previous explanation. Phrase by phrase, movement by movement, there was a constant expression of pleasure and surprise on his part. And he repeated: "There is nothing like Bach. He is wonderful. Delightful." etc., etc. When I finished, I told him: Do you know who has written this? And he, who was left very surprised at the possibility that it had been someone else other than Bach, said: "Who?" Well Manuel Ponce, I let fall softly... His astonishment was genuine and he did not take the trouble to disguise it. ${ }^{60}$

Numerous changes occur between the manuscript and the Segovia edition of the

Sonata Romántica. The revisions came mostly because of certain idiosyncrasies that made certain passages unplayable. It is unclear, due to lack of documentation, as to whether these changes came in response to technical impossibilities. Unfortunately, the fourth movement, for which Segovia suggested the most revisions, is not extant in manuscript form. Segovia commented in his letter:

I threw myself into the finale like a hungry dog... and I am furious with the guitar. What you least imagine - for the first time with your music!! comes out impossible: the arpeggios... And you have coincided with the same type of difficulty that makes the prelude in E major by Bach unbridgeable for guitar.

Example: You do like this: ${ }^{61}$

\footnotetext{
${ }^{59}$ Manderville, 27-29.

${ }^{60}$ Alcázar, 214.

${ }^{61}$ Graphic recomposed to include clef and time signature.
} 


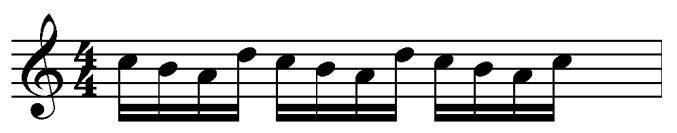

And Bach like this:

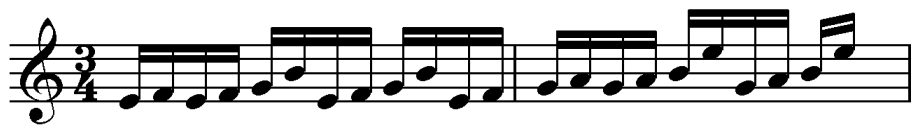

And the difficulty, in both passages, is that it is necessary to have a succession of stepwise intervals on the same string, staying, at the same time, in one position, at times senselessly, in order to strike the disjunct note of the arpeggio. Do you understand? On the guitar, the technique of the arpeggio is derived almost strictly from the possibilities of the blocked chord. What is not possible in a chord struck together, is not possible in arpeggiation, unless it is played very slowly.

How are you going to fix this? I am truly desperate, because I like it as it is. Rescue it however you can, please! Do not modify the rhythm, nor the melodic disposition of the chords: change the form of the arpeggio.

You will see how well the three previous movements go. The andante is delightful: among the best that Schubert left without doing. I spend all day playing it. The guitar sounds delightful. ${ }^{62}$

This passage exemplifies how Segovia attempted to guide Ponce in the idiosyncrasies of the guitar without altering the primary material. Segovia suggests moments of recomposing due to personal tastes in other letters to no avail:

...I have already studied the Schubert Sonata. I am enthusiastic about it. The last movement is splendid. The chords come out magnificently, but I think the arpeggios that follow the chords, cool-off the finale a little. What do you think? I did not notice it before because the study of the full work was not yet constituted. The arpeggios I refer to are these:

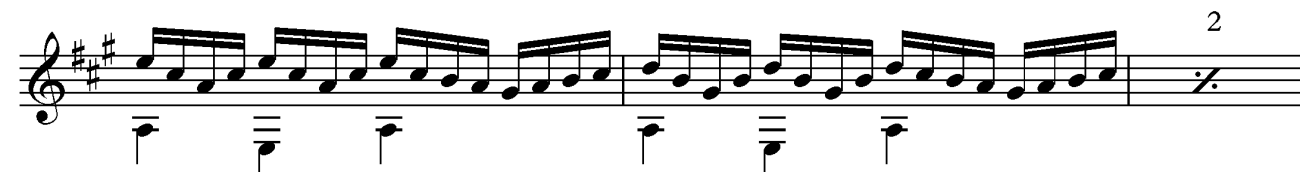

${ }^{62}$ Alcázar, 39. 
The ones that follow these, decrescendo, are fine, for example:

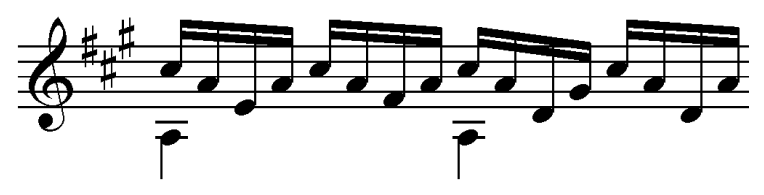

This is fine. Why don't you set up that first phrase with some other one that leads to this passage better? Do it and send it to me at once. ${ }^{63}$

While there is no record of the final-movement manuscript of which to compare, the final edition reveals that Ponce ignored these requests from Segovia, at least in this particular passage, thereby limiting Segovia's compositional influence. It is clear from these exchanges that while Ponce respected the technical input of Segovia, Ponce possessed the final creative opinion.

By eliminating Segovia as a co-composer and imagining Ponce as the sole creative force, one may speculate as to the specific sources of inspiration. Segovia's request of a sonata composed in the manner of Schubert compelled Ponce to explore the composer's repertoire and convincingly grasp the movements, genres, and forms that were distinctly unique. Ponce does not directly reveal the specific sources of inspiration; however, one may begin to deduce such choices by examining the Schubert canon.

Although Segovia requested an original work for the guitar, it is likely Ponce first composed the piece at the piano. This manner of composing is quite common; however, it is ironic that a piece intended as an original guitar work imitating the piano compositions of Schubert manifested first on the piano. The first unofficial performance of the Sonata Romántica occurred on the piano by Ponce himself. Segovia remarks to Ponce's wife in a letter on this subject:

${ }^{63}$ Alcázar, 45 
(...) Manuel is with me now. We have gone to the Avenue Mack Malcon and there he had me hear the Sonata on Schubert, which made me come unglued. Now I have work for Geneva-! ${ }^{64}$

Perhaps in an effort to retain the characteristics of Schubert, Ponce found it helpful to originally conceive the piece as a piano composition. The Sonata's close association with the piano provides a deeper understanding as to its development and conception as Schubert piano work reimagined for the guitar.

\section{Schubert and the Sonata Romántica}

The Sonata Romántica contains numerous elements of Schubert's solo instrumental works. The frequency in which Schubert composed in a particular genre is debatable due to their overlapping nature throughout his career. However, certain periods of Schubert's lifetime produced quantifiably more works in particular forms. Schubert composed his lieder throughout his life, while the short character pieces came during the years just before his death. Schubert established his command of four-movement sonata form by 1828 , composing three complete four-movement piano sonatas. Each of Schubert's four-movement piano sonatas contain a predictable tempo indication within each movement reflective of its formal structure. That is, each sonata contains a fast firstmovement, typically in sonata-allegro form, an adagio or andante second-movement, a third-movement, usually indicated as a scherzo or minuet and trio with an allegro vivace indicator, and a fast fourth-movement. Thus, after observing the similar tempo indicators in the Sonata Romántica, it is apparent that Ponce implicates Schubert's piano sonata form through a similar treatment of these elements.

\footnotetext{
${ }^{64}$ Alcázar, 36.
} 
Beginning from the last movement of the Sonata Romántica, the tempo indicator Allegro non troppo exhibits a connection to the final movement of Schubert's last piano sonata, D. 960. Of Schubert's complete four-movement sonatas, only D. 960 contains this specific indicator. Interestingly, it is also the indicator of the first movement of his first piano sonata attempt, D. 157 . The third movement indicates Allegro vivace, typically seen in the Scherzo third movement of Schubert's later piano sonatas, such as D. 784, 845, 850, 959 and 960. The Andante second movement occurs concurrently throughout Schubert's piano sonatas. Schubert features the Allegro moderato in the earlier piano sonatas, more commonly in the incomplete editions of D. 279 , the somewhat awkward five-movement D. 459, and D.s 557, 567/8, and 664.

Such observations, I propose, are beyond speculation or coincidence. These demarcations provide the framework of a complete Schubertian piano sonata realized throughout his catalogue. Ponce manifests these ideas and alters their model to appropriate Schubert's other genres, including the lied and moment musical. The subsequent sections of this chapter exhibit evidence for this hypothesis supplemented with specific citations within Schubert's compositions. The Schubert catalogue is as complex as it is extensive, providing numerous creative possibilities. However, by limiting these observations to solo or chamber repertoire, one discovers Schubert's most prolific and popular genres to be the lied, short character pieces (moment musical and Impromptus) and solo piano sonatas. It is possible Ponce himself restricted his scope to these works in order to work with more applicable models. Considering Schubert's fourmovement sonata form, one may speculate as to how these forms may manifest within an existing paradigm. Because the Sonata Romántica contains four-movements and 
composed for a solo instrument, one may choose to investigate Schubert's piano sonatas as the primary source.

Ponce imparts the Sonata Romántica with a large-scale form that matches Schubert's sonatas, balancing the movements according to similar length, harmonic characteristics, and tempo markings. However, Ponce's manuscript reveals a more intimate and intentional relationship to other Schubert compositions, such as the Moments Musicaux, which he models in the third movement of the Sonata Romántica. The following chapters categorize and interpret these distinct forms of Schubert following historical comparisons and applying specific instances of Schubert to the work of Ponce. This investigation explores those characteristics that recognize Ponce's sonata as distinctly Schubertian, describing the distinct physiognomies of Schubert's forms and citing specific findings within the Sonata Romántica.

To discover the wealth of other Schubertian references within the Sonata Romántica requires a more in-depth exploration of Schubert's approach to sonata form, particularly as it relates to Ponce's perception and understanding of Schubert.

Formulating a more complete understanding of the first movement - indeed the entirety of Schubert's sonata form, necessitates a descriptive distinction of Schubert's form and characteristics. 


\section{CHAPTER 2}

\section{SCHUBERT'S FIRST MOVEMENT SONATA-ALLEGRO FORM}

The first movement of the Sonata Romántica contains the most direct influence of Schubert's piano sonata style. The formal structure reflects Schubert's earlier firstmovement sonata form, which exhibited many Classical tendencies. That is, Schubert retains the general outlines of sonata-allegro form with an exposition, development, and recapitulation. Schubert's early piano works still followed the model of the classical piano sonata; however, Schubert varied the treatment of the sonata principle, distinguishing his works from his predecessors and contemporaries. His earliest piano works attempt to alleviate the restrictive qualities of Classical sonata form by incorporating compositional elements from his fantasy that fixate on thematic or motivic development as opposed to tonal objectives. The Sonata in A minor, D. 537 exhibits Schubert's motivic fixation featured in his earlier piano sonatas.

The rhythmic motif, shown in the treble clef in measure 1, persists throughout the opening passage; it acts as a sequential pattern left unresolved by the whole rest in measure 27, only to alter character in the next measure. That is, Schubert abruptly changes from an increasingly frantic trajectory to a contrasting calm and resolute passage, typically in a different key. While the sonata structure remains intact (retaining an exposition, development, and recapitulation), Schubert's lyrical and motivic treatment causes a sense of aimlessness, focusing primarily on motivic ideas instead of 
MUSICAL EXAMPLE 2.1

Piano Sonata in A Minor, D. 537-Schubert

Measures 1-28

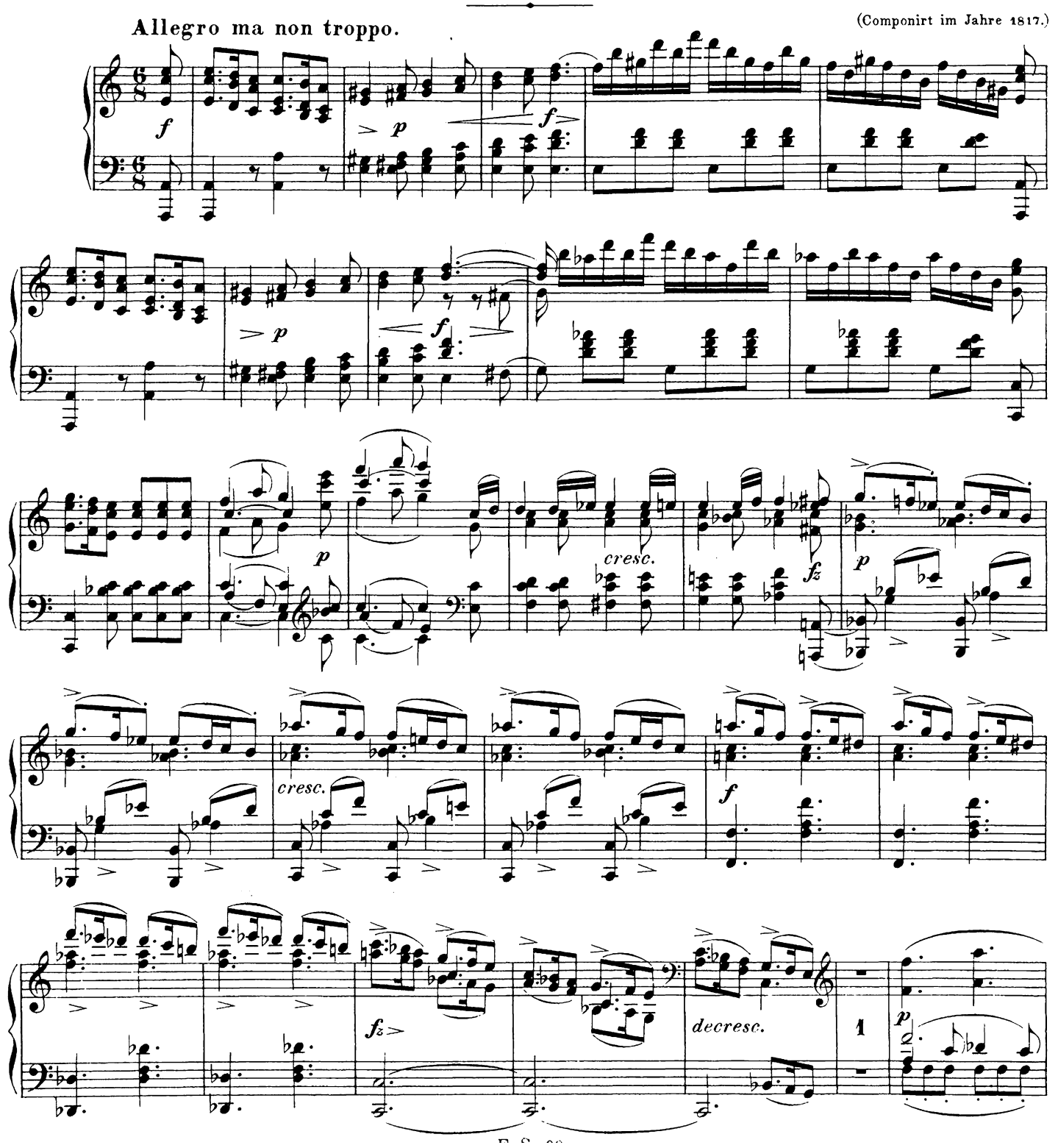


tonal objectives. Schubert's fixation with either thematic or motivic development shapes the structure of the piece. The dotted rhythmic motif, seen in measure 1 of D. 537, persists throughout the piece, delaying the arrival of the dominant. Schubert averts the expected tonal objective of the dominant by consistently delaying its arrival, prolonging the predominant areas. The primary difference in Schubert's sonatas from Beethoven and other Classical composers is the methods Schubert utilizes to retrieve motivic and thematic material during moments of remembrance in the recapitulation. Carl Dahlhaus states:

In Schubert, unlike in Beethoven, the most lasting impression is made by remembrance, which turns from later events back to earlier ones, and not by goal-consciousness, which presses on from earlier to later... In Schubert, the elements of the "introduction" -the rhythmic pattern, the isolated half step, and the major minor alternation - are related in a way that images of recollection overlap with one another. ${ }^{65}$

This observation offers a possible explanation as to why Schubert's unusual tonal centers and modulations are able to function within the Classical model. The Sonata in A minor reveals Schubert's free, almost improvisational writing style in his earlier first movement sonata-allegro form, unlike the deliberate motions of Beethoven; we might speculate that this tendency served Schubert well in his approach to the more elastic fantasy form.

Schubert's earlier compositional period has been described as a time of experimentation and tepidness, as a large amount of incomplete sonatas occur during his earlier period ${ }^{66}$ His omission of a fourth movement was possibly due to his hesitancy with the first movement. ${ }^{67}$ Twenty-four of his piano sonata movements were composed in

\footnotetext{
${ }^{65}$ Carl Dahlhaus, "Sonata Form in Schubert," in Schubert: Critical and Analytical Studies, ed., Walter Frisch (Lincoln and London: University of Nebraska Press, 1986), 8-9.

${ }^{66}$ Brian Newbould, Schubert: The Man and the Music (Los Angeles: University of California Press, 1997), 93.

${ }^{67}$ Ibid.
} 
sonata-allegro form, seventeen of which are first movements. Schubert's consistency in structure and harmonic exploration near the end of his lifetime reflects his growth in sonata-allegro form.

Schubert's first piano sonata that may be seen as fully characteristic of his compositional style came with the completion of the Piano Sonata in A major, D. $664{ }^{68}$ D. $537,557,567 / 8$, and 575 represent Schubert's experimental period, as many of his sonatas remained incomplete. These compositions attempted to emulate Beethoven's piano sonata form; however, Schubert seems to have initially struggled with the sonataallegro model, resulting in unbalanced or incomplete compositions.

David Garrett claims D. 664 as Schubert’s ‘joyous breakthrough’ into his unique sonata form, and that "the voice is Schubert's own, without any tension with (sic) the classical models". ${ }^{69}$ While the sonata omits a fourth movement, Schubert obtains a more convincing originality and subsequent break from Beethoven in the first movement form. The first movement of the Sonata Romántica conveys many similarities to D. 664 not only structurally, but also thematically and harmonically.

Assuming the hypothesis of the Sonata Romántica as a representation of Schubert's form is correct, Ponce's first movement sonata form should provide similar instances to Schubert's breakthrough piano sonata. An examination of D. 664 immediately implicates Ponce's derivation of thematic and melodic material, containing representations of Schubert's formulaic phrase, tonal, and motivic structures. Ponce utilizes these gestures, rhythmic motifs, and harmonic navigation, including similar melodic motion, in the Allegro moderato of the Sonata Romántica.

\footnotetext{
${ }^{68}$ John Reed, Schubert (New York: Schirmer Books, 1997), 64.

${ }^{69}$ David Garrett, Program Notes, "Schubert Piano Sonata in A, D664" (Sydney Symphony, June $192008) 12$.
} 


\section{Allegro moderato}

The opening four-bar phrase begins in the same key as D. $664,{ }^{70}$ containing similar rhythmic contours, phrase length, and a prolongation of $\mathrm{C} \#$ as a cover tone after the initial ascent to E. Ponce possibly intended the first movement of the Sonata Romántica to indirectly reference D. 664. Ponce exhibits Schubert's command of lyrical material by stating the primary theme in a simple meter, in addition to the notable placement of dotted rhythms. Leo Welch's treatise offers numerous instances of possible source material from Schubert. While his analyses provide intriguing results, certain comparisons are possibly coincidental as they coincide with many Schubert pieces. It is possible to overstate certain comparisons to specific works of Schubert, as many of his piano sonatas share similar characteristics and mannerisms, such as rhythmic structures, harmonic progressions, and whole measure rests used as an interruption to change character. However, we may still identify moments in the Sonata Romántica that embody the salient features of Schubert's early sonata style. As Welch explains, ${ }^{71}$ certain aspects of Ponce's work seem too similar to Schubert's Piano Sonata in A major to ignore. For instance, Ponce seems to correlate his first movement with D. 664 through key, tempo, and harmonic treatment.

A distinct characteristic of Schubert's piano sonatas is his modulation to the mediant key. Schubert frequently utilizes the mediant to prolong the tonic, as they share two common-tones, and as a method of modal mixture. To follow the sonata-allegro paradigm of Schubert, Ponce establishes the mediant relationship between A and $\mathrm{C} \#$ by

\footnotetext{
${ }^{70}$ The similarities in key may be coincidental, as A major is one of the more idiomatic keys for the guitar

${ }^{71}$ Welch, 91-93.
} 
emphasizing $\hat{3}$ throughout the expositional material. D. 664 exhibits a similar motion to $\mathrm{C} \#$, acting as a third relation in $\mathrm{mm}$. 9-12. Ponce even includes a similar initial ascent to $\mathrm{E}$ in the opening measure. Figure 2.1, which contains a reductive analysis of $\mathrm{m} .1-14$ and shows the progression from I-III, shows how the C\# may be heard as a cover tone to $\hat{5}$. This figure displays the prolongation of the $\mathrm{C} \#$ under $\hat{5}$ through the first thematic material until the dominant preparation. The tonicization of $\mathrm{C} \#$ major in $\mathrm{D}$. 664 supports the $\mathrm{C} \#$ as a cover tone on a larger interpretive level. Similarly, Ponce establishes the $\mathrm{C} \#$ as a cover tone, creating a stabilizing factor for the eventual transition to the mediant. Figure 2.2 represents the accentuation of $\mathrm{C} \#$ under the established fundamental line as it unfolds throughout the first phrase.

The utilization of the mediant and its chromatic partner create a fundamental difference in tonal structure of Schubert's form, establishing part of his aesthetic quality. Schubert's focus on mediant relationships creates more unique harmonic possibilities, such as progressing the tonal centers through the tonic triad (I-III-V). His extended use of the mediant causes instability within the expositional material by interrupting the tonal progression from I-V. This process begins to define Schubert's three-key exposition.

Figure 2.3 shows a middleground reduction of the first movement, accounting for the displacement of the fundamental line during the recapitulation. This graph exemplifies the possible interpretation of a fundamental line beginning on $\hat{5}$. 
MUSICAL EXAMPLE 2.2A

Piano Sonata in A major, D. 664 - Schubert

Measures 1- 15
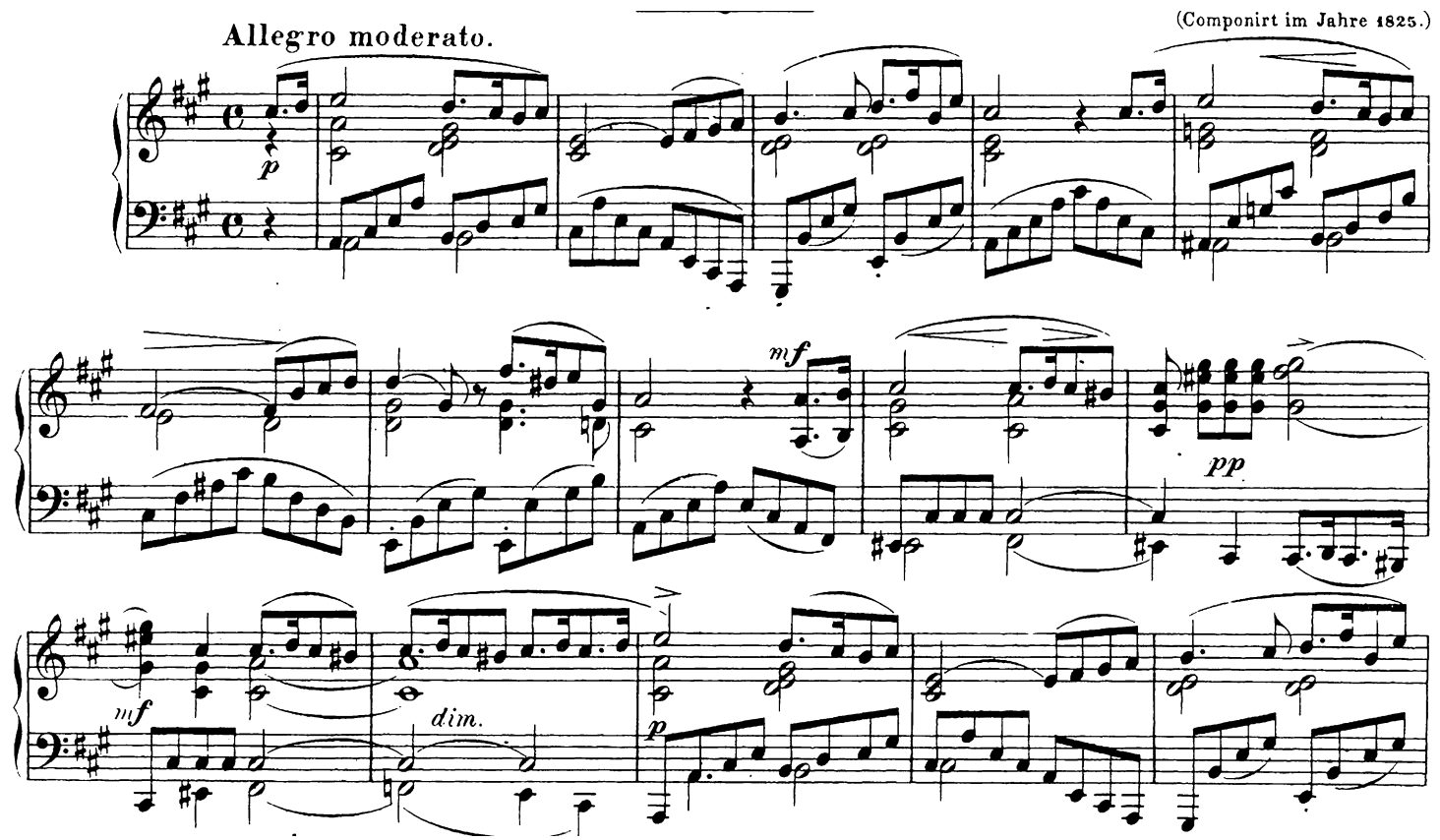

MUSICAL EXAMPLE 2.2B

Sonata Romántica I. Allegro moderato - Ponce

Measures 1- 17

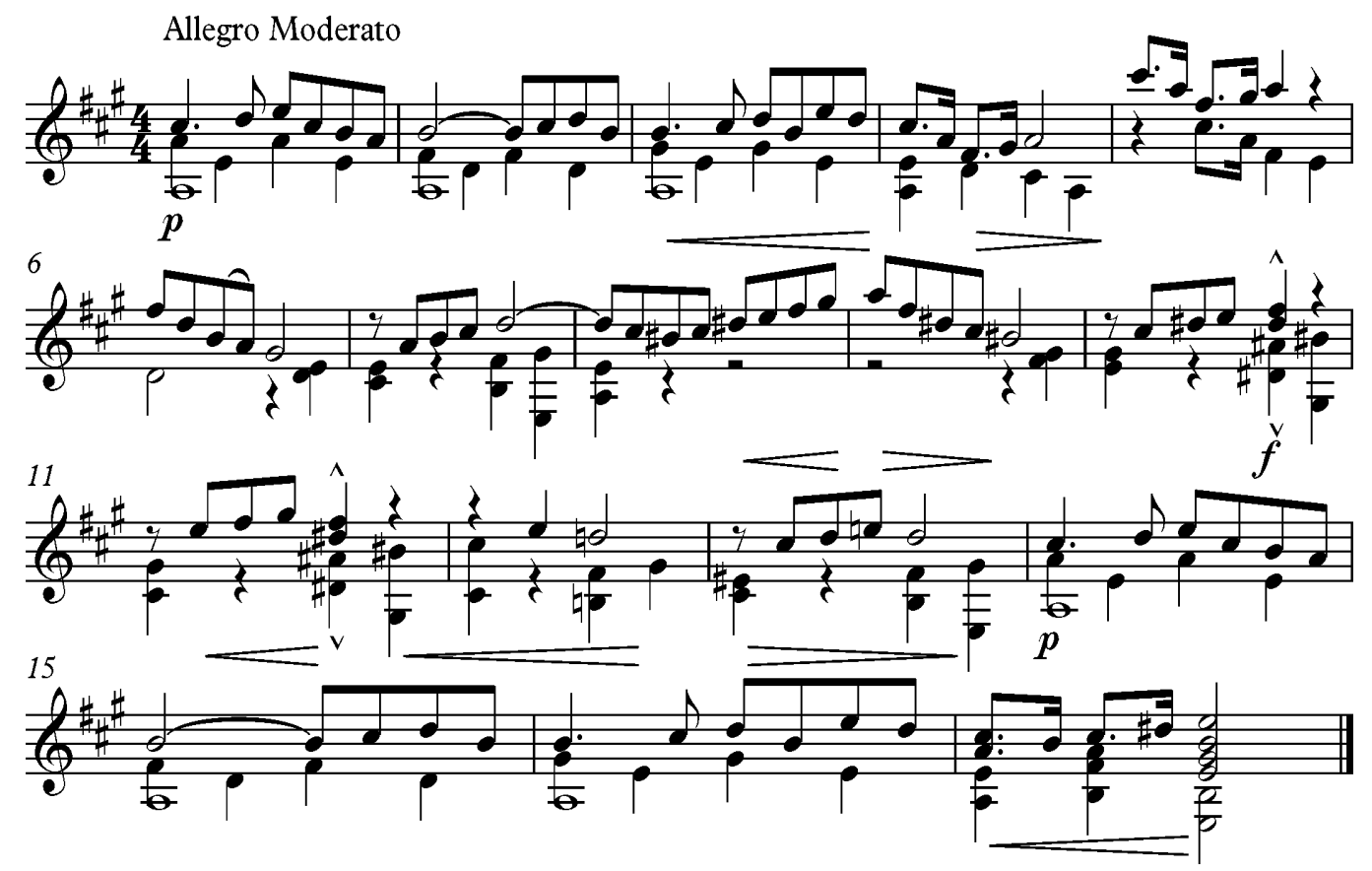


The descending fundamental line from $\hat{5}$ seems to satisfy the more traditional Schenkerian approach to sonata form. However, interpreting the emphasis and prolongation of $\mathrm{E}$ seems to contradict the cover tone and emphasis of $\mathrm{C} \#$. For this reason, it is possible to interpret $\hat{3}$ as the primary note of interest, as Ponce appears to emphasize the scale degree harmonically and melodically. The register transfer in measure 5 reinforces a descent from $\mathrm{C} \#$, foreshadowing the eventual register displacement of the Urlinie. Either approach becomes inconsequential, as the primary purpose of each interpretation is to place a structural emphasis on $\mathrm{C} \#$.

It is also possible to interpret these two descending melodic lines as occurring at different structural levels. Figure 2.4 accounts for a deeper middleground understanding of the treatment of $\mathrm{C} \#$ prolonged through the exposition, development and false recapitulation through a large-scale voice exchange. While these models may seem inconsequential for a comparative analysis, it reveals the treatment of the mediant throughout the piece, including how Ponce embodies Schubert's treatment of the mediant.

Schubert's expositions frequently contain a predictable rhythmic and tonal progression: A lyrical statement in a simple meter containing the tonic, followed by a brief tonicization or modulation to the mediant key including a dotted rhythmic figure, followed by a triplet motif in the dominant, establishing rhythmic tension to reinforce the expected arrivals. However, this last theme typically ends with an unresolved cadence and a full measure rest, returning in a completely different key. All of these elements are present in the exposition of the Sonata Romántica. Ponce derives these characteristics from the first movements of D. 279, 459, 537, 566, 625, and 664. 


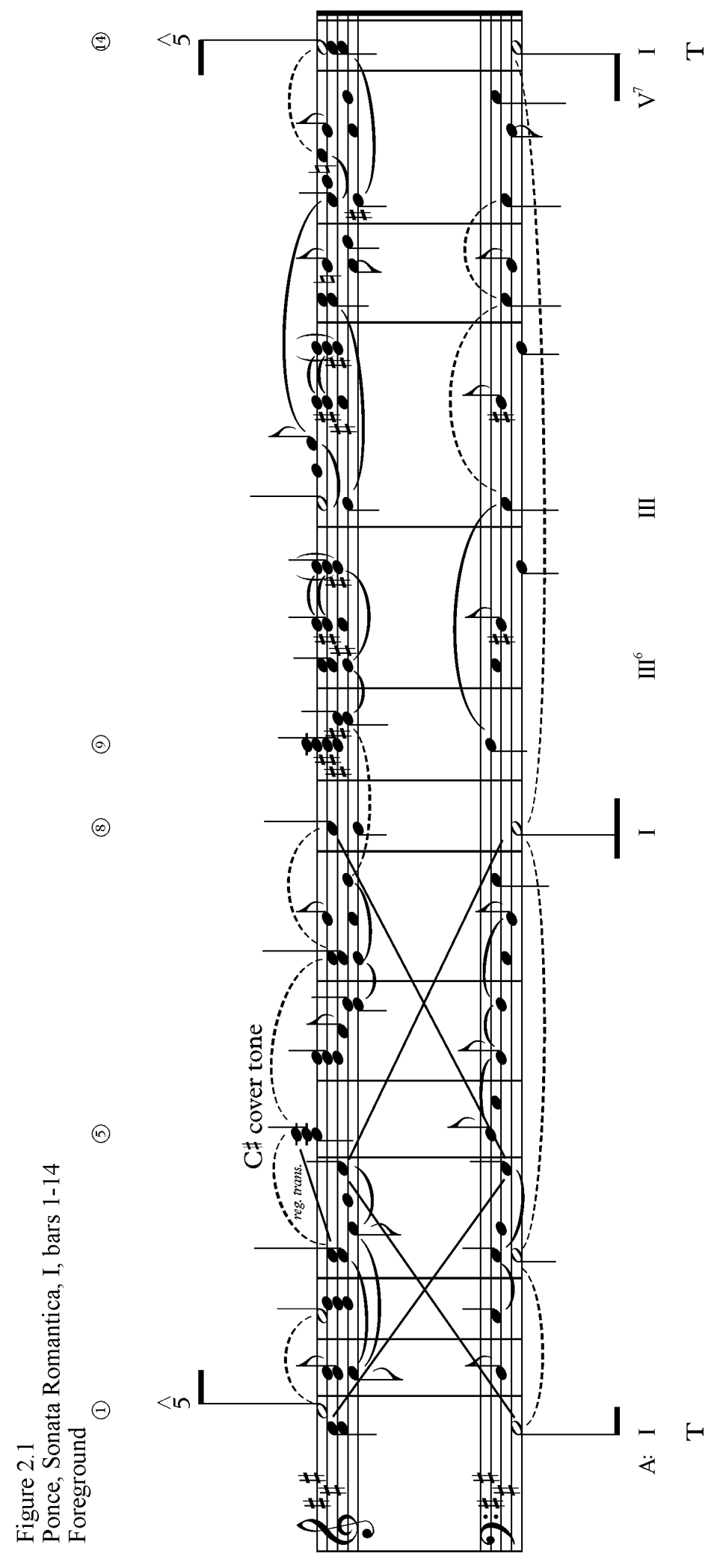




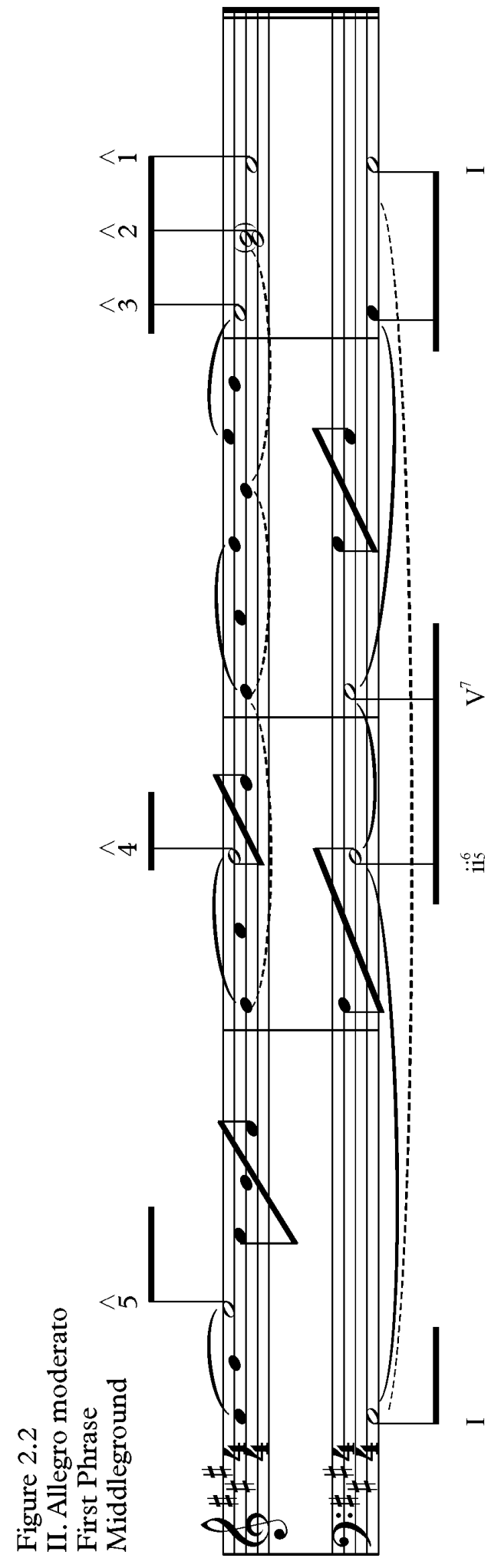




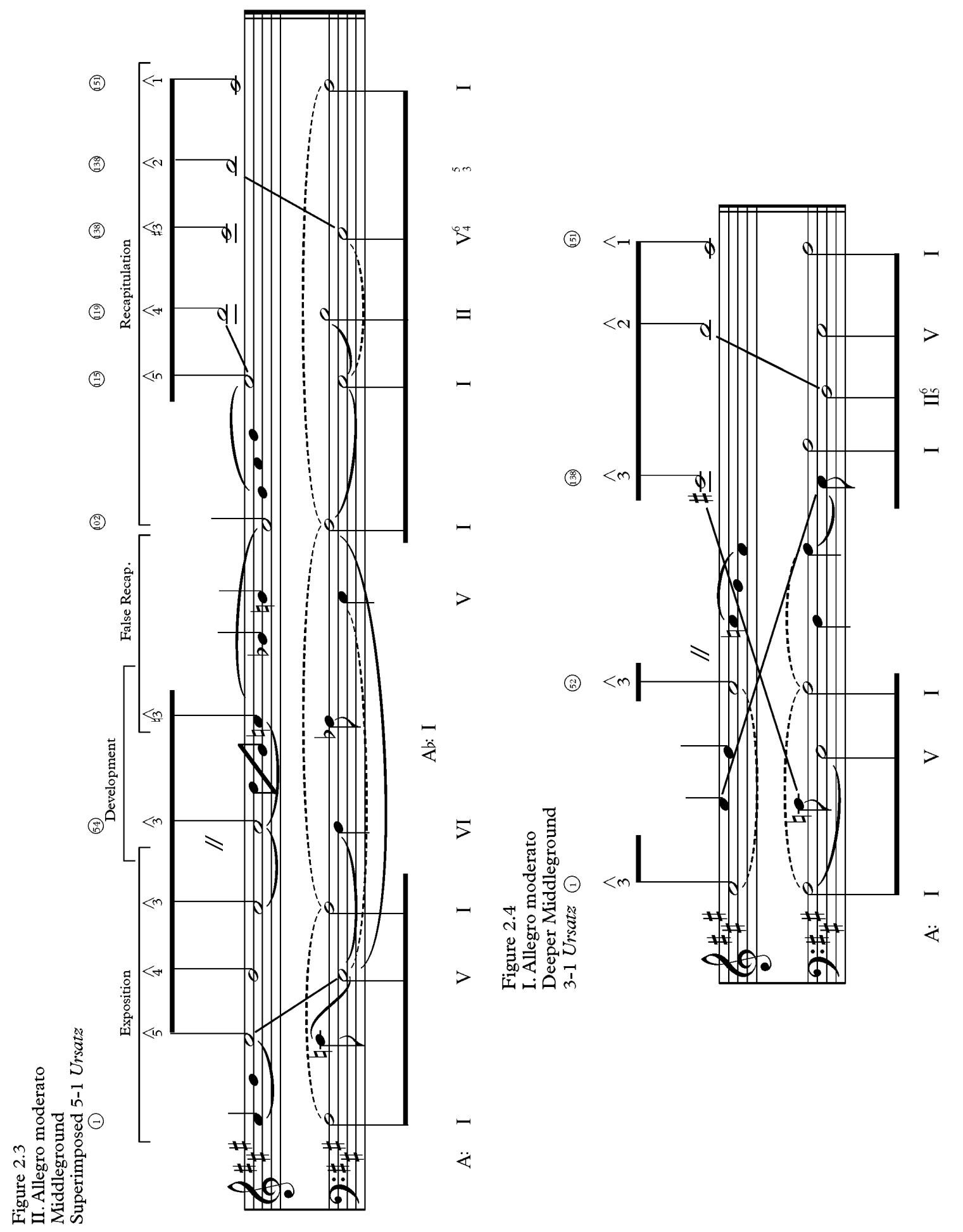


Figure 2.5 displays the motivic and thematic material and their functions in the exposition and development The first thematic statement of the piece exhibits an enclosed melodic and harmonic unit stating the primary material over an open A string, displaying Ponce's original bass rhythm in parentheses. Alfred Brendel asserts that the pedal in Schubert's piano compositions brings the music to life. ${ }^{72}$ Without this added element of the pedal, the music becomes either grotesque or banal. Ponce employs this characteristic of Schubert's music from the onset. The open A string allows for the grand nature of the pedal to be fully realized. The manuscript displays a different realization of the pedal as a dotted half note; however, Segovia's correction in the final edition make the A more effective due to the decaying nature of the instrument.

Additionally, a representation of the Ursatz occurs at the local level in this first thematic unit. Ponce's fixation on this theme persists throughout the piece, and acts as an auditory cue to the original theme. This thematic treatment allows Ponce to manipulate the arrival of the recapitulation with chromatic alterations. The strength of the motivic structure in Schubert's first movement sonata form influences the design as much as, if not more than, the tonal structure. That is, each motif represents a particular structural purpose.

The first phrase repeats in A major after the tonicization of $\mathrm{C} \#$ minor and ends with a half cadence in E major in measure 17. Measures 18-21 present an atypical progression of chords beginning with an arpeggiated E minor triad. Ponce progresses through the upcoming harmonic progression by pivoting on the $\mathrm{G} G$ in measure 17 .

\footnotetext{
${ }^{72}$ Brendel, 144.
} 


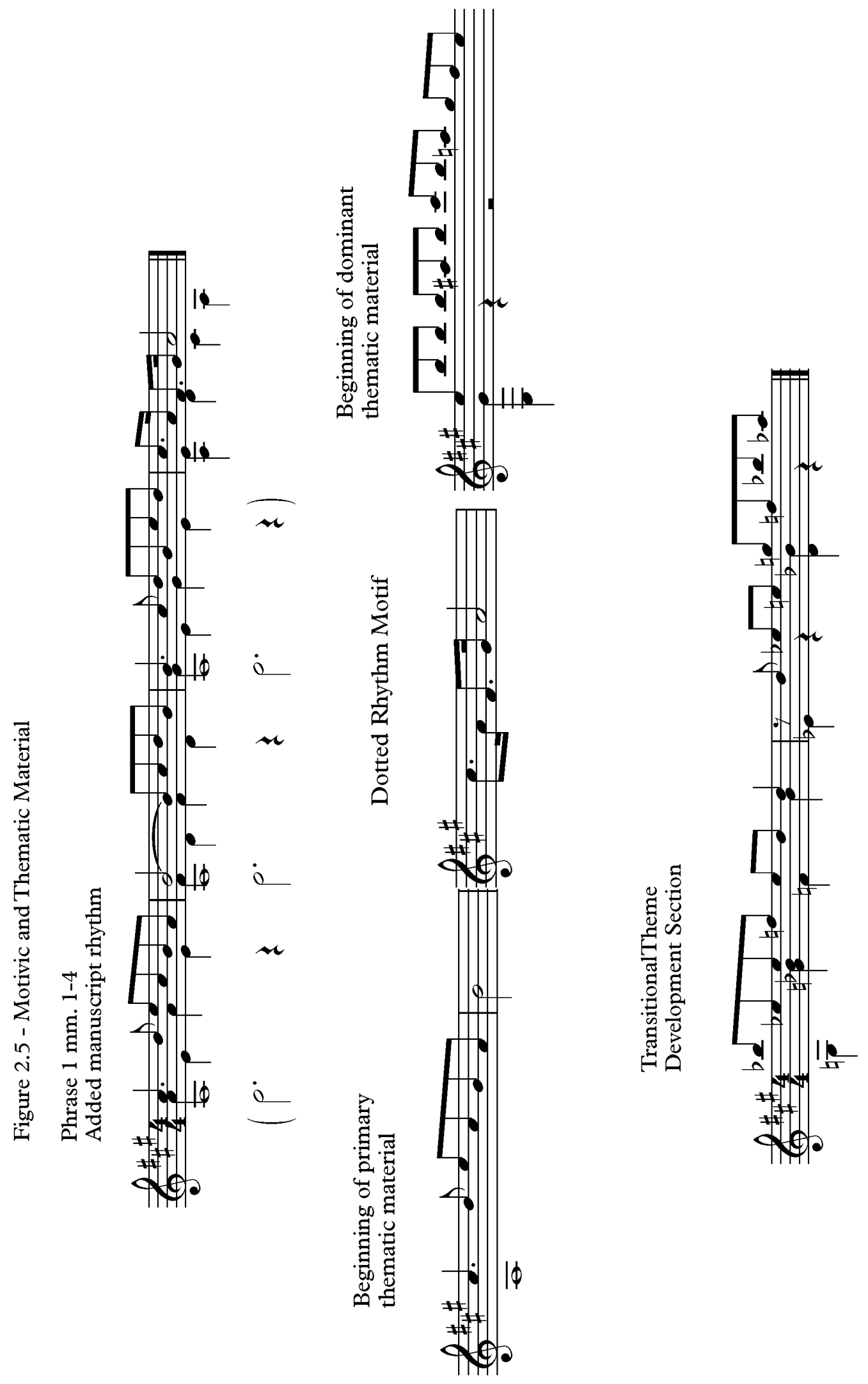


The piece progresses through the mediant of the dominant, similar to the first theme tonicization of $\mathrm{C} \#$. The chord progression in $\mathrm{mm}$. 18-21 suggests a relative and parallel motion through the Tonnetz. ${ }^{73}$ The $\mathrm{C} \#$ minor triad in measure 19 supports the descending progression through the circle of fifths- $\mathrm{C} \#, \mathrm{~F} \#, \mathrm{~B}$ and $\mathrm{E}$-in measures $20-22$. The arrival of E major begins the embellishment and prolongation of the dominant key. The motion of $\mathrm{C} \#-\mathrm{F} \#-\mathrm{B}-\mathrm{E}$ may also reflect the similar tonal progression in Schubert's Moment Musicaux, op. 94 No. 2 in C\# minor.

As mentioned previously, Ponce leaves the cadential motion of the dominant rhythmic figure in measure 40 unresolved, interrupted by the caesura in measure 41. (See Figure 2.5) The rhythmic figure, in addition to the rest in measure 41, averts the expected arrival on the dominant. Abrupt caesuras and unresolved cadences are characteristic of many Schubert piano sonatas, allowing a change in character to divert the listener's expectations.

Ponce emulates this character alteration with a statement of the primary thematic material in $\mathrm{C}$ major. The expected arrival of $\mathrm{E}$ occurs as a prolonged mediant, analogous to the first part of the exposition. Schubert's comfort with the dominant motion developed in his later works, though he frequently displayed reluctance to this idea. ${ }^{74}$ The bIII tonicization in measure 41 delays the expected arrival of $\mathrm{V}$ through an enharmonic transforming to an augmented sixth resolving to B (V/V). However, Ponce averts the dominant again with the addition of $\mathrm{D}$, creating a cadential motion back to A major,

\footnotetext{
${ }^{73}$ Recent analyses of Schubert's works typically feature neo-Riemannian applications to explain the unusual harmonic relationships. I do not wish to apply this method further as it would not be conducive to the present topic; however, this progression provides sufficient explanations for the non-functioning harmonic progression. A more thorough explanation of this theoretical application may be viewed in Richard Cohn, "Introduction to Neo-Riemannian Theory: A Survey and a Historical Perspective," Journal of Music Theory, 42, no. 2 (1998): 167-180.

${ }^{74}$ Hali Annette Fieldman, "The Grundgestalt and Schubert's Sonata Forms" (Ph.D. diss., University of Michigan, 1996), 42.
} 
repeating the entire expositional material. Although Ponce prepares the return of the exposition with this added chordal seventh, he has by this point already modulated to $\mathrm{E}$ major to conclude the exposition in the dominant, as Schubert does in his sonatas. The parenthetical modulation to $\mathrm{C}$ creates a crucial disruption before the development, placing the expected arrival of $\mathrm{E}$ in the soprano. The placement of the E, acting as the major third of $\mathrm{C}$, becomes more important in regards its placement and treatment within the recapitulation, of which I elaborate in subsequent paragraphs. Chapter 5 further explains Schubert's treatment of unusual recapitulations.

Schubert's sonatas often contain similarly extended expositions, as they permit greater listening focus toward the lyrical elements and thematic material of the movement. The arrival of the dominant in the Sonata Romántica reveals the disproportionate nature of Schubert's developments, displaying an imbalanced treatment in terms of lyricism and weight. The beginning of the development prolongs $\mathrm{C} \#$ through a deceptive cadence to the relative minor, $\mathrm{F} \#$. Between mm. 42-53, Ponce traverses from $\mathrm{C}$ (bIII) to F\# (VI), counterbalancing the chromatic modulation before the cadence in the dominant. He accomplishes this seamless transition by altering the $\mathrm{C}$ major triad into a dominant seventh chord, respelling it as an augmented sixth to E major, maintaining the significance of the $\mathrm{E}$ in the soprano voice. The cadential $6 / 4$ motion that previously led to the return of the exposition in measure 52 becomes a $V^{6} / V I$. Ponce uses the primary thematic material from the exposition, establishing a connective texture to the developmental section. Ponce uses the dominant rhythmic figure from the exposition to create sequential pattern, leading to the transitional motif (Figure 2.5), establishing a 


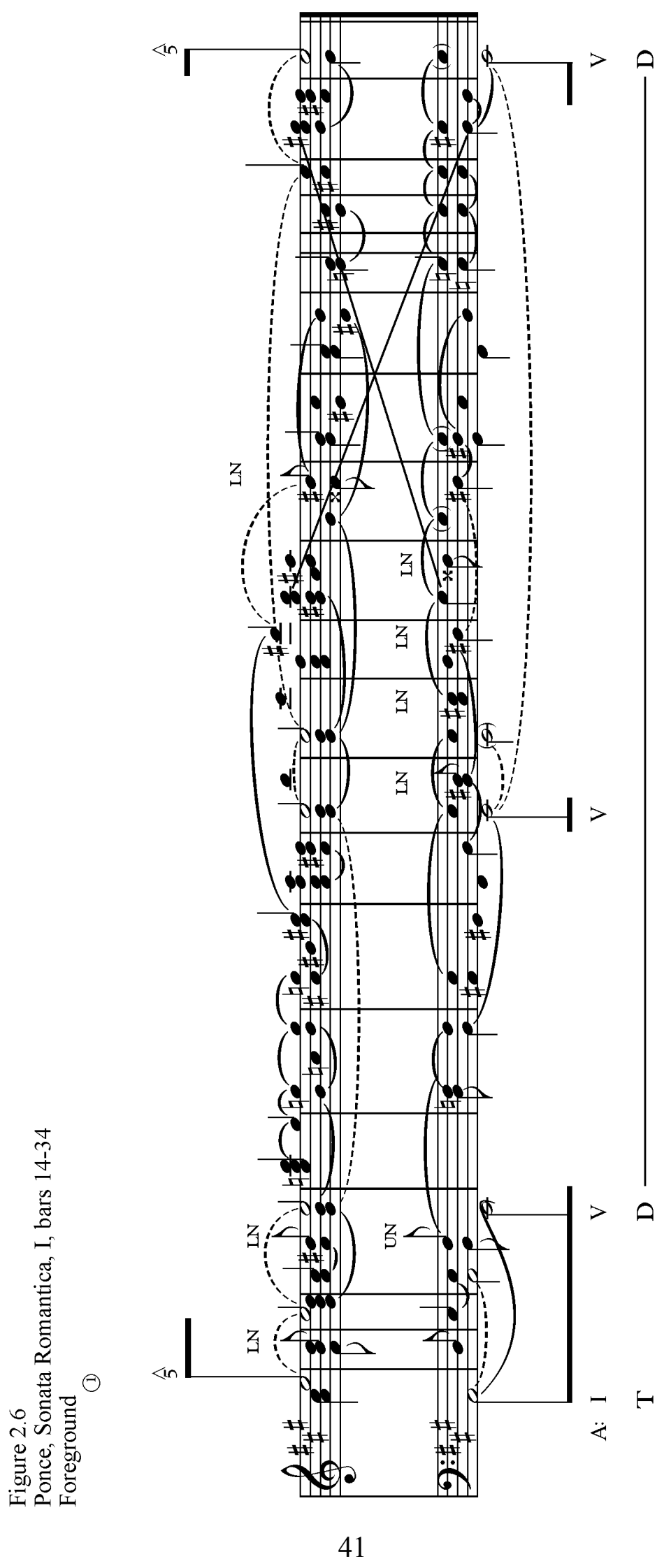




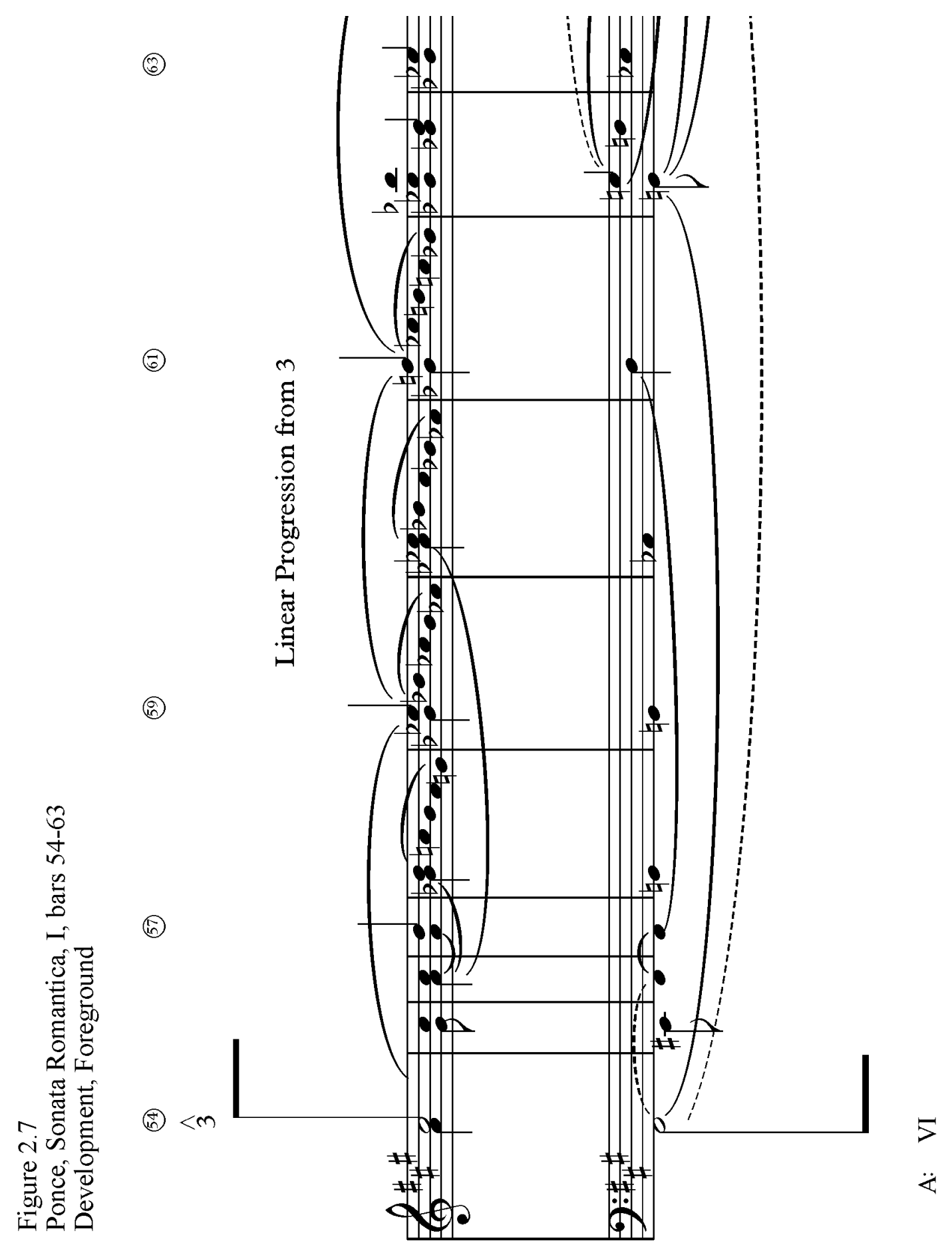




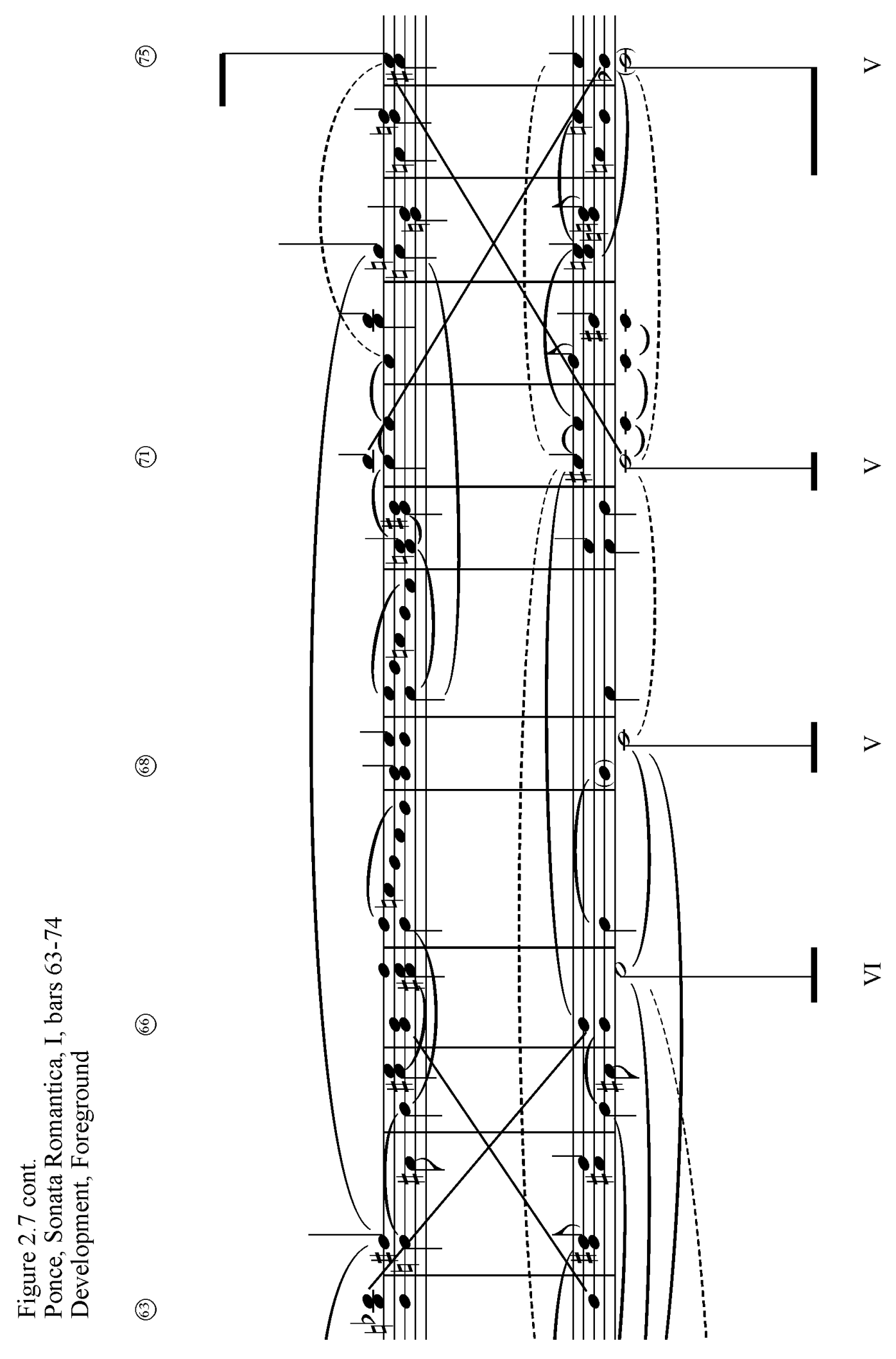


dialogue between the two characters. Each statement (transitional motif) and response (dominant rhythmic figure) occurs between distant tonal centers, such as $\mathrm{E} b$ and $\mathrm{B}$ minor. ${ }^{75}$ The abrupt modulations between these figures reflect the instability of Schubert's developmental sections, while prolonging $\mathrm{C} \#$ in the process. The $\mathrm{C} \#$, at the beginning of the development, instigates a linear progression to $\mathrm{A} b$, establishing the beginning of the false recapitulation. Schubert's piano sonatas frequently contain a chromatic half-step shift in tonal centers during the false recapitulation, emphasizing the arrival to the actual recapitulation through an enharmonic leading tone.

In the case of the Sonata Romántica, Ponce uses the $\mathrm{A} b$ as the enharmonic equivalent to $\mathrm{G} \#$, both creating a leading tone to tonic and establishing the dominant preparation for the recapitulation. Figure 2.7 shows the $\mathrm{C} \#$ creating a linear progression to the false recapitulation. Ponce uses the dominant rhythmic figure as a vehicle to create rhythmic tension in the linear progression to $\mathrm{A} b$. The arrival of $\mathrm{A} b$ justifies the abrupt arrival on $\mathrm{Eb}$ in the transitional theme (Figure 2.5) during the development, representing a moment of chromatic substitution to prolong the tonic triad.

During the transition to the recapitulation, Ponce creates a dominant preparation to under the primary thematic material in mm. 99-101. The definitive return of the tonic in measure 102 resolves the previous dominant preparation, creating an emphasis on $\mathrm{C \#}$ in measure 103 in the upper register, analogous to measure 5. Ponce displays Schubert's aversion to the dominant by repeatedly emphasizing $\hat{3}$ to some extent throughout the exposition, development, false recapitulation, and recapitulation. Ponce constructs the

\footnotetext{
75 James William Sobaskie cites these moments in Schubert as precursive prolongations in James William Sobaskie, "Tonal Implications and the Gestural Dialect," Schubert the Progressive, ed. Brian Newbould (Ashgate: Burlington, Vermont: 2003), 56. The precursive prolongations define a musical span designed to manipulate expectations, elicit anticipation and capture an idea.
} 
piece to reflect the tonic prolongation through the mediant relationship, in addition to its connection to the thematic material.

The recapitulation concludes the piece with a descent from $\mathrm{C} \#$ in the upper register established by measure 118. Measures 131-132 contain the first complete perfect authentic cadence in the original tonic, establishing the beginning of the closing coda material. In measure 138, Ponce again creates false expectations by delaying the arrival of the tonic through an unresolved cadential motion with a measure rest. The arrival in bVI in this measure is analogous to the arrival of bIII in the exposition. Since Ponce remains in the tonic during the recapitulation, bVI contains the expected arrival of the tonic in the soprano voice, creating a similar cadential motion to conclude the movement. The presence of $\mathrm{F}$ major corrects the diminished fifth relationship between $\mathrm{C}$ in the exposition and F\# in the development, allowing for a more conclusive cadence in the recapitulation.

Ponce encapsulates the unique elements of Schubert's early piano sonatas through similar harmonic structure and thematic treatment. Schubert's rhythmic motifs are apparent in the expositional material with march-like dotted rhythms followed by a triplet motif to accentuate the motion to the dominant. Ponce supplements these rhythmic ideas with similar harmonic progressions reminiscent of Schubert's Piano Sonata, D. 664. The modulation to the mediant, in addition to Ponce's focus on $\hat{3}$, contributes to the manifestation of Schubert's aesthetic realized on the guitar. The mediant modulations throughout the piece allow for the unique and unexpected harmonic arrivals, such as the deceptive cadence in measure 42 . The extended attention to thematic material 
complemented with an imbalanced development help to complete the illusion of Schubert's early first-movement piano sonata form. 


\section{CHAPTER 3}

\section{SCHUBERT'S LIED}

No other genre in Schubert's canon separates him more from his Classical predecessors than the lied; while the lied is not unknown in earlier works, Schubert's compositional approach and aesthetic sensibility positions his works as unique within the history of German art music. Schubert provided a 'profundity and complexity' in the lied not present in his Classical predecessors. ${ }^{76}$ The works of Schubert do not show a hierarchical preference of the voice to the accompaniment; they treat the piano and voice as equal members within a musical duality. ${ }^{77}$

Schubert's mastery of song form arrived before his achievement in instrumental

form. Newbould rationalizes Schubert's early success with song form:

Composing a song is a reactive task, composing an instrumental piece is a proactive one. In that sense, the instrumental project taxes creativity the more, whether it's is an undertaking large or small. A necessary part of what a composer has to do is impose a limitation on himself... Thereafter the range of options narrows, for in the succession of one thought by another, coherent continuity is demanded... However, the adoption of a verbal text creates a context before a note of music is written or conceived. ${ }^{78}$ Perhaps the most distinct characteristic in Schubert's lieder is the significance of the text as an influence to the frequent harmonic ambiguity, thereby enhancing the dramatic experience. Text-painting and onomatopoeic elements are present; however, these are merely vehicles

${ }^{76}$ Susan Youens, "Franz Schubert: The Lied Transformed," German Lieder in the Nineteenth Century, ed. Rufus Hallmark (New York and London: Schirmer Books, 1996), 35.

${ }^{77}$ Marie-Agnes Dittrich, "The Lieder of Schubert," in The Cambridge Companion to the Lied, ed. James Parsons (Cambridge: Cambridge University Press, 2004), 86.

${ }^{78}$ Newbould, Schubert: The Music and the Man, 45. 
for Schubert to express a particular persona or character in purely musical terms. $^{79}$

While the second movements of Schubert's four-movement sonata form are usually reserved for a much slower, expressive opportunity, they are typically still rhythmically active. This is not the case with the second movement of the Sonata Romántica, as its rhythmic texture deviates considerably from Schubert's second movement sonata form. The relatively simplistic yet beautiful melodic content of the Andante espressivo suggests this movement as a reference to Schubert's lied rather than to the second movement of Schubert's piano sonatas. The second movement of the Sonata Romántica emphasizes the lyrical element in the soprano voice, suggesting a correlation with Schubert's song form.

Many nineteenth-century theorists believed that Schubert's mismanagement of musical form and inferior technical ability led to his liberal treatment of harmony. ${ }^{80}$ However, Schubert's songs are typically reflective of their subject matter and literary source, relying on the textual material as the primary directive. Schubert utilizes the unusual harmonic deviations to reflect an alteration in the character's psychological or emotional state. Susan Youens cites these atypical harmonic gestures in Schubert's lieder:

In lieder, sudden tonal shifts are often emblematic of removal from one sphere to another, whether from night to day, from waking consciousness to dreams, or from present experience to memory. One example occurs in (Schubert's) setting of the twelfth stanza of Friedrich Schiller's ode "Die Götter Griechenlands" (The Gods of Greece, D. 667)... expressing the essence of longing for the 'grandeur that was Greece"...

\footnotetext{
${ }^{79}$ Youens, 40.

${ }^{80}$ Suzannah Clark, Analyzing Schubert, (Cambridge University Press, 2011), 58.

${ }^{81}$ Youens, 44.
} 
Schubert uses multiple methods to create the sudden tonal shifts, such as common-tone and mediant modulations, and parallel major and minor key relationships. Youens continues to state:

...the use of contrasting parallel major and minor keys (was) one of Schubert's favorite devices. In the songs, the minor mode often symbolizes tragedy, whereas the major represents bygone happiness, the antithesis of dark and light keys that share the same tonic, underscoring their kinship. ${ }^{82}$

Each song contains strong emotional components reflected in a combination of musical elements. For instance, Schubert establishes a thematic idea in particular keys to reflect certain ideas within the text. The restatement of the same material in its parallel minor reflects the altered emotional state of the character. Example 3.1 A and B shows the contrasting parallel major and minor keys within Schubert's Der Lindenbaum from Winterreise, D. 911. In the first statement, the narrator of the poem, from which Schubert extracted the melody, exhibits joy and contentment from sleeping under the tree, as it reminds him of his love in the spring. The second statement reflects the change in the season to winter and the sadness the tree now causes him as he passes it at night. Schubert exhibits the dramatic change in character by restating the same material in the relative minor. The difference in character is typically supported with instances of textpainting. The direct modulation from E major to $\mathrm{E}$ minor represent the falling leaves in the sharps falling from the key signature. Schubert also uses the word 'Nacht' to represent the dark contrasting the light.

The second movement of the Sonata Romántica deviates from the content of Schubert's standard piano sonata form in both content and structure, while using the

${ }^{82}$ Ibid. 

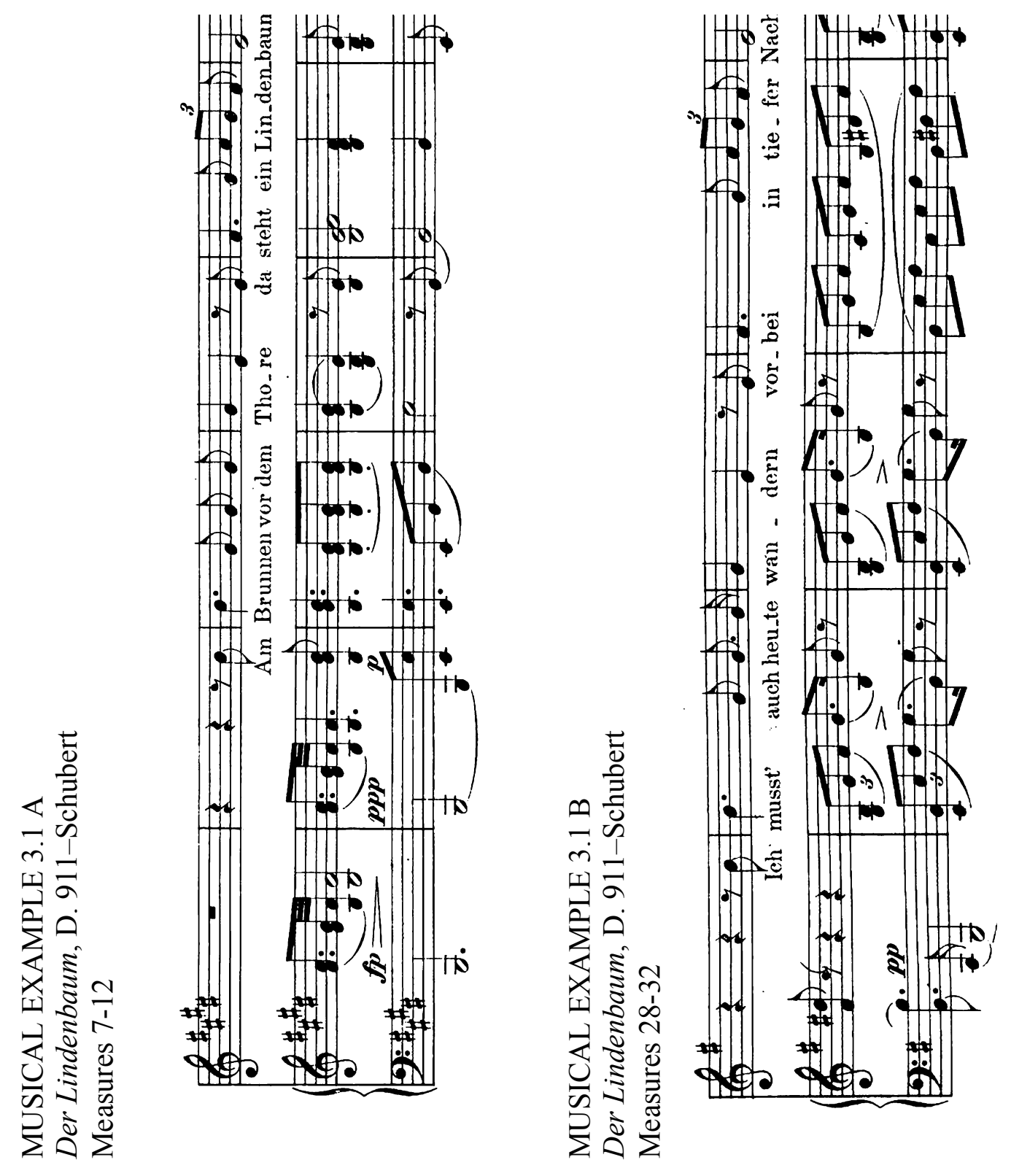
typical tempo marking of Andante. The argument for the Sonata Romántica reflecting a linear progression of Schubert's genres becomes problematic due to his continuous work with the lied throughout his life. However, if Ponce's intention is to emulate both Schubert's four-movement sonata paradigm in addition to paying homage to his various forms, the placement of the lied in the second movement becomes a convenient alternative.

Schubert constructs the motivic and thematic structures in a manner that logically coincided with the meter and syllabic placement within the literary source from which it was inspired. Obviously, since Sonata Romántica is a solo work for classical guitar, any text-based comparative analysis is inadmissible. However, the Andante does contain many of the expressive qualities that support other characteristics correlating with Schubert's lied, such as unusual harmonic treatment, common tone modulations, similar formal structure, and contrasting parallel major and minor keys.

As mentioned previously, the segmented nature of the phrase structure in Schubert's lied reflects the different characters of each stanza. That is, each large section or period may represent a single emotional concept. Ponce's treatment of the phrase structure within the second movement of the Sonata Romántica suggests a relationship to the textual treatment of Schubert's lied. Ponce's emulation of this in the Andante exhibits his understanding of voice and accompaniment expressed through the polyphonic ability of the guitar.

The Andante establishes a more distinct separation of melody and accompaniment from the other movements, demonstrating the musical duality between voice and accompaniment in Schubert's songs. Ponce's second movement evokes a more emotional 
response than the other movements, exhibiting feelings of longing and sadness, supporting the notion that Ponce possibly intended this to be a lament to Schubert. Due to the obvious textual omission in Sonata Romántica, Ponce substitutes an implied vocal line with the natural, lyrical quality of the instrument. In the absence of text to guide the music, as in Schubert, Ponce is able to encapsulate the emotional components of Schubert's songs by incorporating the diverse timbral colors of the guitar.

The polyphonic nature of the guitar allows Ponce to access the lyrical nature of the lied, similar to how Liszt arranges Schubert's songs for the piano in 12 Lieder von Franz Schubert, S. 558. Liszt's arrangements include added instructional elements to bring forth the vocal aspects, such as the addition of the term espressivo, which Ponce happens to also utilize in the Andante; this addition is significant, in that no other Schubert piano sonata contains such an indicator in the tempo indication. It is possible to suggest that Ponce referenced Liszt's arrangements in the process of composing this movement, as many similarities transpire due to their similar compositional goals. Both Liszt and Ponce attempt to embody the characteristics of Schubert's lied within a single polyphonic instrument. As the Sonata Romántica obviously contains no vocal accompaniment, Ponce expresses the textual relationship through contrasting characters between the bass and soprano voice, emphasizing the voice/accompaniment relationship.

\section{Andante espressivo}

Ponce constructs the second movement in an ABA form, possibly in reference to the frequent ternary forms found in many of Schubert's lieder. ${ }^{83}$ Ponce utilizes the

\footnotetext{
${ }^{83}$ Robert Winter, "Franz Schubert: Works," in Grove Music Online https://Grovemusiconline.com (accessed April 14 2014).
} 

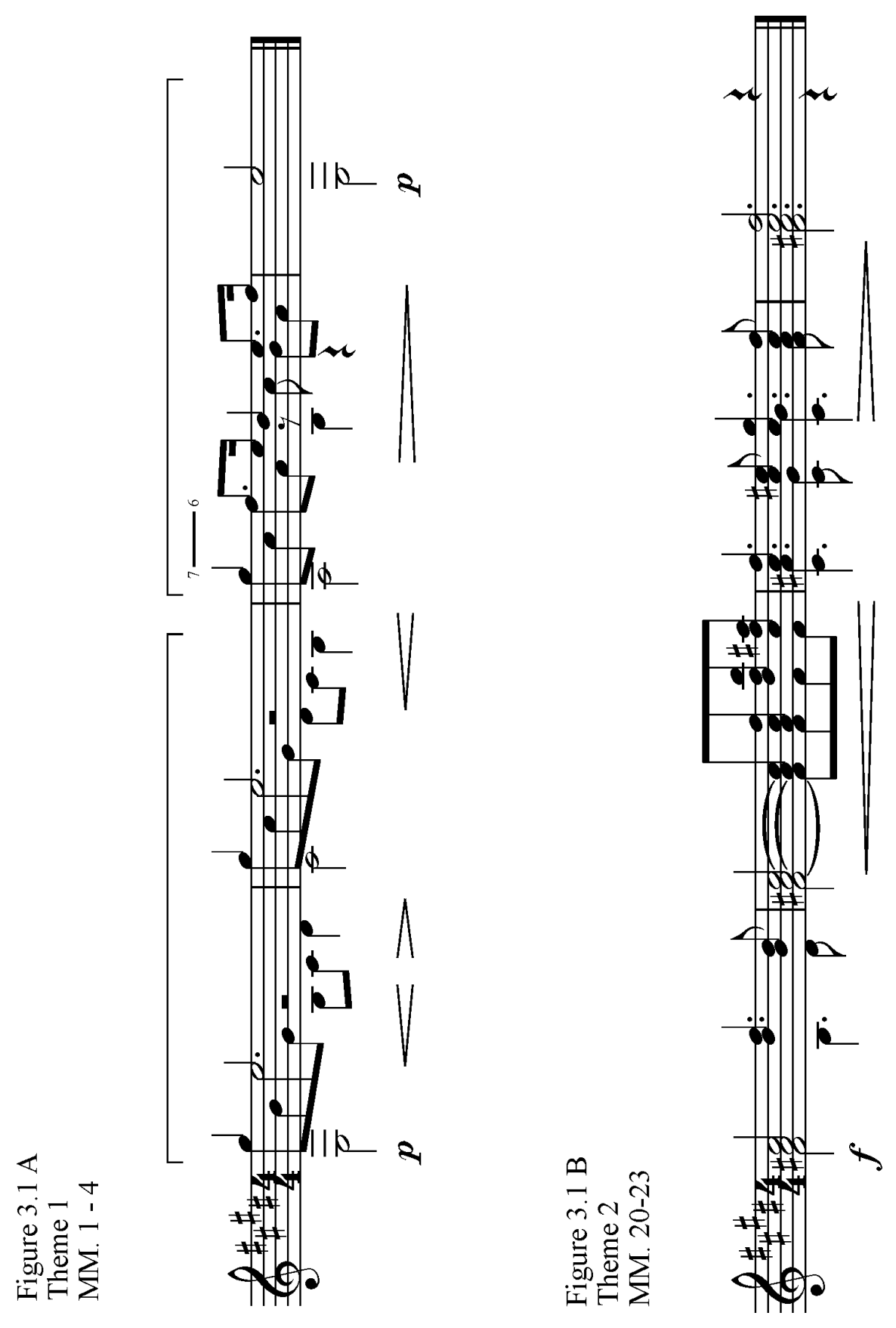
thematic material as structural indictors to delineate larger sections and differentiates each section by the contrasting nature of the thematic material. Schubert's lieder often begin with a piano introduction that establishes the primary theme and/or motifs. The first four-bar phrase begins this task by outlining the thematic material. The statements of the first two themes in the beginning perform similarly to the introductory statement of the piano in Schubert's lied, as they each provide key thematic material to highlight their significance and use throughout the piece. The introductory statement creates a dialogue between the two motivic ideas, foreshadowing their relationship and conflicting nature with the second theme, throughout the piece. The use of motivic material as a primary factor allows Ponce to create the necessary character interaction without the presence of text.

Ponce precedes the movement to the relative minor by emphasizing F\# as a predominant function. Measures 7-9 contain repeated gestures of $\mathrm{E} \#^{0} 7-\mathrm{F} \#$, causing ambiguity between $\mathrm{C} \#$ and $\mathrm{F} \#$ as possible tonic keys. Ponce alludes to $\mathrm{C} \#$ through a half cadence in measure 8 in $\mathrm{F} \#$ minor. He obtains the $\mathrm{C} \#$ as the tonic through the cadential motion of the second half of the first theme, as seen in Figure 3.1A. The utilization of this motif establishes a new character or key area. Both Schubert and Ponce limit the available melodic and motivic material from the beginning, establishing each section based on the modal treatment of each idea. As seen in Figure 3.2, Ponce prolongs the A section by tonicizing the relative minor to begin the linear progression to the B section. The prolongation of II and VI create an expansion of the predominant area to establish the arrival of $\mathrm{B}$ at the end of the A section. This extended focus on the subdominant relationship reflects the delayed dominant arrival used by Schubert. 


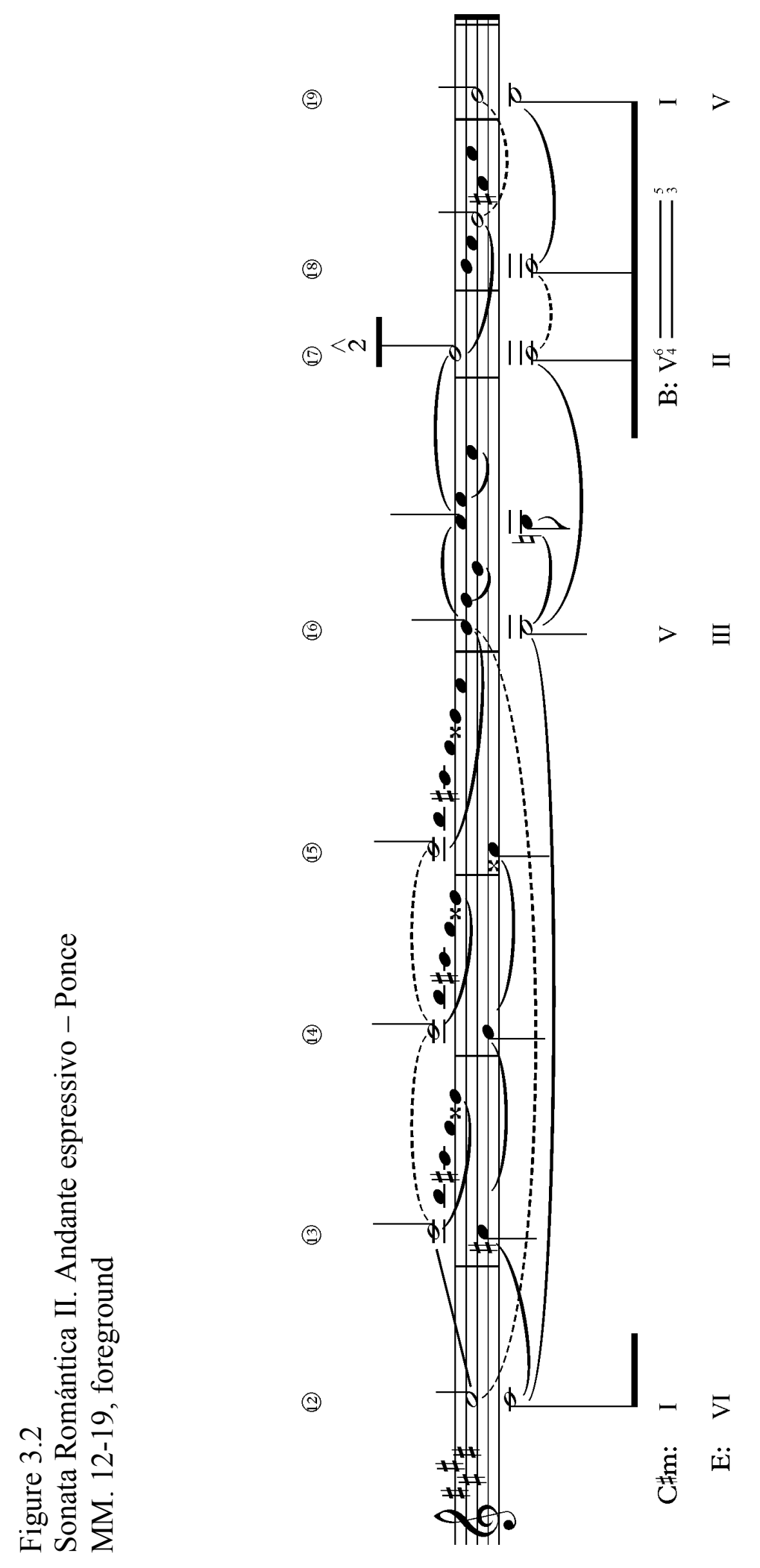


Figure 3.2 displays the $\mathrm{C} \#$ prolongation and the linear progression to $\mathrm{F} \#$. The cadential motif in Figure 3.1A reinforces the dominant arrival in measure 19. As can be seen in Figure 3.2, Ponce temporarily displaces the $\mathrm{C} \#$ by the ascending register transfer. Ponce prolongs the $\mathrm{C} \#$ through the second register shift to D5 in measure 16, concluding the ascending linear progression to $\mathrm{F} \#$ in measure 17 . The A section maintains a relatively unstable progression of phrases and cadences, contributing to the storytelling nature of Schubert's lied. The resulting phrase structure becomes an asymmetrical period relying heavily on episodic and thematic development, as is characteristic of Schubert. The arrival of $\mathrm{F} \#$ major in the B section continues the prolongation of the subdominant by creating a V/V relationship. Ponce places more emphasis on the subdominant treatment of the A section by prolonging the $\mathrm{C} \#$, as opposed to the brief arrival of $\mathrm{B}$ major, reflecting the predominant fixation in Schubert's work. The aversion to the dominant is quite noticeable at this point due to the strong statement in II.

The arrival of F\# major in the B section establishes new thematic material, contrasting the nature of the first. The restatement of the theme in the parallel minor enforces the contrasting character difference while simultaneously reflecting the modal complement seen in Schubert's lieder. Ponce prolongs the F\# through the B section prolonging the predominant and delaying the dominant arrival. The fundamental line reflects Schubert's avoidance of the dominant by interrupting and delaying the support for $\hat{2}$ until the conclusion of the B section. Figure 3.3 displays the interrupted fundamental line and the large-scale linear progressions used to prolong the predominant area in sections A and B. The dominant arrival in measure 39 occurs as it does in the second theme and features the same restatement in the parallel minor. However, the 


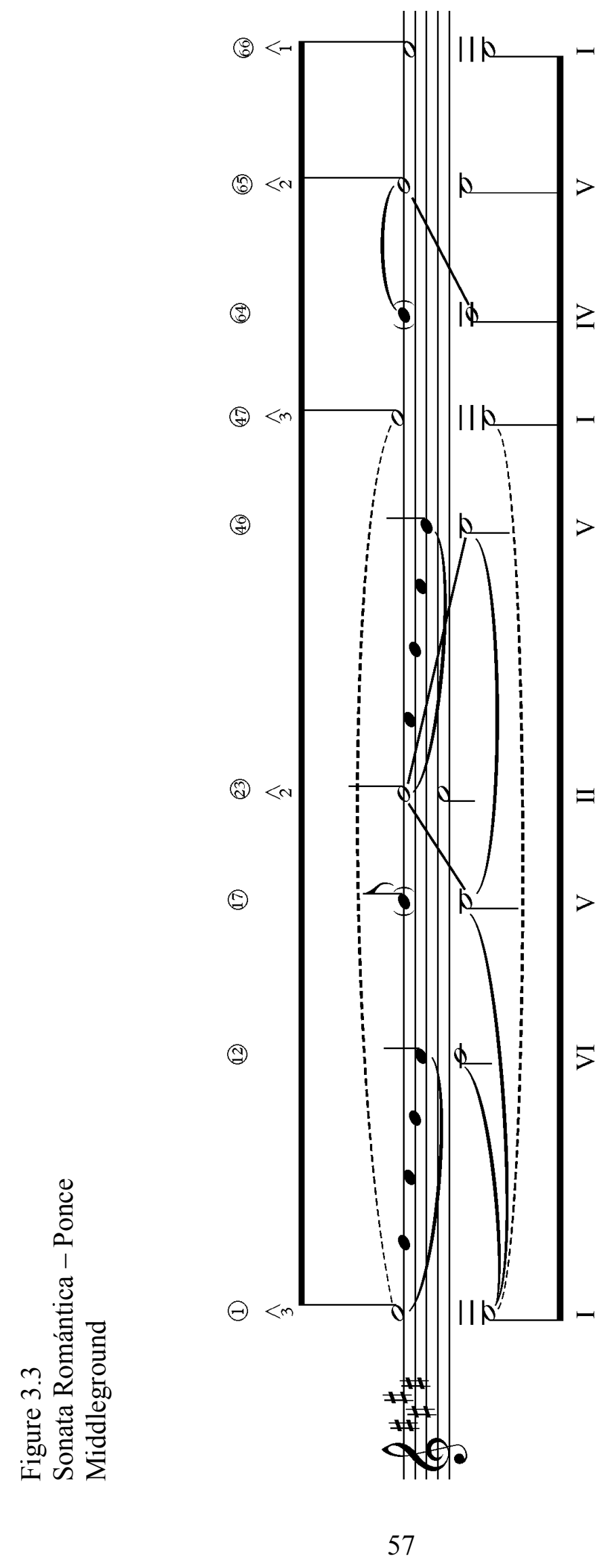


conclusion of the second statement contains a Picardy third, reestablishing its dominant function in its return to A'.

As with the first movement, Ponce's second movement utilizes root motion by thirds to progress through different harmonies. The descent from $\mathrm{E}$ major to $\mathrm{C} \#$ minor in the A section is inconsequential, as it functions as the parallel minor. However, the descent in in $\mathrm{mm}$. 26-37 from $\mathrm{F} \#$ major/minor $-\mathrm{D}$ major $-\mathrm{B}$ minor $-\mathrm{G}$ major, which becomes an augmented sixth in B major, presents a similar progression from mm. 18-34. Ponce concludes the harmonic descent of fifths in the first movement with a similar transformation to an augmented sixth to the dominant. Through this harmonic treatment, Ponce is able to maintain a similar harmonic relationship to the previous movement, creating a valuable cohesive element within their contrasting nature. These descending third relationships exemplify the unusual harmonic progressions and tonal centers that separate Schubert's aesthetic from that of his predecessors.

Ponce reflects the conflicting, dramatic nature of Schubert's lieder through the contrasting nature of the two primary themes in sections A and B. Each represents a contrasting character created for dramatic purposes. The differences in the two themes are reconciled by the return of the A section by altering the cadential motion of the second half of the first theme in measure 58. Instead of prolonging the $\mathrm{C} \#$ as in the $\mathrm{A}$ section, Ponce resolves the conflict between the first and second theme by applying them concurrently to perform a cadential extension. Ponce accomplishes this due to the locallevel representation of the fundamental line in each theme, as seen in Figure 3.4. Ponce emulates the dramatic nature of Schubert's lied by establishing a conflicting relationship 

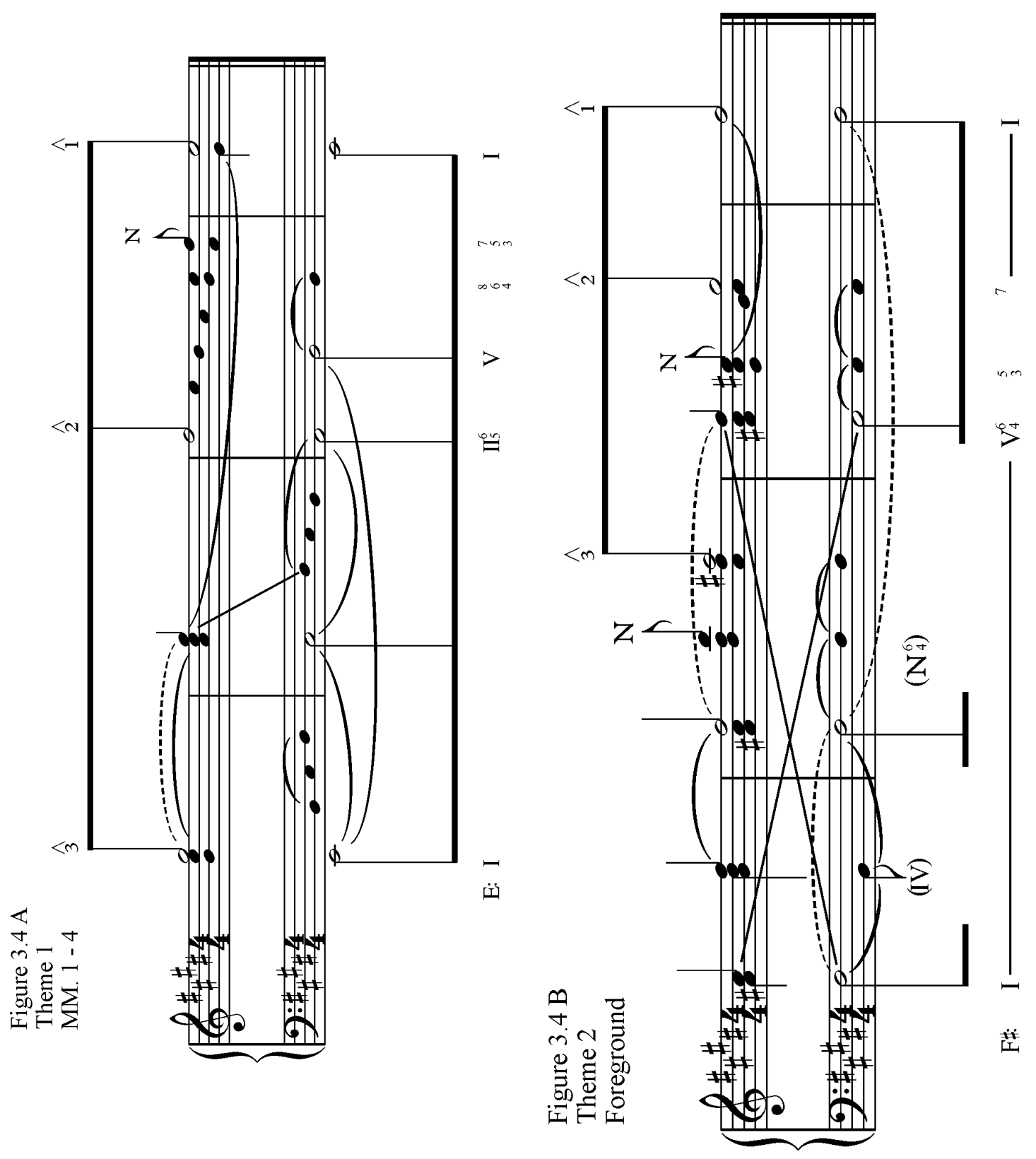
between the two thematic ideas and resolves them by complementing their cadential tendencies. In the absence of textual support, Ponce is able to emulate the dramatic structure of Schubert by creating a similar conflict between the two thematic characters. 


\section{CHAPTER 4}

\section{SCHUBERT'S MOMENT MUSICAL}

Next to the lied, Schubert's short character pieces offer the clearest examples of his command of short, lyrical, and structurally sound forms. Schubert's composition of the Moment Musicaux, op. 94 begins with two short pieces in 1823, with additional movements included up to the year of his death in 1828. Alfred Einstein classifies the Moment Musicaux as Schubert's last original contribution as a keyboard composer, in regards to form and character. ${ }^{84}$ However, Schubert had yet to compose his last three piano sonatas before beginning the Moments five years before their publication. The character pieces created by Schubert in his later years typically involve simplistic processes and forms. Each acts as a vehicle for the 'sorrowful expressions' that encapsulate the works of Schubert. ${ }^{85}$ John Reed states:

(...) nothing is more idiosyncratic, more typical of the essential Schubert, than these eloquent miniatures. ${ }^{86}$

Reed continues in another text:

They belong to the diversified literature of short pieces which grew up as the potentialities of the new pianos, and the expressive impulses of Romantic composers, came to be realized, a literature variously represented by Field's nocturnes, Beethoven's bagatelles, and Chopin's waltz's, experimental in technique and Romantic in feeling, which was to

${ }^{84}$ Alfred Einstein, Schubert: A Musical Portrait (New York: Oxford University Press, 1951), 288.

${ }^{85}$ Robert Winter, "Franz Schubert: Works," in Grove Music Online, http:/grovemusic.com/ (accessed 14 February 2014).

${ }^{86}$ Reed, Schubert, 149. 
be brilliantly exploited in different ways by Chopin, Liszt, Mendelssohn, Brahms, and many others. ${ }^{87}$

Like Schubert's Impromptus, the Moments are of Bohemian origin, encapsulating a dance-like quality-a reference to the their folk elements. They encompass a wide variety of temperaments, yet remain consistent in their quality and tempo. The constancy in their gait and 'quasi-balletic' charm suggest Schubert's comfort with dance pieces and forms. ${ }^{88}$ Many of the movements are monothematic, containing a stubbornly persistent theme within the tonic expansion. The Moments are in simple meter and are mostly static rhythmically. Some of the Moments contain experimental harmonic progressions and chromatic half-step slides that would come to define the harmonic characteristics of the Romantic period. It is not the structure and notes in and of themselves that form the unique quality of these pieces, but the "dependence on the recognition of the whole, of the Gestalt, which characterizes all forms of perception." ${ }^{89}$ This concept defines the piece's ability to manipulate the listener's expectations over time and supplements the musical moment of the harmonically contrasting middle section. The relative simplicity in both structure and design places these pieces among Schubert's most popular works. Their approachability, expressive nature, and lack of virtuosic necessity enhance their universal appeal.

In the Sonata Romántica, the third movement shares many of these characteristics by utilizing the phrase structure and conservative harmonies associated with the practices of the Classical period. The third movement's placement within the structure of the fourmovement sonata is representative of the chronology in which Schubert composed his

\footnotetext{
${ }^{87}$ John Reed, Schubert: The Final Years (New York: St. Martin's Press, 1972), 153.

${ }^{88}$ Reed, Schubert, 148-9.

${ }^{89}$ Reed, Schubert: The Final Years, 154-5.
} 
Moments Musicaux. However, it is known that both Rachmaninoff and Paderewski composed in this style in the late nineteenth-century. ${ }^{90}$ Fittingly, Ponce places these two paradigms beside one another in the sequence of the four-movement sonata form.

While the final edition does not include a subtitle, only a tempo indication of Allegro vivace, the manuscript reveals its original classification as a moment musical. No other movement of the Sonata Romántica contains a specific subtitle in the manuscript or printed edition. It is possible to speculate that Ponce initially intended to attribute each movement to a different Schubert genre, then altered the work to emulate Schubert's piano sonata paradigm. The duality of the Allegro vivace's role as indicative of Schubert's scherzi and moments musicaux becomes apparent when comparing the similar characteristics of the two forms.

Traditionally, Schubert included a scherzo or minuet and trio as the third movement of his sonata. The typical characteristics of this movement are similar to the Classical model in that he includes a minuet in the original tonic, containing distinct $3 / 4$ meter, and a trio in a contrasting key; however, not all of Schubert's scherzi have trios. Schubert's moments musicaux contain several similarities to the third-movement of Schubert's piano sonatas as they both share a similar formal structure (ABA) and place an emphasis on their dance-like qualities. Each of these forms contain a contrasting middle section, balancing the characteristic differences between the two sections. Alfred Einstein compares two of Schubert's scherzi in $\mathrm{B} b$ major and $\mathrm{D} b$ major: ${ }^{91}$

\footnotetext{
${ }^{90}$ Maurice J.E. Brown, “Moments musical,” in Grove Music Online, http://grovemusic.com/ (accessed 15 February 2014).

${ }^{91}$ Einstein, Schubert: A Musical Portrait, 133. Schubert composed these scherzi independently and did not include them in his piano sonatas. Einstein believes that the scherzo in Bb may have been composed for Schubert's piano sonata in $\mathrm{E} b$, due to the similar trios, and removed later by Schubert.
} 
The first Scherzo has a typically South-German sense of humor and a leisurely and distinctive charm; the second, alternating between D-flat and $\mathrm{E}$ major in the main section, is full of underlying restlessness and passion with which the pure 'Minuet' character of the Trio (in A-flat major) contrasts very happily. If these two Scherzi were included among the Impromptus or 'Moments musicals' (why not keep Schubert's inaccurate French!), they would be universally similar. ${ }^{92}$

Through these similarities, Ponce is able to effectively produce a work that simultaneously emulates Schubert's moment musical and fulfills the role of his third movement sonata paradigm.

\section{Allegro vivace}

The Sonata Romántica pays homage to Moments Musicaux Nos. 5 and 6 in particular through various methods of quotation and stylistic references. Composed in $2 / 4$, as the majority of the six Moments, the third movement uses the simple march-like rhythm to establish a connection to Moment Musical No. 5 in F minor, as seen in Example 4.1. Ponce references this movement by the consistent use of static harmonic progressions and rhythmic figures. The structure, based on the provided double bar-lines, is a five-part rondo in $\mathrm{ABCAB}^{\prime}$ form, reminiscent of Schubert's Moment Musical No. 2 in $A b$, the only one containing a similar structure. Through the sudden differences in the $\mathrm{C}$ section, in congruence with the similar rhythmic patterns of $\mathrm{A}$ and $\mathrm{B}$, one may suggest a larger structure of ABA. The static harmonic and rhythmic nature of Schubert's fifth Moment creates additional tension due to the desire to move away from tonic. The composite rhythm of the Allegro vivace provides similar results, in addition to the similar harmonic monotony. Ponce creates this intentional static progression through tonic arpeggiation and a prolongation of $\mathrm{E}$ in the soprano. Both passages place strong accents

\footnotetext{
${ }^{92}$ Einstein, 133.
} 

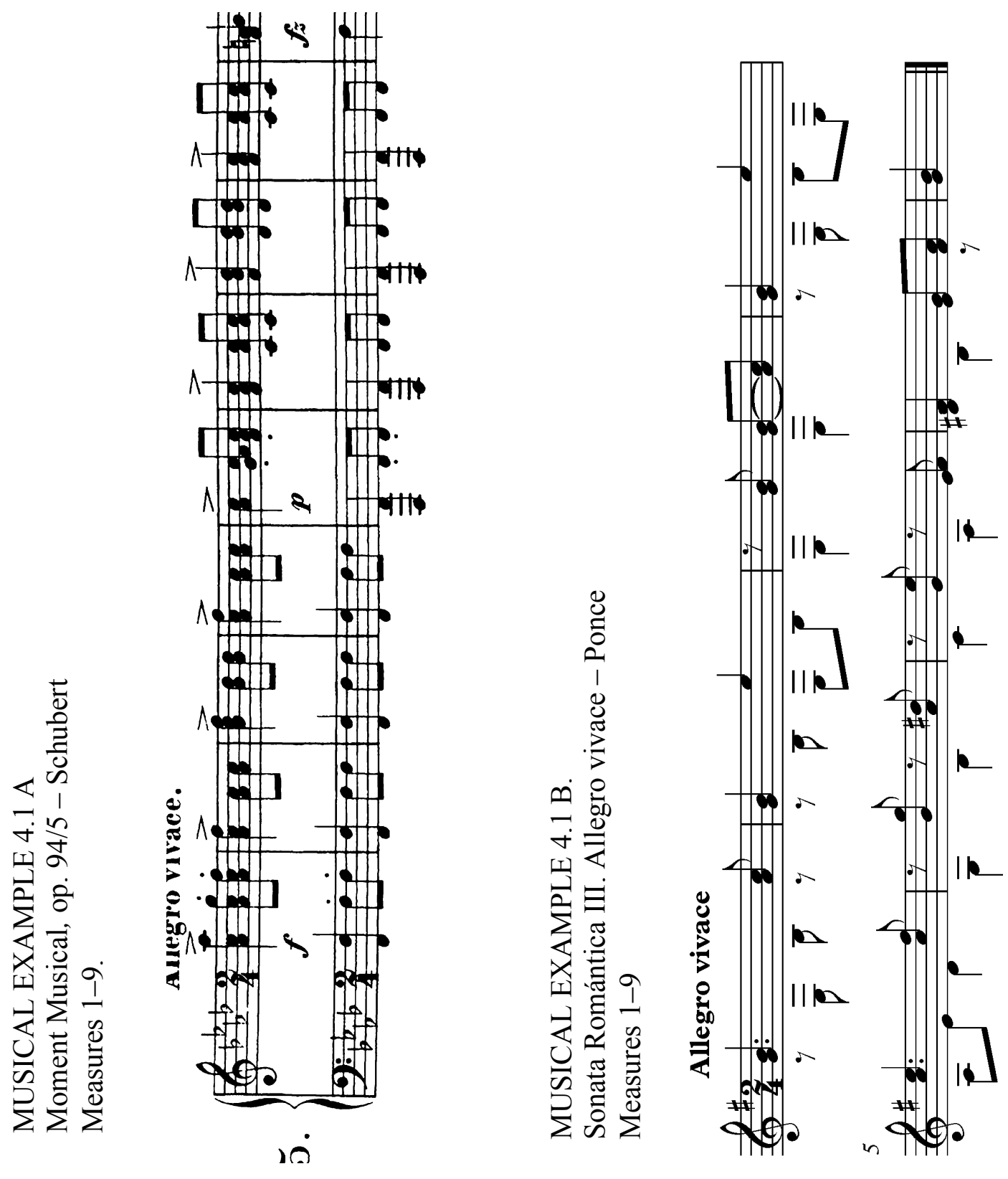
on the tonic and limit the use of prolongation, creating additional tension. The contrast in the B section of the third movement is more prominent than the Moments, suggesting either a break in character or an additional application by Ponce. Further analysis reveals the B section as reflective of Moment Musical No. 6 in Ab major. The weak placement of the tonic chord permits an emphasis of IV in the proceeding measures. In the Schubert work, the $\mathrm{C}$ in measure 1 acts as a 7-6 suspension over a supertonic (II) harmony in measure 3 . Ponce emulates the same pattern in $2 / 4$ but does not resolve the suspension, leaving the added coloration of the chordal seventh in a subdominant seventh $\left(\mathrm{IV}^{7}\right)$ harmony, perhaps to further distinguish the B section from the stagnant nature of the A. In Schubert's moments musicaux, the placement of the tonic on weak beats alters the hypermetric structure leading to the strong half-cadence resolution in measure 8 . Ponce utilizes similar weak-strong relationships in the Allegro vivace, with differences lying in the metric accents. Ponce appears to compensate for the rigid duple meter by making limited use of the weak-strong relationship that becomes present at the cadences. However, the hypermetric relationship remains similar to Schubert.

The stagnant tonic statement in the A section delays the initial ascent to the Kopfton. Ponce references Schubert's Moment Musical in Ab in the B section by prolonging the initial ascent through the A section. Example 4.1B shows the early suggestions of $\mathrm{G}$ as the Kopfton through modal mixture and a $\mathrm{V}^{7} / \mathrm{III}-\mathrm{III}$ in measures 5-6; however, there is no harmonic support to claim this as the arrival of $\hat{3}$. The interplay between the inner-voice and the soprano creates an ascent to the tonic without 

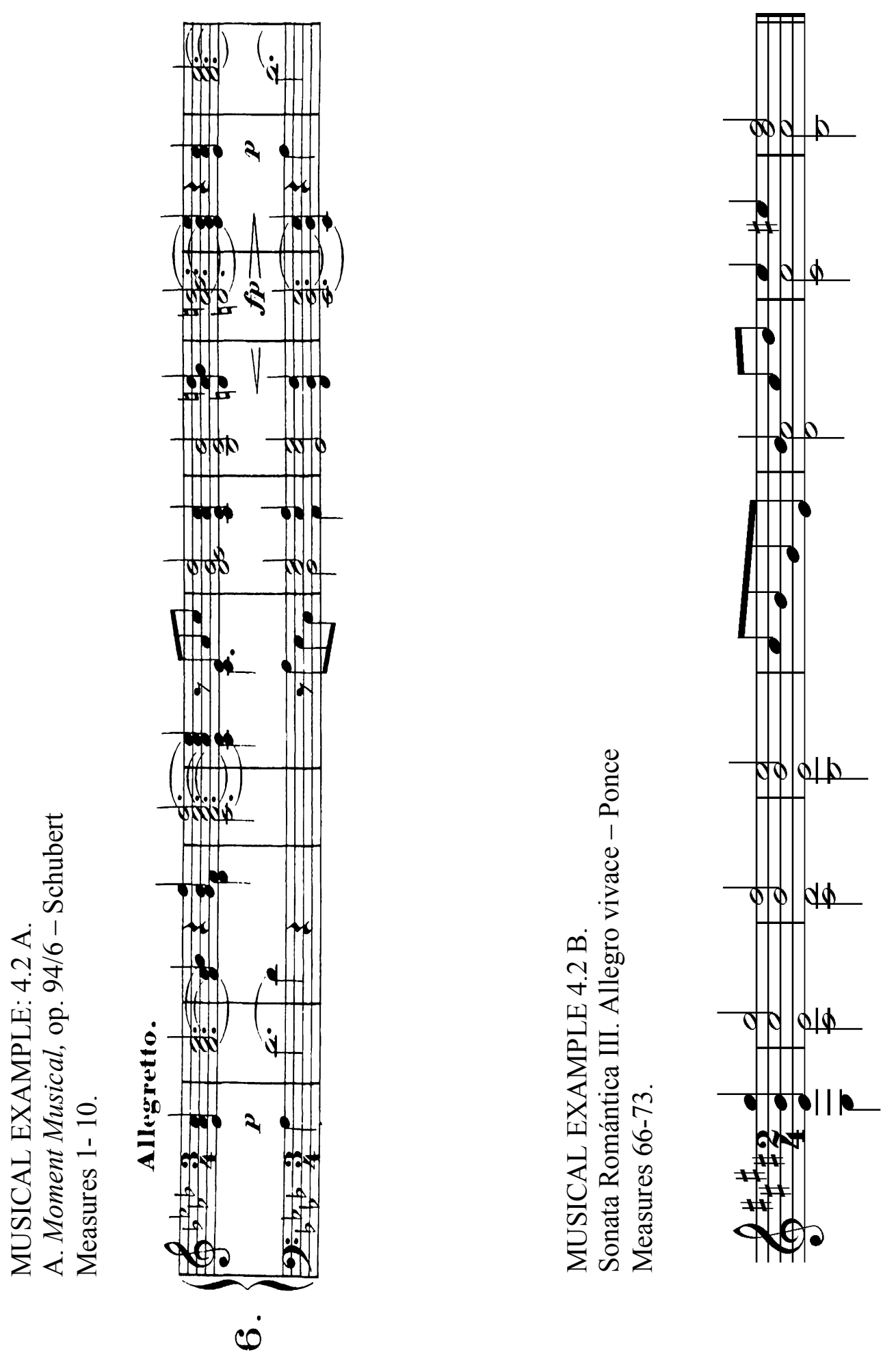
obtaining the Kopfton. The rising motion to the tonic in the upper-voice throughout the A section contributes to its delayed arrival.

The musical tactic used by Ponce in the opening statement is occasionally found in Schubert's works. The delayed arrival of $\mathrm{G}$ is a reference to what Edward Cone describes as Schubert's 'promissory note'. ${ }^{93}$ Cone introduces the concept in his article as a means to describe a pointed note of cognitive expectation and delay. ${ }^{94}$ This instance is analogous to a large portion of Schubert's Moments and Impromptus. The promissory note suggests an incomplete realization that must be eventually 'repaid' - much as the paronomastic term suggests. Cone utilizes the concept towards a singular idea of musical interpretation extending into the field of psychoacoustics referring to the more subjective interpretive qualities of music, such as emotion. The striking occurrence that places this promissory note beyond an initial incomplete tonicization is Ponce's use of modal mixture and the obligated correction to $\mathrm{G} \#$.

The use of the minor mode, with its more variable scale-degree qualities, allows for a variety of harmonic possibilities not typically found in the major mode. Schubert's use of modal mixture causes a dramatic juxtaposition resulting in an ambiguous relationship between bIII and bVI. ${ }^{95}$ The opening phrase reflects these harmonic variations with a VII $\left(\mathrm{V}^{7} / \mathrm{III}\right)$ to III that reinstates the ambiguity between the relative modes of $\mathrm{E}$ minor and $\mathrm{G}$ major. The isolated motion of dominant to tonic harmonies within the sequential pattern supersedes the accentual placement of the $G$, and its

\footnotetext{
${ }^{93}$ Edward T. Cone, "Schubert's Promissory Note: An Exercise in Musical Hermeneutics," $19^{\text {th }}$ Century Music, 5, no. 3 (1982): 235.

${ }^{94}$ Ibid., 236.

${ }^{95}$ David Beach provides a more substantial investigation to Schubert's modal mixtures in his Moment Musicaux and Impromptus in his article: David W. Beach, "Modal Mixture and Schubert's Harmonic Practice” Journal of Music Theory, 42, no. 1 (Spring 1998) 73-100.
} 
traditional treatment to the initial ascent. Therefore, modal mixture contained within the tonic foreshadows the eventual acquisition of $\hat{3}$ with harmonic support in the B section.

Ponce frequently suggests $\mathrm{G}$ within the first section supported by subdominant harmonies. Figure 4.1 exhibits the delayed initial ascent to the B section with the arrival of the altered third, $\mathrm{G} \#$. The tonicization of $\mathrm{C}$ in $\mathrm{mm}$. 16-17 retains the promissory $\mathrm{G}$ within the soprano voice, utilizing the $\mathrm{C}$ as a predominant in both relative keys.

Dominant support for the $\mathrm{F} \#$ occurs in measure 28 suggesting a local prolongation of $\hat{2}$ as the primary step of the initial ascent. However, this motion to the dominant is merely the beginning of a more prominent Schubertian characteristic.

The A section contains elements of Schubert's three-key exposition ${ }^{96}$ without fully committing to the significance of each tonal center. Additionally, the formal structure as stated previously suggests an $\mathrm{ABA}^{\prime}$ form, not sonata form, similar to Schubert's third movement Scherzo. The prominence of three distinct tonal centers promotes an argument for a three-key exposition. Deborah Kessler provides evidence of the three-key exposition occurring in Schubert's Impromptu op. 90 No. 2 (D. 899) ${ }^{97}$. The emphasis of I, V, and bVI coincide with this feature. The abrupt modulation to V in measure 28 represents the first aspect of Schubert's three-key paradigm.

The arrival of the Kopfton on $\mathrm{G} \#$ in the B section contrasts the characteristics of the previous section through the alteration of the mediant. The musical release of tension in the B section counters the monotony of the A section. The chromatic alterations seen

\footnotetext{
${ }^{96}$ Deborah Kessler, "Schubert's Late Three-Key Expositions: Influence, Design, and Structure" (Ph.D. diss., City University of New York, 1996, 21-22.

${ }^{97}$ Kessler, "Schubert's Late Three-Key Expositions: Influence, Design, and Structure," 211.
} 


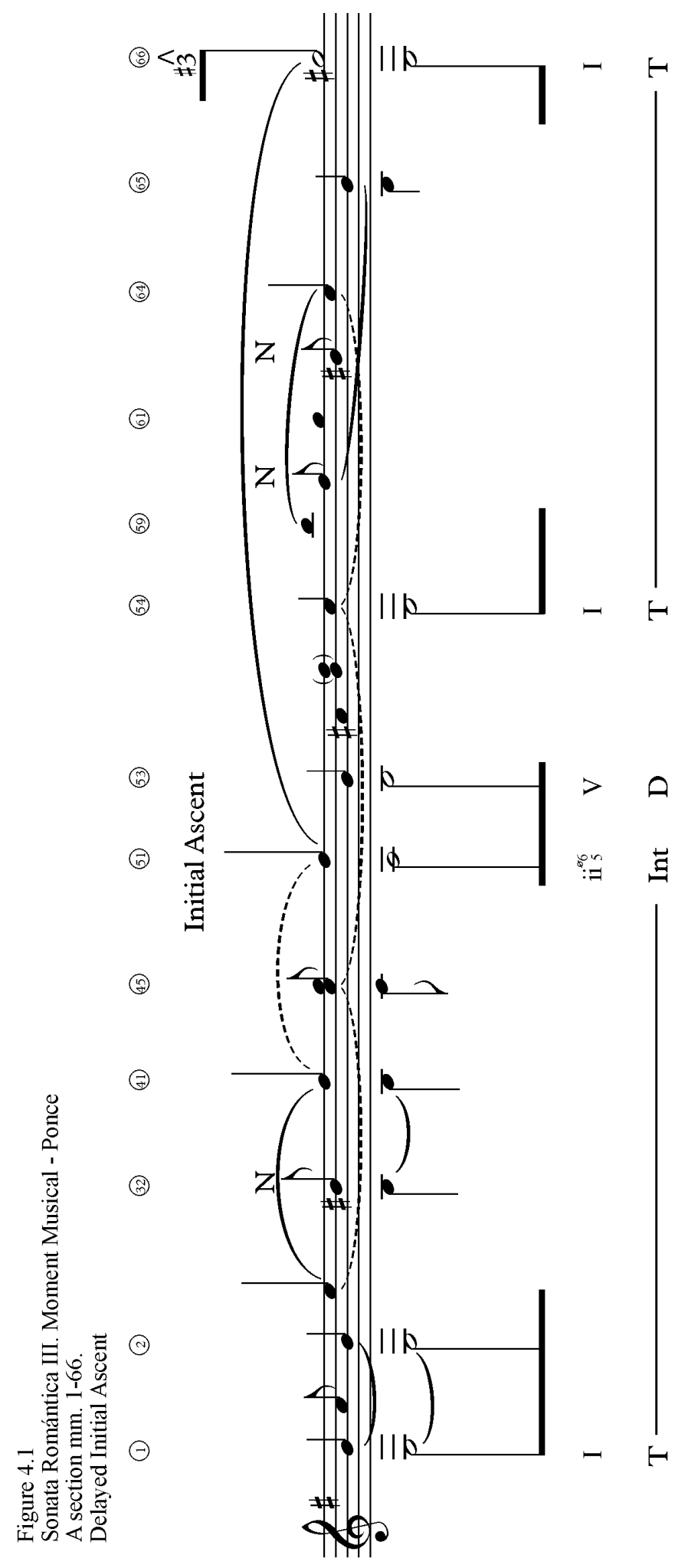


in the B section of the Allegro vivace are representative of the unique characteristics of Schubert's moments musicaux.

Although the $\mathrm{G}$ is consistently suggested throughout the A section, the true Kopfton is obtained in measure 66 . The prolongation of $\mathrm{F} \#$ from measure 28 gradually initiates the ascent to G. Convincing harmonic support for the G until this point is faint and the change in mode and rhythmic density suggests a more significant moment. Yet, even with the harmonic support of $\mathrm{E}$, in addition to the motion to the parallel major, the metric placement weakens an otherwise convincing arrival. $\mathrm{The} \mathrm{IV}^{7}$ becomes more prominent; however, $\mathrm{G} \#$ is still the emphasized in the soprano.

Ponce, as does Schubert, prolongs the tonic and subdominant harmonies until the return to the A section where he supplies the final cadential motion. The function of the B section is to accentuate and prolong the long anticipated $\hat{3}$ with chromatic alternations. Figure 4.2 displays this prolongation and its return to $G$ ต in measure 106. Again, the prominence of the modal mixture supersedes any harmonic expectations through its chromatic implications on the Urlinie. The significant contribution of B is to provide additional ambiguity of $\hat{3}$ during a moment of release from the monotonous rhythms and harmonies of A. Thus, the musical moment becomes more pronounced. The arrival of $\hat{1}$ in the soprano voice on the downbeat of the recapitulation justifies the delayed initial ascent throughout the section. The static nature and unsupported harmonies are now clarified as the second A section convincingly acts as a coda, prolonging the tonic harmony.

The amalgamation of Schubert's scherzo and moment musical in the third movement supports the notion of the Sonata Romántica as a manifestation of Schubert's 
multiple forms. Ponce exploits the similarities in formal structure and harmonic contrast in Schubert's scherzo and moments musicaux to fulfill the role of Schubert's thirdmovement sonata paradigm. Additionally, Ponce synthesizes the characteristics of Schubert's final Moments Musicaux to establish a sense of compositional continuity of on the part of Schubert. 


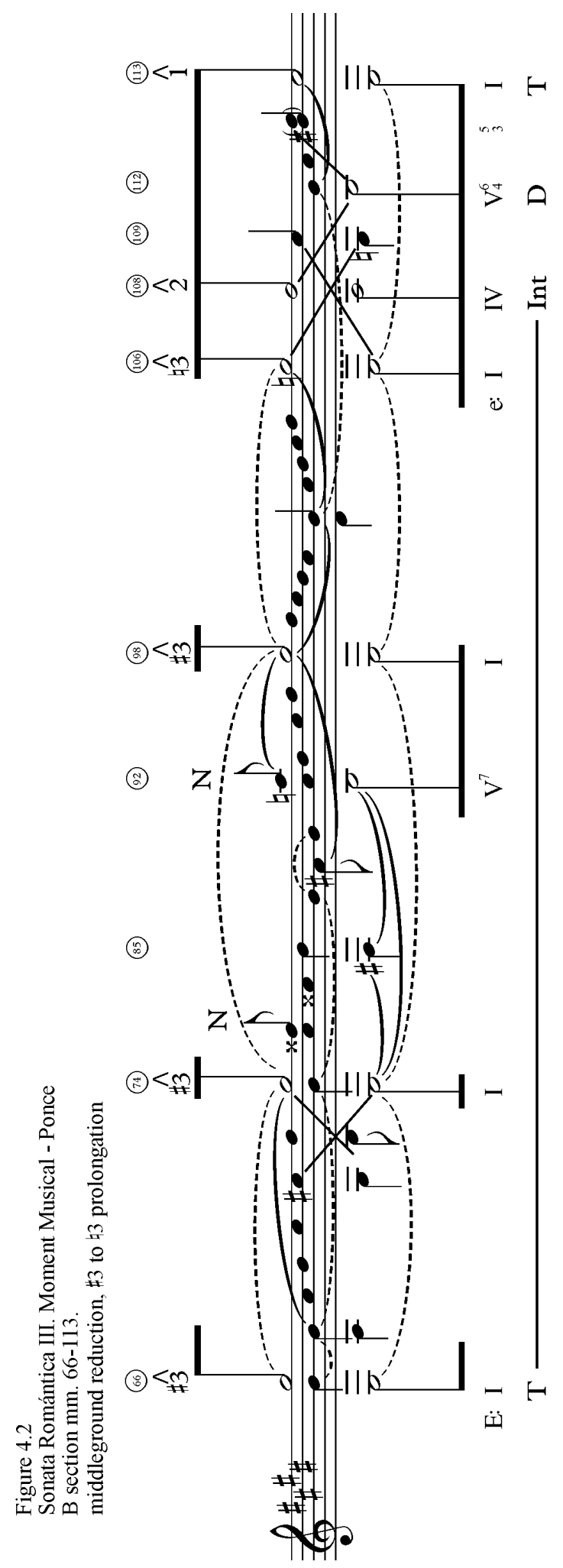




\section{CHAPTER 5}

\section{SCHUBERT'S FINALE: RONDO, VARIATION, AND FANTASY}

Schubert's music is the music of the wanderer. It is also the music of a tourist. The difference between wandering and touring is largely a matter of teleology. Tourists seek a change of scene and travel so that they can return home; wanderers set forth without a predetermined goal, although they may discover one en route. The tourist's return home is predetermined; if, by contrast, the wanderer begins and ends up in the same place, such a return is a potent surprise, a portentous coincidence. ${ }^{98}$

Perhaps no other movement of Schubert's sonata receives less attention and study than his fourth-movement finale. The fourth movement of the Sonata Romántica reveals an even greater connection to Ponce's interpretation of Schubert's compositional style. Schubert's music creates a musical journey, allowing the listener to appreciate the harmonic and lyrical content without concern for tonal objectives. The harmonic freedom of Schubert's finale allows the listener to react objectively to harmonic devices instead of expecting them. Applying this idea, Schubert typically prolongs certain motifs or themes and, much like the single movement fantasy, allows for a certain amount of freedom to explore distant or unusual keys.

Labeled as either Finale or Rondo, the fourth movement of Schubert's piano sonatas varies greatly in both structure and harmonic treatment. The large number of incomplete or omitted fourth-movements indicates a sense of insecurity on the part of Schubert as many are classified as such due to an omitted recapitulation or fourth

\footnotetext{
${ }^{98}$ Jeffrey Perry, "The Wanderer's Many Returns: Schubert's Variations Reconsidered," The Journal of Musicology, 19, no. 2 (Spring 2002), 374.
} 
movement. Newbould suggests that Schubert's omission of a fourth movement could have been due to Schubert's lack of conviction of his first movement, due to similar structural difficulties. ${ }^{99}$

Most of Schubert's later piano sonata finales contain a sonata-rondo form, creating multiple options for unique key areas and thematic ideas. No rondo form appears in Schubert's final movements until his Piano Sonata in A minor, D. 845, and from there it is used exclusively. ${ }^{100}$ While Ponce's other movements employ a more direct representation within the Schubertian paradigm, the fourth movement of the Sonata Romántica reveals a more dispersed relationship to Schubert's fourth movement rondo form and his final complete four-movement sonata. The inclusion of a fourth movement within the Sonata Romántica completes the homage to Schubert's later piano works, as many of Schubert's earlier sonatas remained incomplete. Thus, the inclusion of a fourmovement is an amalgamation of Schubert's piano sonata form, lieder, and moment musical with the first and fourth movement referencing Schubert's first and last piano sonatas.

\section{Allegro non troppo e serioso}

The final movement of the Sonata Romántica created numerous compositional obstacles for Ponce. The delay between the completion of the first three movements and the fourth, in addition to Segovia's frustration with the arpeggios, demonstrates the Ponce's struggle to complete the work. Perhaps this apparent difficulty offers a possible explanation as to the missing fourth movement manuscript.

\footnotetext{
${ }^{99}$ Newbould, Schubert: The Music and the Man, 95.

${ }^{100}$ Helen Doris Haupt, "Form in the Pianoforte Sonatas of Franz Schubert" (Thesis, University of Illinois, 1941), 6 .
} 
Confirming the hypothesis of the Sonata Romántica as a chronological realization of Schubert's works, Ponce references numerous characteristics from the finale of Schubert's last piano sonata. The fourth movement of the Sonata Romántica is similar to the final movement in D. 960 through three distinct characteristics:

1. The tempo indication, Allegro ma non troppo

2. A notable prolonged emphasis of similar sixteenth-note figure

3. Similar structural elements with differences in tonal areas

Ponce utilizes the similar tempo indicator as Schubert's final movement D. 960, the only occurrence of which in his four-movement sonata. The tempo marking provides conclusive evidence to support the chronological theory. As mentioned in Chapter 1, the relationship to the Schubert's piano sonata is twofold, as this indicator represents the first movement of his first piano sonata, D. 157 and the last movement of D. 960. Ponce creates a grand finale under the same tempo indicator to frame the work as a reference to Schubert's entire body of piano sonatas.

The sixteenth-note figure plays a notable role in each respective movement. Segovia discusses this arpeggiated sixteenth-note pattern in a detailed letter to Ponce. ${ }^{101}$ Schubert, as does Ponce, comprises entire sections based on this singular idea. Ponce and Schubert utilize this figure primarily in the B section of each respective piece. Such rhythmic figures occur in Schubert's other piano works; however, the similarities of the contour, intervallic quality, and length of utilization suggest this as an intentional reference to D. 960.

\footnotetext{
${ }^{101}$ See page 23 .
} 

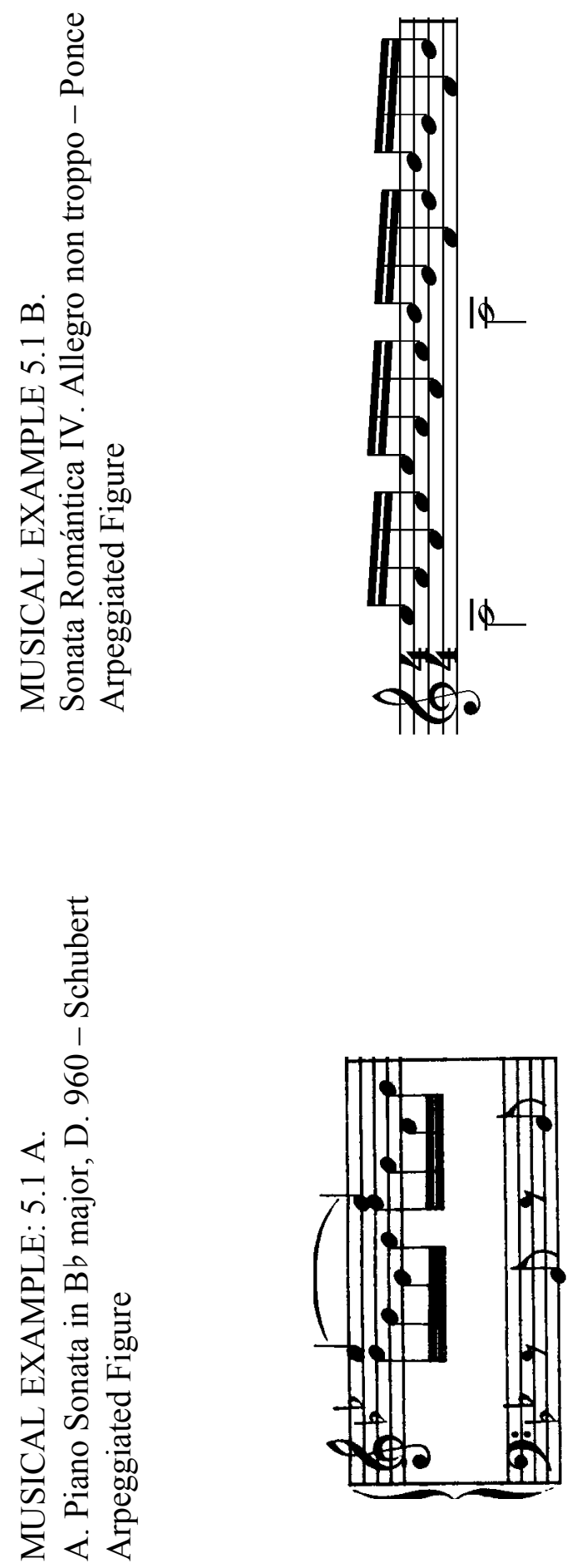
The arrival of A minor within the final movement creates more harmonic possibilities than its parallel major counterpart in addition to referencing the initial harmonic ambiguity of D. 960. Whereas A major is the nominal key of the Sonata Romántica, neither of the middle movements contain a single passage within A-major key area; Ponce's use of A minor, therefore, provides a return to the tonic in its parallel minor. The onset of a minor key is another nod to Schubert, as the fourth movement of his D. 960 begins ambiguously in $\mathrm{G}$ minor/Bb major.

The formal and tonal structure of this movement combines multiple characteristics of Schubert's finales. Schubert frequently utilizes a sonata-rondo form with elements of fantasy, due to the rhapsodic nature and thematic development of the latter. Ponce remains authentic to this model by utilizing many of these same elements. While Schubert's finales vary in form, they remain consistent throughout the movement; Ponce, however, combines the varied forms into a single movement. The first section begins with the expositional material until the sixteenth note figure, as seen in Figure 5.1B, in measure 15 . This rhythmic figure continues until measure 36 , initiating the second section in the parallel major. Measure 90 contains a complete recapitulation of the first and second section until measure 115 , which begins a transition to the coda in measure 126. Ponce reveals the actual formal structure to be a variance of sonata-rondo (ABA'B'A''(coda)).

The first section begins with a strong homophonic rhythmic texture, reminiscent of the march-like rhythms seen in many Schubert piano sonatas. (See Example 5.2) The rhythmic development that occurs during the first two periods suggests a variation form as Ponce presents the harmonic structure, followed by the same harmonic progression 
with rhythmic variance. The onset of the sixteenth note figure alludes towards a continuation of the variation structure; however, the harmonic and tonal structures reveal a motion away from this form. This embodies the thematic fixation of Schubert, who would become distracted by a particular thematic idea or motif, consequently creating ambiguity in the formal structure. Ponce follows this characteristic of Schubert by converting to a fantasy form. This structural ambiguity allows Ponce to elaborate on the episodic nature of the movement.

By measure 37, Ponce establishes a new theme in the parallel major, effectively retrieving the long-awaited tonic. The introduction of the second theme is restated in various keys, suggesting the beginning of the development section. The tempo indication at the beginning of the second theme in measure 37 suggests that Ponce borrows features from the other movements in Schubert's sonata form. Labeled 'Tempo, scherzando', this section acts as a reference to the playful nature of Schubert's third movements of his piano sonatas. While this section does not contain a rounded binary formal structure or a triple meter, as mentioned previously, its placement and classification is enough to give one pause. Schubert's scherzos typically occur before the fourth movement, providing lyrical contrast and a change of key, presented in a playful character. ${ }^{102}$ Similarly, this second section contributes a contrasting element to the previous section and retrieves the original tonic of A major. Ponce uses the marker of 'scherzando' similar to Beethoven, who used the term as an indicator of character and pace as opposed to an indication of formal structure. ${ }^{103}$. Ultimately, Ponce is able to allude towards four different forms

\footnotetext{
${ }^{102}$ Hugh McDonald, "Scherzo," in Grove Music Online, http://grovemusic.com (accessed 23 March 2014).

${ }^{103}$ Ibid.
} 


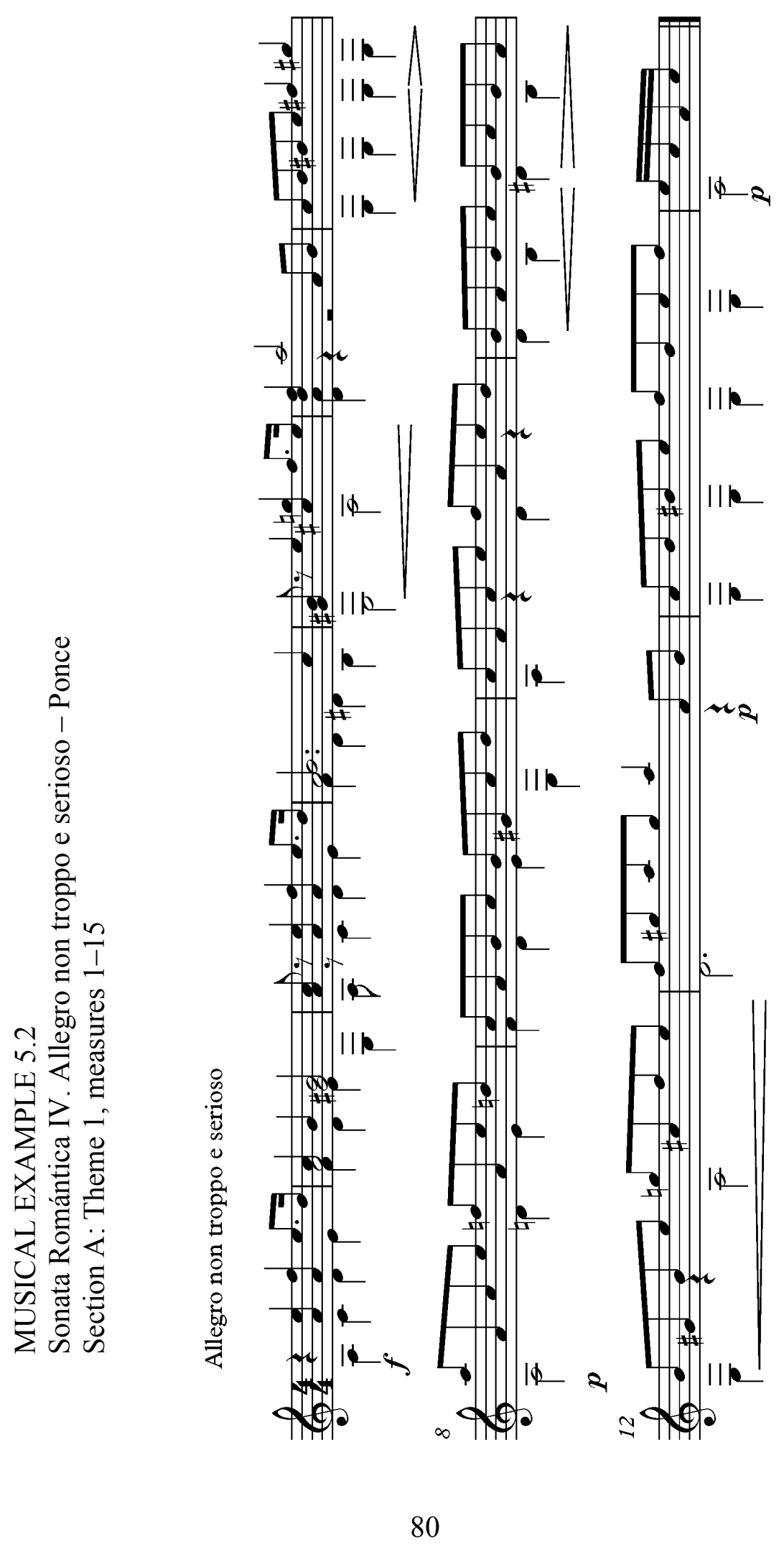


of Schubert's piano sonatas (variation, fantasy, scherzo, and sonata-rondo) within a single movement.

The tonal structure contains other significant similarities to Schubert's piano sonatas. The first A section (mm. 1-36) progresses through the mediant, and its chromatic neighbor, implying a transition to the dominant. The mediant progression of a third is similar to the harmonic development in the first movement; however, Ponce uses the $\mathrm{C}$ $\mathrm{C} \#$ relationship to return to the parallel major instead of A minor. Measure 37 establishes the second theme in A major, acquiring the original tonic key for the first time since the conclusion of the first movement. The arrival of the B section begins the development, establishing new thematic material. Ponce progresses with the second theme in A major, immediately restates the material in the parallel minor, emphasizing the emotional duality mentioned in Chapter 3. Ponce ends the phrase in the dominant contributing to its continuous nature, as seen in Example 5.3 B. The improvisational nature of this section reflects the wandering characteristics of Schubert's fantasy. The dominant arrival in measure 44 is brief and the piece continues to develop the second theme through sequential treatment and harmonic exploration.

Throughout the development, one may expect a return to the tonic or dominant; however, Ponce avoids this by proceeding through the circle of fifths (E - B minor - F\#), and preparing the $\mathrm{F} \#$ as a dominant to $\mathrm{B}$ minor in the recapitulation. This return to $\mathrm{A}^{\prime}$ ' in measure 83 presents a complete break from Schubert's sonata paradigm. No other Schubert sonata presents a direct recapitulation in the minor supertonic. Figure 5.1 


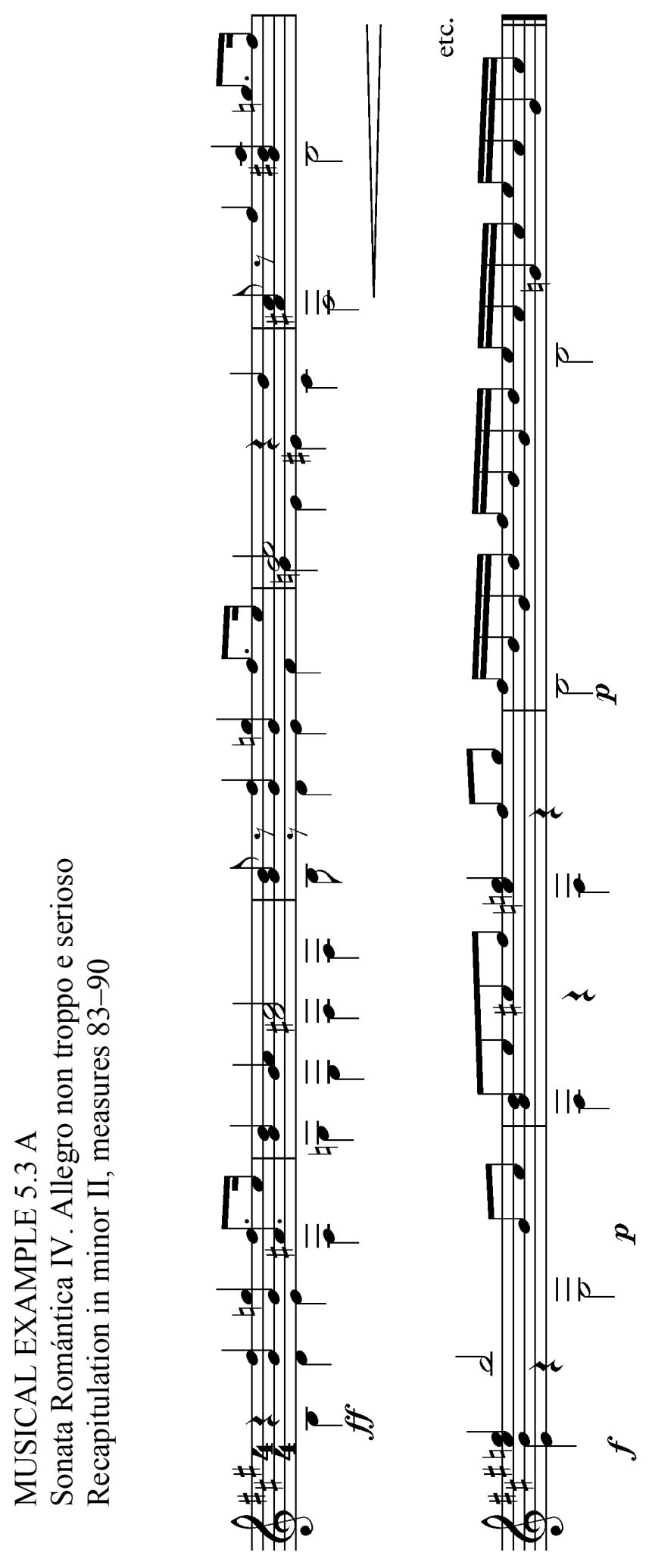




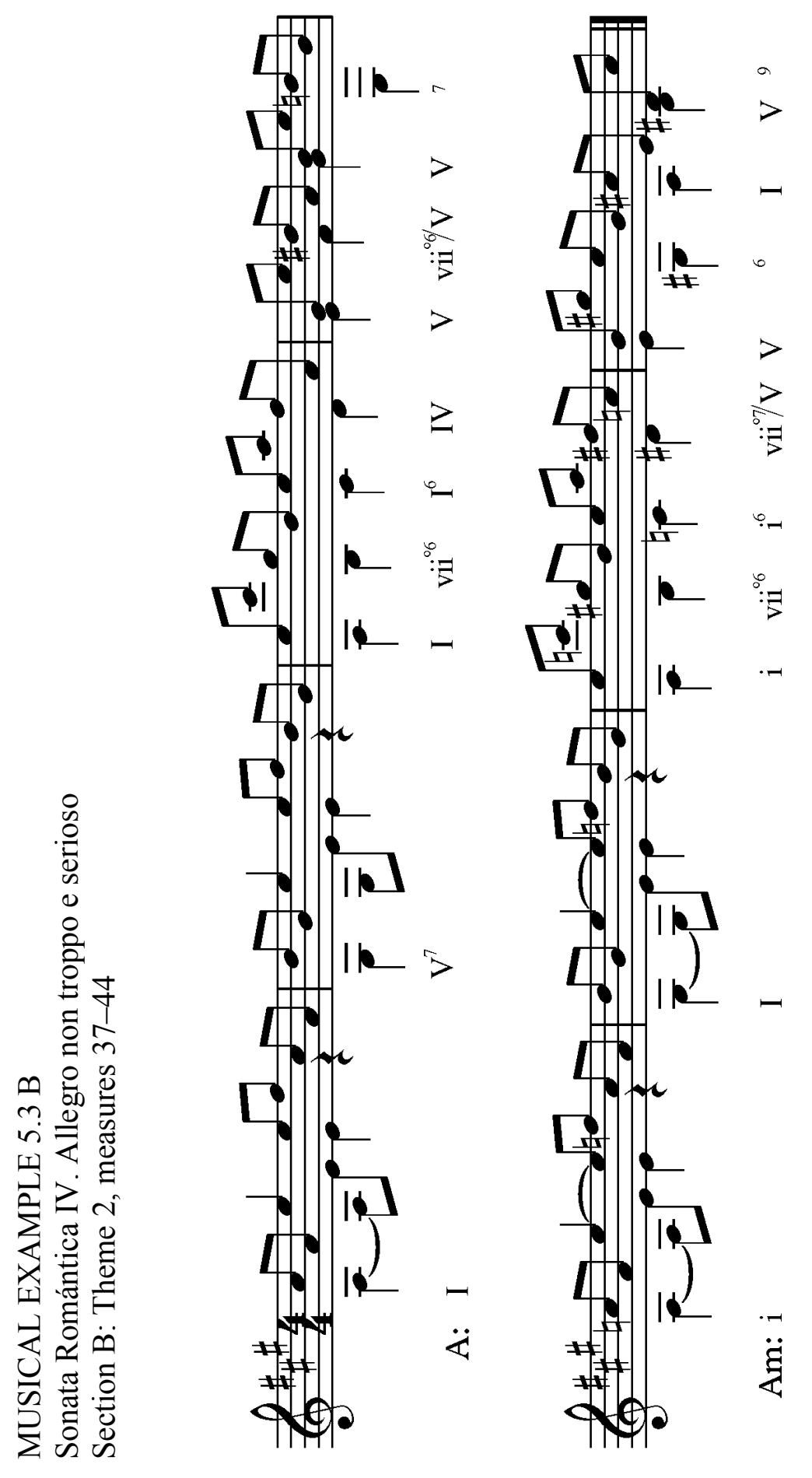


presents the unusual recapitulations of Schubert's sonatas. ${ }^{104}$ As the table demonstrates, Schubert frequently presented the recapitulations in the subdominant (IV) in his earlier works, then later became more adventurous with unusual harmonies. However, there is no indication of a complete return in minor II. A possible explanation for this strange return may be due to the physical limitations of the guitar. If Ponce intended to follow Schubert's later sonata paradigm and include a recapitulation in a key other than tonic, his choices are limited. Had Ponce attempted a return in IV, the lower register D would be unavailable due to the original tuning of the guitar, forcing a displacement of the bass and creating a less emphatic return. A possible return in the dominant presents similar difficulties.

The utilization of B minor becomes somewhat vindicated by the return of the B section in measure 111 . The mediant motion to III in measure 96 briefly tonicizes $\mathrm{D}$ major, the subdominant of the original tonic. While this harmonic treatment is highly unusual for Schubert, it adequately provides the necessary predominant prolongation to accentuate the arrival of $\mathrm{E}$ in measure 120. Analogous to the scherzando in the $\mathrm{B}$ section, Ponce presents the second theme in the parallel major. This modulation creates a V/V, transforming the B into a predominant harmony and delaying the dominant arrival. The return of the dominant reflects the nature of the wanderer as observed by Jeffrey Perry in the beginning of the chapter.

The unexpected acquisition of the dominant allows for a conclusive cadence in A major, revealing a possibility for its absence in measure 83 . The cadential motion through

104 Daniel Coren, “Ambiguity in Schubert's Recapitulations," The Musical Quarterly, 60, no. 4 (1974): 569-570.This table is a reproduction of Daniel Coren's research into the ambiguous recapitulations within Schubert's sonata form. 


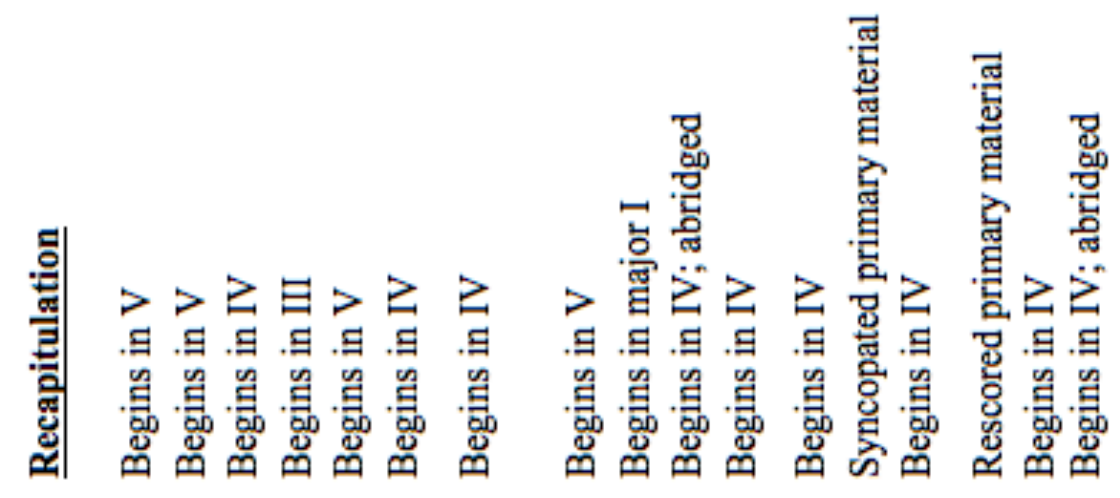

(1)

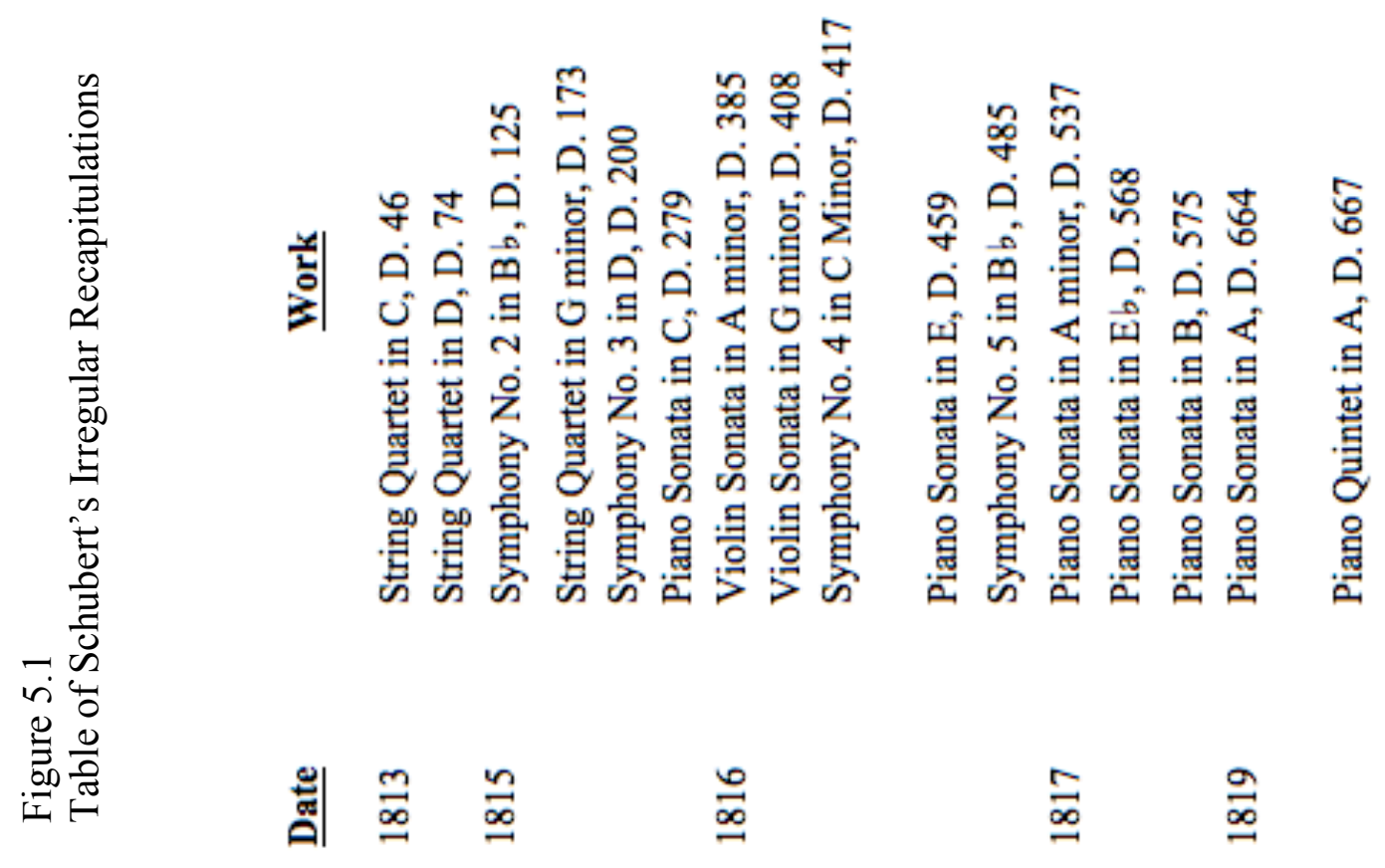




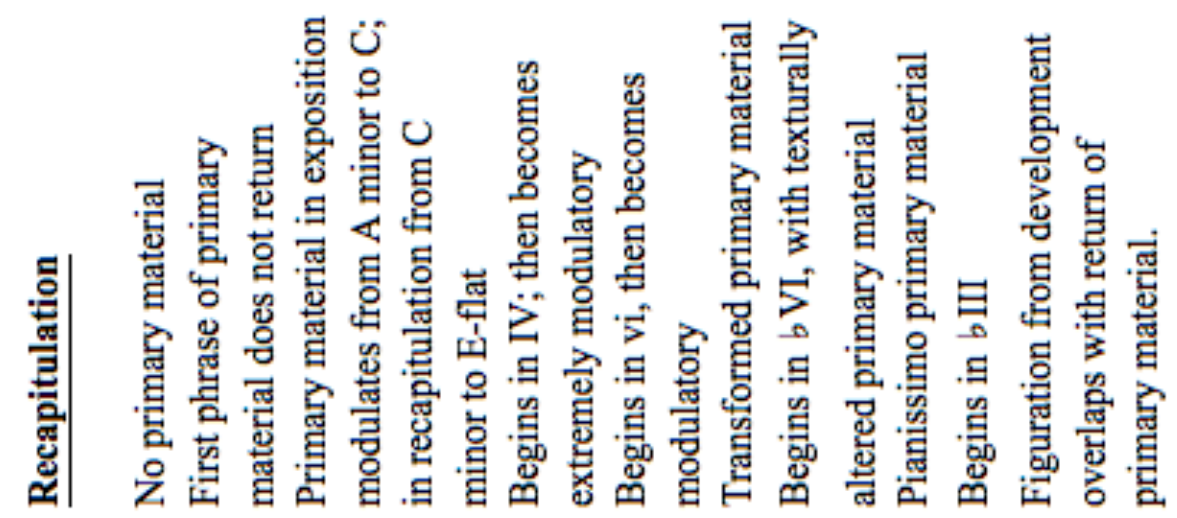

I

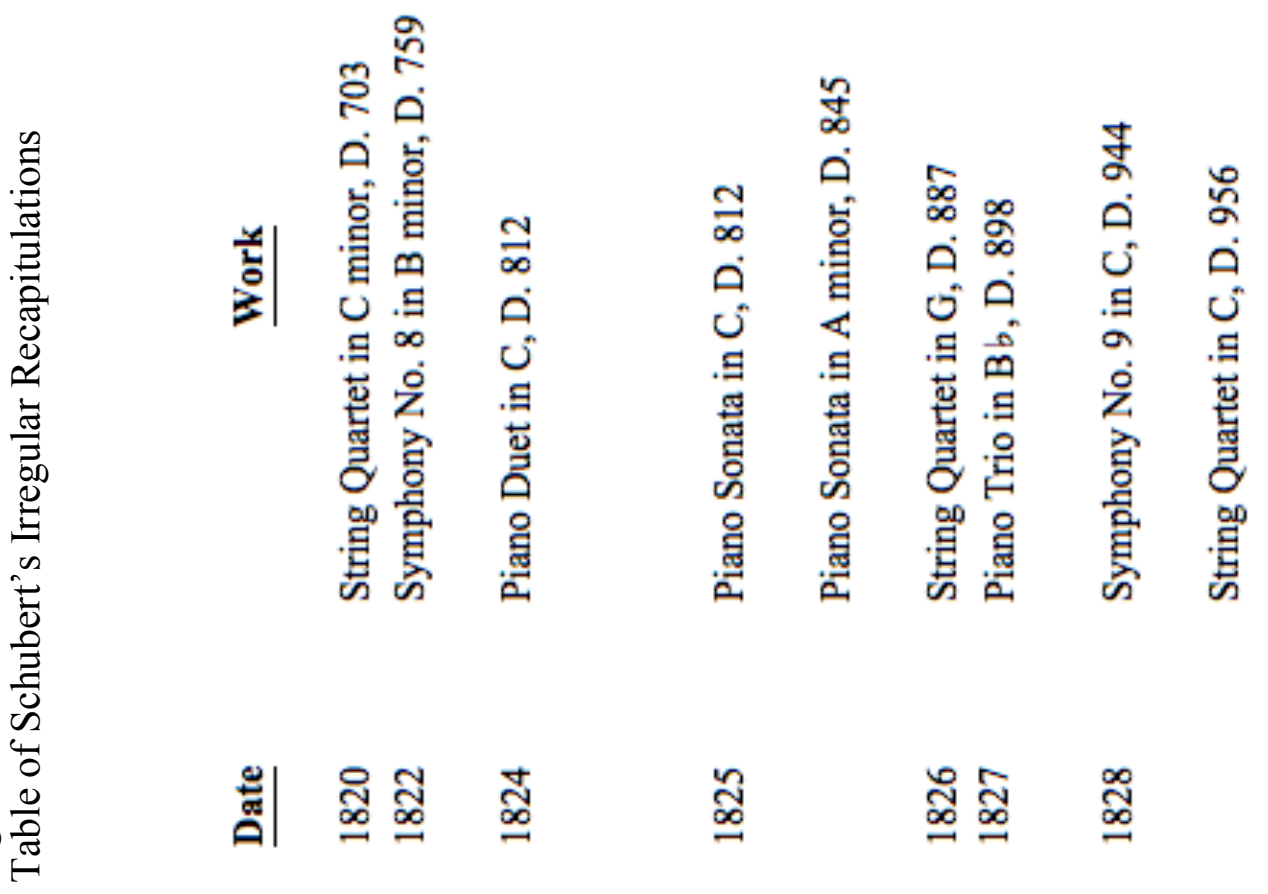

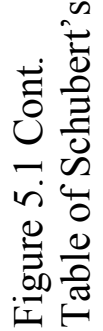

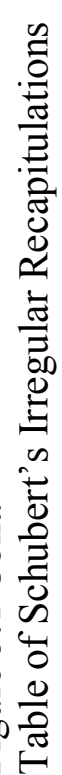


mm. 120-126 creates the most conclusive and satisfying cadence throughout the twentytwo minute work. The coda repeats the first theme of the A section in A major, then proceeds with the emphatic homophonic half-note figure seen in Example 5.4 B. The dramatic half-note figure in the coda is a reference to Schubert's Piano Sonata in A minor, D. 845. This seemingly abrupt and disproportionate half-note figure justifies the onset of A minor at the beginning of the movement. Similarly, Ponce utilizes the E pedal tone throughout the passage, although in a different voice and register, while emphasizing the tonic structure of A through arpeggiation. The piece concludes with the sixteenth-note figure in an alternating dominant to tonic progression, then extending the tonic in the same manner for six measures until the final chord. The use of the arpeggios in mm. 169176 helps to balance the powerful half note progression in mm. 142-168.

Due to the formal variances in the fourth movement of Schubert's piano sonatas, it is difficult to effectively capture a preferred form or harmonic plan with which to compare Ponce's piece. However, Schubert's final three four-movement piano sonatas (D. 958-60) all conclude with a similar sonata-rondo finale. Ponce summarizes the various formal procedures witnessed in Schubert's finales within a sonata-rondo form, referencing Schubert's final piano sonata, D. 960. The fourth-movement works in Schubert's later sonatas reflect Schubert's ability to alter the Classical form to a "unique and expressive end", ${ }^{105}$ establishing Schubert's individuality. Newbould states:

The finale is one of those gently flowing movements in which Schubert cannot bring himself to close the exposition. The player or the listener who perseveres (for the piece does not divulge its pleasures straight off)

${ }^{105}$ Robert S. Hatten, "Schubert the Progressive: The Role of Resonance and Gesture in the Piano Sonata in A, D. 959," Intégral, 7 (1993): 78. 

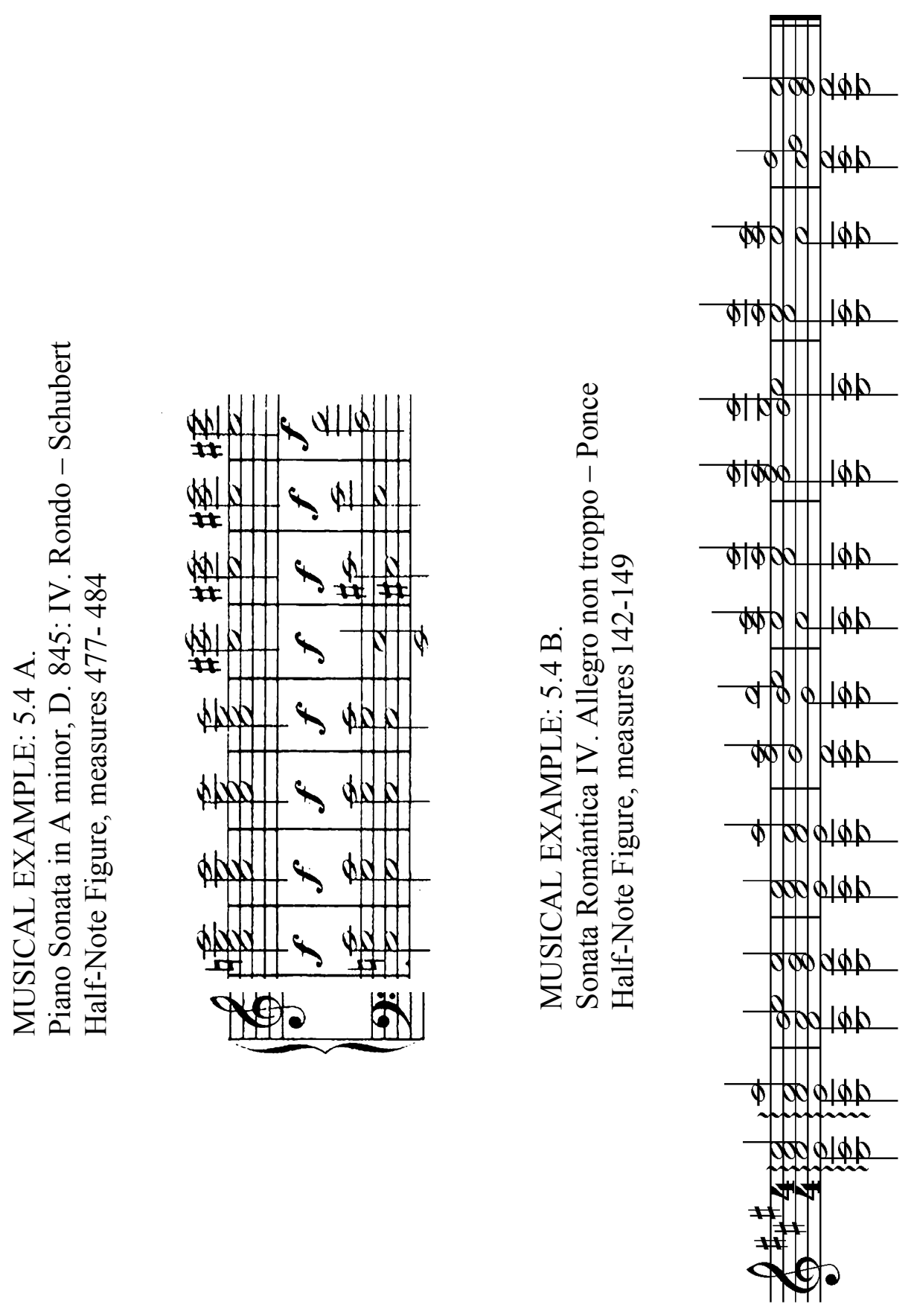
and soldiers on through the place where Schubert seems to lose his way will be rewarded. ${ }^{106}$

Similarly, Ponce delays dominant arrival until the final cadence through the dominant prolongation and unusual harmonic treatment of the recapitulation. The long-anticipated dominant arrival, in addition to its cadential expansion, provides a significant and rewarding conclusion.

${ }^{106}$ Newbould, Schubert: The Music and the Man, 103. 


\section{CONCLUSION}

The centenary of Schubert's death in 1928 coincided with numerous documents and claims in favor of Schubert as a guitar composer and enthusiast, as stated in Chapter 1. Schubert experts, including O.E. Deutsch, countered these claims with equal vigor and intensity as there lacked any sufficient evidence to support the erroneous assumptions of Schubert's affection for the guitar. However, the combined efforts of Ponce and Segovia, attempting to salvage the guitar from its modest roots as a folk instrument, effectively circumvented such criticisms and performed the Sonata Romántica to much acclaim, as noted in Segovia's letter to Ponce:

I am sending you some programs from Tokyo where your name appears. They gave the Sonata Romántica much applause... to sum up, your work is what has the most value, for me and for all the musicians who hear it, of all the guitar literature. ${ }^{107}$

By speculating about Schubert's interest in the guitar rather than attributing the piece as a lost work-as would occur later with the Suite in A minor-Ponce and Segovia create a difficult claim to counter or disprove.

My analysis of the movements in the Sonata Romántica suggests that Ponce intended to evoke one or more of Schubert's compositional idioms. The liberties Ponce exercised created a realization of Schubert's works without merely replicating his piano sonata form. Furthermore, Ponce effectively encompasses the forms and procedures of Schubert's career within a four-movement piano sonata paradigm, maintaining the

\footnotetext{
${ }^{107}$ Alcázar, 50.
} 
integrity of each movement. Ponce's ability to mimic Schubert's compositional style, while simultaneously expressing compositional continuity, exhibits his thorough understanding of Schubert's catalogue. No elements of Ponce's salonesque ${ }^{108}$ compositional quality are apparent in the Sonata Romántica, as Ponce uses only those characteristics that may define a work as distinctly Schubertian. With these connections established through documentation and analysis, we may suggest that Ponce's knowledge of Schubert's compositional idioms permits him to compose a seemingly original work by Schubert for the guitar by encompassing the distinct characteristics of Schubert's various forms.

Ponce's treatment of the first movement suggests a reference to Schubert's earlier piano sonatas, encompassing Schubert's sonata-allegro form and emulating his frequently utilized harmonic structure. The lyricism of the second movement, in addition to the major-minor thematic restatements, exemplifies Schubert's textual characteristics within his lieder. While Schubert composed numerous lieder throughout his career, Ponce strategically places many of the salient features of Schubert's songs within the expressive second movement of Schubert's piano sonata form. Comparisons to Schubert's moment musical in the third movement reveal Ponce's organizational approach using similar metric and harmonic treatment. The fourth movement provides conclusive supporting evidence for the theory of the Sonata Romántica acting as a chronological realization of Schubert's works with the numerous references to Schubert's final Piano Sonata in Bb major, D. 960.

${ }^{108}$ Noted distinctions of Ponce's musical style categorized in Dahlia Guerra, "Manuel M. Ponce: A Study of his Solo Piano Works and his Relationship to Mexican Musical Nationalism," (Ph.D. Diss., University of Oklahoma, 1997), 138. 
However, this chronological organization only definitively pertains to Schubert's piano sonatas, referencing D. 664 and D. 960. It is possible to speculate that Ponce placed the second and third movement in their respective positions due to similar structural similarities without considering their chronological placement within Schubert's catalogue. The harmonic and structural similarities of Schubert's scherzi and moment musical mark the third movement as the logical placement for such a reference, consequently allowing the lied to fulfill the role of the more expressive second movement of Schubert's piano sonatas. If this is the case, the chronological identity of the moment musical in third movement is created by consequence as this would be the only option for its placement within a four-movement piano sonata by Schubert.

The prejudicial comparisons of Schubert's music to Beethoven in the nineteenthcentury are in some ways similar to the prejudices Ponce faced when writing for the guitar a century later. That is, both the guitar and its repertoire faced an equal discrimination through comparisons to other solo instrumental works of the time. Perhaps Ponce considered these prejudices in the conception of the Sonata Romántica, citing Schubert as an example of an undervalued genius who won the favor of audiences worldwide, only after such comparisons to Beethoven began to ease. Of course, one can only speculate as to the connections Ponce may have had towards such an inclination; however, the timing of Schubert's centenary and resurgence of his works in 1928 is enough to justify this speculation beyond mere coincidence. 


\section{REFERENCES}

Adrian, Jack. "The Ternary Sonata Form." Journal of Music Theory. no. 1 (1990): 57-80.

Ahedo, Virginia Covarrubias. "Three Main Chamber Music Works for Strings and Piano by the Mexican Composer Manuel M. Ponce." Doctoral essay, University of Miami, 2008.

Arizmendi, Omar Herrera. Manuel Ponce: Style and Aesthetics. D.M.A. treatise, University of Houston, 2012.

Beach, David. "Harmony and Linear Progression in Schubert's Music." Journal of Music Theory. no. 1 (1994): 1-20.

. "Modal Mixture and Schubert's Harmonic Practice." Journal of Music Theory. no. 1 (1998): 73-100.

Black, Leo. Music and Belief. Woodbridge, England: The Boydell Press, 2003.

Brendel, Alfred. On Music. Chicago: Chicago Review Press, 2007.

Brennan, Michael S. "Compositional Process as Dialogue: The Collaboration Between Manuel Ponce and Andrés Segovia.” Manuscript, Northwestern University, 2010.

Clark, Suzannah. Analyzing Schubert. Cambridge: Cambridge University Press, 2011.

Cohn, Richard. "Introduction to Neo-Riemannian Theory: A Survey and a Historical Perspective." Journal of Music Theory. no. 2 (1998): 167-180.

. "Neo-Riemannian Operations, Parsimonious Trichords, and Their 'Tonnetz' Representations." Journal of Music Theory. no. 1 (1997): 1-66.

Cone, Edward T. "Schubert's Promissory Note: An Exercise in Musical Hermeneutics." 19th-Century Music. no. 3 (1982): 233-241.

Coren, Daniel “Ambiguity in Schubert's Recapitulations." The Musical Quarterly. no. 4 (1974): 568-582.

Corvera, Jorge Barrón. Manuel María Ponce: A Bio-Bibliography. Westport, CT: Praeger Publishers, 2004. 
Dahlhaus, Carl. Sonata Form in Schubert: The First Movement of the G-Major String Quartet, op. 161 (D. 887). In Schubert: Critical and Analytical Studies, edited by Walter Frisch, 1-12. Lincoln and London: University of Nebraska Press, 1986. Damschroder, David. Harmony in Schubert. Cambridge: Cambridge University Press, 2010.

. "Schubert, Chromaticism, and the Ascending 5-6 Sequence." Journal of Music Theory. no. 2 (2006): 253-275.

Deutsch, O.E. "Schubert ohne Gitarre" in Schubert-Gabe der Oesterreichische GitarreZeitschrift, edited by Jakob Ortner and Gustav Moissl, 18-26. Verlag der Oesterreichische Gitarre-Zeitschrift. Wien: Friedrich Hofmeister \& Co., 1928.

. "Franz Schubert: Quartett fur Flöte, Gitarre, Bratsche und Violoncell. Besprechung." Zeitschrift fir Musikwissenschaft. Leipzig, October 1928, 124-126.

Dittrich, Marie-Agnes. "The Lieder of Schubert." In The Cambridge Companion to the Lied, edited and revised by James Parsons, translated by Sven Hansell, 88-100. Cambridge: Cambridge University Press, 2004.

Einstein, Alfred. Schubert: A Musical Portrait. New York: Oxford University Press, 1951.

Feil, Arnold. Two Analyses: Moment Musical in F minor, op. 94, no. 3 (D. 780). In Schubert: Critical and Analytical Studies, edited by Walter Frisch, 104-125. Lincoln and London: University of Nebraska Press, 1986.

Fieldman, Hali Annete. "The Grundgestalt and Schubert's Sonata Form.” Ph.D. diss., University of Michigan, 1996.

Garret, David. Program Notes., "Schubert's Piano Sonata in A major, D. 664." International pianists recital. Sydney, Australia: Sydney Opera House, June 19, 2008 .

Guerra, Dahlia. "Manuel M. Ponce: A Study of His Solo Piano Works and His Relationship to Mexican Musical Nationalism." D.M.A. treatise, University of Oklahoma, 1997.

Han Hur, Mi-Sook. "Irregular Recapitulation in Schubert's Instrumental Works.” Ph.D. diss., City University of New York, 1992.

Harbinson, William G. "Beethoven and Schubert: A Comparative Analysis of the Structural Subdominant in Selected Sonata Form Movements.” Ph.D. diss., Florida State University, 1982.

Hatten, Robert S. "Schubert the Progressive: The Role of Resonance and Gesture in the Piano Sonata in A, D. 959.” Intégral 7 (1993): 38-81. 
Haupt, Helen Doris. "Form in the Pianoforte Sonatas of Franz Schubert." Thesis, University of Illinois, 1941.

Hidalgo, F. Gómez. “Creadores de México. El maestro Ponce.” Estampa (Mexico City), 2 February, 1943. Cited in Jorge Barrón Corvera, Manuel María Ponce: A BioBibliography. Westport, CT: Praeger Publishers, 2004.

Hiller, Lejaren, and Calvert Bean. "Information Theory Analyses of Four Sonata Expositions." Journal of Music Theory. no. 1 (1966): 96-137.

Holt, Marilyn Barnes. "Developmental Procedures in the Sonata Form Movements of the Symphonies of Beethoven, Schubert, Mendelssohn, and Schumann.” Ph.D. diss., Case Western Reserve University, 1973.

Ingwerson, John Clyde. "Manuel Ponce's Variations Sur Folia De España et Fugue: A Study of Compositional Procedures and Ponce's Use of the Folia Theme.” D.M.A. treatise, University of Arizona, 1996.

Kessler, Deborah. "Schubert's Late Three-Key Expositions: Influence, Design, and Structure." Ph.D. diss., City University of New York, 1996.

Kramer, Lawrence. "The Schubert Lied: Romantic Form and Romantic Consciousness." In Schubert: Critical and Analytical Studies, edited by Walter Frisch, 200-236. Lincoln and London: University of Nebraska Press, 1986.

Lewin, David. "Auf dem Flüsse: Image and Background in a Schubert Song." In Schubert: Critical and Analytical Studies, edited by Walter Frisch, 126-152. Lincoln and London: University of Nebraska Press, 1986.

Madrid-González, Alejandro L. "Writing Modernist Avant-Garde Music in Mexico: Performativity, Transculturation, and Identity After the Revolution.” Ph.D. diss., Ohio State University, 2003.

Manderville, Kevin. "Manuel Ponce and the Suite in A Minor: Its Historical Significance and an Examination of Existing Editions." D.M. treatise, Florida State University, 2006.

Mak, Su Yin Susanna. "Structure, Design, and Rhetoric: Schubert's Lyricism Reconsidered.” Ph.D. diss., University of Rochester: Eastman School of Music, 2004.

Mattingly, Stephen. "Franz Schubert's chamber music with guitar: A study of the guitar's role in Biedermeier Vienna." D.M. treatise, Florida State University, 2007.

McDonald, Hugh. “Scherzo.” In Grove Music Online. http://grovemusic.com (accessed 23 March 2014). 
Messing, Scott. Schubert in the European Imagination. Vol. 2. Edited by Ralph P. Locke. Rochester, New York: University of Rochester Press, 2007.

Miranda, Ricardo. "Exploration y Sintesis en la Musica de Manuel M. Ponce (primera parte)." Pauta, July-September, 1998. Cited in Virginia Covarrubias Ahedo, "Three Main Chamber Music Works for Strings and Piano by the Mexican Composer Manuel M. Ponce.” Doctoral essay, University of Miami, 2008.

Newbould, Brian. Schubert: The Music and the Man. Berkely, Los Angeles: University of California, 1997.

Newcomb, Anthony. Structure and Expression in a Schubert Song: Noch einmal. Schubert: Critical and Analytical Studies. Edited by Walter Frisch. Lincoln and London: University of Nebraska Press, 1986.

Newman, William G. The Sonata Since Beethoven. New York: W. W. Norton \& Company Inc., 1972.

Otero, Corazón. Manuel M. Ponce and The Guitar. Trans. J.D. Roberts. Dorset, England: Musical New Services Ltd., 1983.

Perry, Jeffrey. "The Wanderer's Many Returns: Schubert's Variations Reconsidered." The Journal of Musicology. no. 2 (2002): 374-416.

Pinnell, Richard. "Feedback: Segovia's exile and his relationship to Ponce, in retrospect." Guitar Review. no. 112 (1998): 35-38.

. "Segovia in Exile: protagonists and projects of the Montevideo Period (19361947)." Guitar Review. no. 110 (1997): 1-8.

Ponce, Manuel M. Sonata Romántica. Edited by Andrés Segovia. Berlin, Germany: Schott, 1929.

Poulos, Peter S. "Towards a Contemporary Style: Manuel M. Ponce's Neoclassical Compositions for Guitar." Masters thesis, University of Cincinnati: College Conservatory of Music, 1992.

Ramirez, Jake Allen. "Perspectives on the Musical Lives and Works of Mauro Giuliani, Manuel De Falla, Manuel Ponce, and Frank Martin." Masters thesis, University of Texas at San Antonio, 2013.

Reed, John . Schubert. New York: Schirmer Books, 1997. . Schubert: The Final Years. New York: St. Martin's Press, 1972.

Rivas, Yolanda Moreno. Rostros del Nacionalismo en la Musica Mexicana: un ensayo de interpretation. 2nd ed. Mexico: UNAM Escuela Nacional de Musica, 1995. Quoted in Virginia Covarrubias Ahedo, "Three Main Chamber Music Works for 
Strings and Piano by the Mexican Composer Manuel M. Ponce.” Doctoral essay, University of Miami, 2008.

Rothgeb, John. "Another View on Schubert's Moment Musical op. 94/1." Journal of Music Theory. no. 1 (1969): 128-139.

Shantz, Bren. "Organic Relationships: Motivic Parallelisms Between the First and Second Themes of Sonata Form." Masters thesis, Michigan State University, 2008.

Siciliano, Michael. Neo-Riemannian Transformations and the Harmony of Franz Schubert. Ph.D. diss., The University of Chicago, 2002.

Slonimsky, Nicolas. Baker's Biographical Dictionary of Musicians. New York: G. Schirmer, 1958.

Sly, Gordon Cameron. "An Emerging Symbiosis of Structure and Design in the Sonata Practice of Franz Schubert." Ph.D. diss., University of Rochester: Eastman School of Music, 1995.

. "Schubert's Innovations in Sonata Form: Compositional Logic and Structural Interpretations." Journal of Music Theory. no. 1 (2001): 119-150.

Smith, Jay. "An Overview and Performance Guide to Manuel Ponce's Sonata III for Solo Guitar." D.M.A. treatise, University of North Texas, 2006.

Smith, Peter H. "Harmonic Cross Reference and the Dialect of Articulation and Continuity in Sonata Expositions of Schubert and Brahms." Journal of Music Theory. no. 2 (2006): 143-179.

Sprayberry, Thomas F. Four Hundred Years of Guitar. Masters thesis, University of Texas at San Antonio, 2010.

Tischler, Hans. "Chromatic Mediants- A Facet of Musical Romanticism." Journal of Music Theory. no. 1 (1958): 94-97.

Van Hoorickx, Reinhard. "Schubert's Guitar Quartet." Societe Belge de Musicologie. (1977): 111-135.

Vidmar-McEwen, Michael. "Prolongational and Transformational Views of Sonata Form in the First Movement of Schubert's Piano Sonata in Bb, D. 960." Masters thesis, University of Notre Dame, 2006.

Webster, James. "Sonata Form.” In Grove Music Online, http://www.grovemusic.com/ (accessed 8 March 2014).

Welsh, Leo. "The First Movement Sonata Style of Manuel Ponce in his Sonatas for Solo Guitar.” D.M. treatise, Florida State University, 1995. 
Winter, Robert. "Franz Schubert: Works." In Grove Music Online. http://grovemusic.com/ (accessed 14 February 2014).

Youens, Susan "Franz Schubert: The Lied Transformed." In German Lieder in the Nineteenth Century, edited by Rufus Hallmark, 35-91. New York and London: Schirmer Books, 1996. 


\section{CURRICULUM VITAE}

NAME:

ADDRESS:

DOB:

EDUCATION

\& TRAINING:

AWARDS:

ROFESSIONAL SOCIETIES
Parker S. Scinta

2802 Kennersley Drive.

Louisville, KY 40242

Louisville, Kentucky - September 14, 1988

B.M. Applied Performance: Classical Guitar

University of Louisville

$2008-2011$

M.M., Music Performance

University of Louisville

$2011-2013$

M.M., Music Theory

University of Louisville

$2012-2014$

School of Music Scholarship

2008-2011

Senior Academic Award

2011

Graduate Teaching Assistantship in Music Theory 2012

Second Prize at the Memphis International Guitar Competition 2013

Louisville Guitar Society

Public Relations Director/Coordinator

2011 - Present 
PROFESSIONAL

SOCIETIES CONT.: Chamber Music Society of Louisville

Student Liaison, Board Member

2013 - Present

Guitar Foundation of America

Volunteer Coordinator

2013 